\title{
Studies on the formation of thrombin : approaching physiological conditions
}

Citation for published version (APA):

Kessels, H. J. J. (1993). Studies on the formation of thrombin : approaching physiological conditions. [Doctoral Thesis, Maastricht University]. Datawyse / Universitaire Pers Maastricht. https://doi.org/10.26481/dis.19930930hk

Document status and date:

Published: 01/01/1993

DOI:

10.26481/dis.19930930hk

Document Version:

Publisher's PDF, also known as Version of record

\section{Please check the document version of this publication:}

- A submitted manuscript is the version of the article upon submission and before peer-review. There can be important differences between the submitted version and the official published version of record.

People interested in the research are advised to contact the author for the final version of the publication, or visit the DOI to the publisher's website.

- The final author version and the galley proof are versions of the publication after peer review.

- The final published version features the final layout of the paper including the volume, issue and page numbers.

Link to publication

\footnotetext{
General rights rights.

- You may freely distribute the URL identifying the publication in the public portal. please follow below link for the End User Agreement:

www.umlib.nl/taverne-license

Take down policy

If you believe that this document breaches copyright please contact us at:

repository@maastrichtuniversity.nl

providing details and we will investigate your claim.
}

Copyright and moral rights for the publications made accessible in the public portal are retained by the authors and/or other copyright owners and it is a condition of accessing publications that users recognise and abide by the legal requirements associated with these

- Users may download and print one copy of any publication from the public portal for the purpose of private study or research.

- You may not further distribute the material or use it for any profit-making activity or commercial gain

If the publication is distributed under the terms of Article $25 \mathrm{fa}$ of the Dutch Copyright Act, indicated by the "Taverne" license above, 


\section{STUDIES ON THE FORMATION OF THROMBIN}

APPROACHING PHYSIOLOGICAL CONDITIONS 


\section{CIP-DATA KONINKLIJKE BIBLIOTHEEK, DEN HAAG}

Kessels, Henricus Johannes Josephina

Studies on the formation of thrombin: Approaching physiological conditions Henricus Johannes Josephina Kessels - Maastricht:

Universitaire Pers Maastricht. - I11.

Thesis Maastricht. - With ref. - With summary in Dutch

ISBN 90-5278-092-7

Subject headings: thrombin / blood coagulation

Omslag: Gé Helsen 


\section{STUDIES ON THE FORMATION OF THROMBIN}

\section{APPROACHING PHYSIOLOGICAL CONDITIONS}

\section{PROEFSCHRIFT}

ter verkrijging van de graad van doctor aan de Rijksuniversiteit Limburg te Masstricht, op gezag van de Pro-Rector, Prof. dr. L. Boon, volgens het besluit van het College van Dekanen,

in het openbaar te verdedigen op donderdag 30 september 1993 om 14.00 uur

door

Henricus Johannes Josephina Kessels 
promotor:

Prof.dr. H.C. Hemker

beoordelingscommissie:

Prof.dr. J.F.M. Smits (voorzitter)

Dr. T.W. Barrowcliffe, Nat. Inst. for Biological Standards and Control, London Prof.dr. F.C.S. Ramaekers

Prof.dr. J. Vermylen, Katholieke Universiteit Leuven

Prof.dr.ir.drs. O.J. Vrieze

Financial support by the Dr. Ir. J.H.J. van de Laar Foundation, and the Netherlands Heart Foundation for the publication of this thesis is gratefully acknowledged. 
De toutes les protéines du plasma sanguin, la trombine est certes celle qui offre au prodigieux et inépuisable thème de la coagulation les plus admirables ressources.

naar Willem Elsschot, Lijmen 


\section{contents}

chapter 1 introduction 11

components and reactions 11

control 19

the present investigation 21

chapter 2 measurement of thrombin generation in whole

blood; the effect of heparin and aspirin 31

chapter 3 analysis of thrombin generation curves 47

$\begin{array}{lll}\text { chapter } 4 & \text { measuring activated factor VIII in plasma } & 67\end{array}$

$\begin{array}{ll}\text { chapter } 5 & \text { the role of thrombin feedback reactions and factor } \\ & \mathrm{Xa} \text { during clotting of human plasma }\end{array}$

chapter 6 analysis of bleeding from bleeding time wounds 107

$\begin{array}{lll}\text { chapter } 7 & \text { summary and conclusions } & 117\end{array}$

samenvatting en conclusies $\quad 125$

$\begin{array}{ll}\text { curriculum vitae } & 135\end{array}$

dankwoord 137 


\section{contents}

chapter 1 introduction 11

components and reactions $\quad 11$

control 19

the present investigation $\quad 21$

chapter 2 measurement of thrombin generation in whole blood; the effect of heparin and aspirin 31

chapter 3 analysis of thrombin generation curves 47

$\begin{array}{lll}\text { chapter } 4 & \text { measuring activated factor VIII in plasma } & 67\end{array}$

chapter 5 the role of thrombin feedback reactions and factor $\mathrm{Xa}$ during clotting of human plasma

chapter 6 analysis of bleeding from bleeding time wounds 107

$\begin{array}{lll}\text { chapter } 7 & \text { summary and conclusions } & 117\end{array}$

samenvatting en conclusies $\quad 125$

$\begin{array}{ll}\text { curriculum vitae } & 135\end{array}$

$\begin{array}{ll}\text { dankwoord } & 137\end{array}$ 


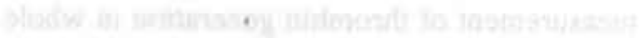

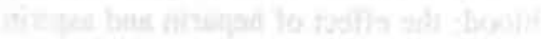

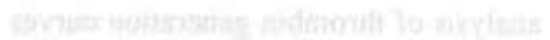




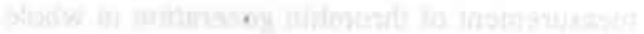

ris

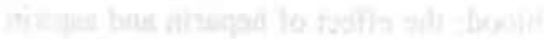

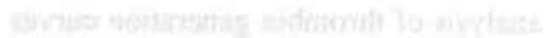

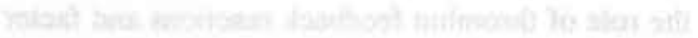

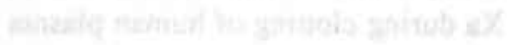

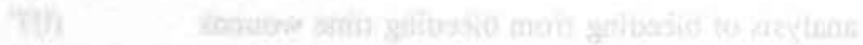




\section{chapter 1}

\section{Introduction}

Bloodclotting is of necessity a fast, dynamic, and strictly controlled process. It is a massive reaction involving a large number of blood components, both cells and proteins, that should be triggered quickly and efficiently, but only when needed. It is as important that clotting does not occur when there is no cause, as that it does when a vessel is damaged. The guiding principle in the control of this hemostatic process is localisation.

Bloodclotting is an emergency mechanism. It occurs when a blood vessel is damaged and blood is exposed to perivascular connective tissue, and the contents of damaged cells. Within seconds, processes start which, in a short timespan, lead to the formation of a seal, or plug, consisting mainly of platelets and fibrin. This plug formation, and therefore the processes involved, remain confined to the damaged area. They are not only limited in place, they are also in time, as the plug does not grow much further when the leak has been closed. Bloodclotting in vivo is thus a phenomenon that is strictly localised temporally and spatially. This, of course, is different from the situation in vitro. Bloodclotting in a test tube is always complete.

Through the years, the participants in the hemostatic process, have been identified one by one. They, clotting factors, platelets, ions, have been put in reaction schemes in order to show the 'city plan' of the events that are taking place during bloodclotting. However, like the map of a city says very little about the life in the city, a map of bloodclotting does in itself not completely reveal the true nature of this intriguing process. Missing from the reaction scheme is a set of principles that are basic to the control of coagulation. In this introduction I will, in addition to the current reaction scheme, try to describe some of these principles, and where they fit into the reaction sequence.

\section{1. components and reactions}

The proteins, cells, and other substances that make up the hemostatic system form a closely coupled and tightly regulated system. As such, they 
all work closely together. It is, therefore, difficult to give a detailed description of the properties of each component separately, without touching upon functions of related components. Consequently, only a brief overview of several key components individually will be provided before discussing hemostasis as a whole.

\section{1. components}

\section{thrombin}

Thrombin, or factor Ila, is the product of the series of proteolytic activation reactions of the coagulation system. Thrombin has many functions, and forms an important link between the various components of the hemostatic process. It is best known for its ability to convert fibrinogen molecules into fibrin monomers that rapidly assemble to form fibrin threads. Thrombin also activates factor XIII, which then has the ability to cross-link the fibrin threads to form a rigid network. It is often less well realised that thrombin is the most potent physiological platelet activator, especially in the presence of collagen. The mechanism of platelet activation by thrombin involves cleavage of a transmembrane molecule, as has been elucidated recently (1). Thrombin has several interactions with intact endothelial cells, which are largely anticoagulant. Most important is probably that thrombin is able to form a complex with thrombomodulin, a protein present on the endothelial cell membrane. This causes a change of the specificity of the proteolytic action of thrombin so that it loses its procoagulant properties and acquires the ability to activate Protein C $(2,3)$, which, possibly together with the cofactor Protein S, forms a potent anticoagulant. Reportedly, thrombin also has a number of extra-hemostatic actions. It has, among other things, been described to enhance wound healing by stimulating proliferation of fibroblasts and a number of other cells $(4,5,6,7)$. Lastly, thrombin plays an important role in the reactions leading to its own formation. By its ability to activate the cofactor proteins factor $\mathrm{V}$ and factor VIII, thrombin accelerates its formation by several orders of magnitude.

\section{platelots}

Blood platelets are small anucleate cells that have an important role in hemostasis. They are activated by a number of substances including thrombin, collagen, and ADP. Activation induces a shape change from discoid to spherical with formation of pseudopodia. The secretory granules of the platelets then release their contents into the open canalicular system. Among the substances released are ADP, blood clotting factor $\mathrm{V}$, platelet factor 4, and vasoactive substances like serotonin. Platelets are capable of 
adhering to proteins of the sub-endothelial matrix, such as collagens, to various plasma proteins, e.g. fibrin and fibronectin, and to other platelets. Platelet adherence is mediated by cell surface receptors of the integrin family. A major platelet surface receptor GPIIb/IIla (integrin $\alpha_{[I b} \beta_{3}$ ) probably has to be activated to be functional $(8,9)$, but it is not clear whether this holds true for other members of the integrin family. Platelet activation by thrombin together with collagen also leads to loss of platelet membrane asymmetry with respect to phospholipid composition (10), resulting in the presence of negatively charged phosphatidyl serine molecules in the outer leaflet of the platelet membrane bilayer. In addition to being localised to the site of injury, a number of reactions of the coagulation system is greatly accelerated when occurring on such a membrane surface, partly because the values of the $\mathrm{K}_{\mathrm{m}}$ are lowered by several orders of magnitude $(11,12,13,14)$. Additionally, small micro vesicles are shed by activated platelets (15). These micro-vesicles have also lost their membrane asymmetry, and can thus serve as a surface for various membrane bound reactions of the coagulation system.

\section{vitamin $\mathrm{K}$ dependent clotting factors}

These include factors II, VII, IX and X. They are serine protease proenzymes that undergo a vitamin $\mathbf{K}$ dependent post-translational carboxylation of certain $\mathrm{N}$-terminal glutamic acid residues to $\gamma$ carboxyglutamic acid residues, or Gla's $(16,17,18)$. These Gla residues play an important role in the $\mathrm{Ca}^{2+}$ dependent binding of vitamin $\mathrm{K}$ dependent coagulation factors to negatively charged lipid membranes (19). Factor VII is proteolytically cleaved to factor VIla by factor $\mathrm{Xa}$, and, at a slower rate, by factor IXa $(20,21,22,23,24,25)$. Factor VIIa, when complexed to its cofactor tissue factor (TF), is able to activate the factors $\mathrm{X}$ and IX. Factor VII is present in plasma in a relatively low concentration of $10 \mathrm{nM}$ (26). It is still a matter of debate whether or not the zymogen factor VII has a physiologically important proteolytic activity $(27,28,29,30)$ or not $(31,32,33)$. If it does, it would be the only known clotting factor to have this capability as a zymogen, and it would provide a ready explanation for the initiation of coagulation (27).

Factor IX, which has a plasma concentration of about $80 \mathrm{nM}$, can be activated to factor IXa by the TF/VIla complex and by factor XIa, although this latter reaction may not have physiological significance. Factor IXa's main function is the activation of factor $X$. To form an efficient enzyme, factor IXa complexes with its cofactor factor VIIIa on a phospholipid surface $(34,35,36)$. Hemophilia B, a sex-linked, recessive bleeding disorder is caused by deficiency of factor IX. 
Factor $\mathrm{X}$, present in a concentration of approximately $160 \mathrm{nM}(37,38)$, is activated by the IXa/VIIla complex, and by the VIla/TF complex. Factor $\mathrm{Xa}$ joins with factor $\mathrm{Va}$ on a phospholipid surface to form the prothrombinase complex $(39,34)$, which activates prothrombin. This vitamin $\mathrm{K}$ dependent thrombin precursor is present in a concentration of around $1.5 \mu \mathrm{M}$ (19).

All vitamin $\mathrm{K}$ dependent clotting factors retain their Gla residues when they are activated, except for prothrombin. Thus, thrombin is unable to bind to a phospholipid surface.

\section{cofactors}

The three main enzyme complexes leading to the formation of thrombin all consist of a phospholipid bound complex of a vitamin $\mathrm{K}$ dependent clotting factor and a protein cofactor. Tissue factor is a small transmembrane glycoprotein that is found in the plasma membranes of many cells, but not normally on the luminal side of the cells of the endothelium. It forms complexes with factor VII or VIla (40). Unlike the other cofactors, tissue factor does not need to be activated.

Factor VIII and factor V are large proteins with similar structural properties. They are cofactors of factor IXa and factor $\mathrm{Xa}$ respectively, and must be proteolytically cleaved by thrombin to their active forms in order to gain cofactor activity $(41,42,43,44)$. Both bind strongly to a phospholipid surface in a calcium independent manner. In plasma, factor VIII circulates in a complex with von Willebrand factor (45) at a low concentration ( $<1 \mathrm{nM}$ ) (46). Deficiency of factor VIII is the cause of hemophilia $A$. The plasma concentration of factor $V$ is about $30 \mathrm{nM}$, but it is also present in the $\alpha$-granules of blood platelets (47). Cofactors increase the catalytic constant of their enzymes by several orders of magnitude $(11,12)$.

\section{physlologic Inhlbitore of the coagulation cascade}

\section{supins}

Several members of the serine protease inhibitor (or 'serpin') super family are able to inhibit serine proteases of the coagulation system (48). These include antithrombin III (ATIII), $\alpha_{2}$-macroglobulin $\left(\alpha_{2} M\right)$, heparin cofactor II, and al-antitrypsin. Their mechanism of action is that of a pseudo substrate, with the reaction arrested near the Michaelis complex (49). Binding is reversible and is thought to be a two step process, with the formation of an initial loose complex which then proceeds to a tightly bound complex $(50,51,52)$. The rate limiting step is the formation of this initial weak complex, which makes that the rate of inhibition is slow $\left(\mathbf{k}_{\text {on }}\right.$ $\left.=1.5 \cdot 10^{-3} \mathrm{nM}^{-1} \mathrm{~min}^{-1}\right)$. The dissociation rate of the tight complex is so 
low however, that binding has long been thought to be irreversible. Very slowly, the reaction between serpin and protease also completes towards proteolysis, resulting in cleaved inhibitor and active protease. AT III based inhibition is accelerated quite considerably by heparin.

TFPI

Tissue Factor Pathway Inhibitor, a Kunitz type serine protease inhibitor circulating in plasma in a concentration of about $1.2 \mathrm{nM}$, is able to form a quaternary complex with factor $\mathrm{Xa}$ and TF/VIla, thereby inhibiting both enzymes $(53,54)$. When sufficient factor $\mathrm{Xa}$ has been produced, TFPI is able to completely shut off TF/VIIa activity.

protein C

A third inhibitory component is formed by protein $\mathrm{C}$ and protein $\mathrm{S}$. Protein $\mathbf{C}$, a vitamin $\mathbf{K}$ dependent, phospholipid binding protein, is activated by the thrombin/thrombomodulin complex on intact endothelium $(2,3)$. In contrast to the inhibitors mentioned above, activated protein $C$ (APC), together with protein S, is not directed against the enzymatic factors but against the cofactors $\mathrm{Va}$ and VIIIa, which are proteolytically inactivated $(55,56)$.

fibrin

Fibrinogen is the most abundant coagulation protein with a concentration of about $10 \mu \mathrm{M}$. Thrombin converts fibrinogen molecules into fibrin monomers by cleaving off two pairs of peptides, the fibrinopeptides A and B (57). This exposes four polymerisation sites, which combine with complementary sites of other fibrin monomers. Fibrin strands are then formed by spontaneous polymerisation of fibrin monomers. Factor XIII, which in plasma is bound to fibrinogen, is activated by thrombin in the presence of fibrin strands. After activation it is able to cross link the fibrin strands to a tight fibrin net. A significant amount of the thrombin formed during clotting binds to generating fibrin $(58,59)$, where it is protected from inactivation by AT III, with or without heparin. Fibrin bound thrombin retains its enzymatic properties.

\section{2. reactions}

Basically, the coagulation system consists of a number of proenzymes of serine proteases. These proenzymes are 'activated' by one or more proteases of the clotting system, to become active proteases themselves. The backbone of this reaction sequence consists of the vitamin $\mathrm{K}$ dependent clotting factors VII, IX, X and II, as shown in figure 1. This scheme differs from the classical coagulation scheme, with its intrinsic- 


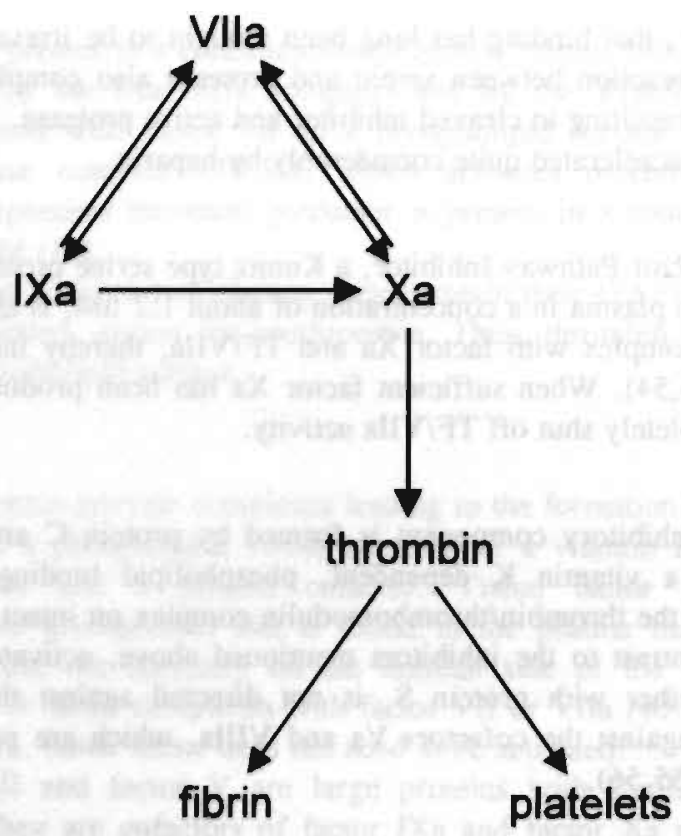

figure 1. skeleton of the clotting cascade

Arrows designate activation, not conversion.

extrinsic dichotomy. The recognition that contact activation of coagulation is of little importance in vivo (60), as well as the discovery of the activation of factor IX by the TF-VIIa complex $(61,62,63,64)$ has led to the demise of this scheme.

\section{enzyme complexes}

Factors VIla, IXa and Xa alone are very slow enzymes. They need accessory components, a phospholipid surface and a cofactor, in order to live up to their full potential. The properties of the prothrombinase complex (the complex of $\mathrm{Xa}$ and $\mathrm{Va}$ on a phospholipid surface) have been investigated in much detail. When factor $\mathrm{Xa}$ is bound to a phospholipid surface, the $\mathbf{K}_{\mathrm{m}}$ for prothrombin conversion is several orders of magnitude lower than when factor $\mathrm{Xa}$ is in free solution. If the cofactor factor $\mathrm{Va}$ is also present, the turnover number of the enzyme is about a thousand fold higher $(11,12)$. This makes prothrombinase a very efficient enzyme that converts prothrombin into thrombin so fast that, under normal physiological conditions, the reaction rate is probably limited by diffusion of prothrombin to the phospholipid surface containing the prothrombinase 
complex (65). In addition, phospholipid-bound factor Va greatly increases the affinity of factor $\mathrm{Xa}$ for the phospholipid surface $(66,67)$. The other enzyme complexes, VIIa/TF and IXa/VIIla (extrinsic and intrinsic tenase) have properties comparable to those of the prothrombinase complex $(68,69,70,34,35,36)$. They are, however, somewhat less efficient.

\section{Initiation}

Normally, clotting enzymes and cofactors circulate in their inactive form, and no suitable phospholipid bilayer is available for coagulation reactions. It has been shown however (71), that, at a very low concentration, activated clotting factors are always present, as indicated by the presence of activation peptides of clotting factors. This 'basal' activity may be important in the initiation of coagulation. When vessel wall damage occurs at a certain location, blood is exposed to extra-vascular connective tissue, and to tissue factor. Furthermore, damaged cells may expose procoagulant phospholipids from their interiors. It is hypothesized by some investigators $(27,28,29,30)$ that the complex of tissue factor and the zymogen factor VII has a certain proteolytic activity towards the factors $\mathrm{X}$ and IX. To date, however, this has not been proven conclusively, and it may not be important in the light of the steady presence of activated clotting factors in circulating blood. Thus, a little factor VIIa may always be present, and factor VII, when complexed to $\mathrm{TF}$, is readily activated by factor $\mathrm{Xa}$.

\section{positive feedback}

The TF/VIIa complex is a rather efficient activator of factors $\mathrm{X}$ and IX, but these factors do not yet have the activated cofactors available. Therefore, prothrombin conversion is initially a very inefficient and slow process, leading only to trace amounts of thrombin. These concentrations of thrombin are far from high enough to convert massive amounts of fibrinogen into fibrin, but do lead to a small scale activation of the cofactors V and VIII, and of blood platelets (fig 2). Formation of low amounts of the complete prothrombinase and intrinsic tenase enzymes ensues, which leads to a speed-up of thrombin production, since the catalytic efficiency of these complete enzyme complexes is more than five orders of magnitude higher than that of the bare enzymes. From this point, the reaction sequence exhibits the typical positive feedback pattern of a burst-like increase of reaction rates and product formation $(72,73)$. Thrombin reaches concentrations which are more than adequate for efficient fibrin formation. In purified systems, also factor $\mathrm{Xa}$ is capable of activating the cofactors $V(74,75)$ and VIII $(56,76,77)$. This ability, however, does not seem to play a role in a plasma milieu (78, chapter 5). 

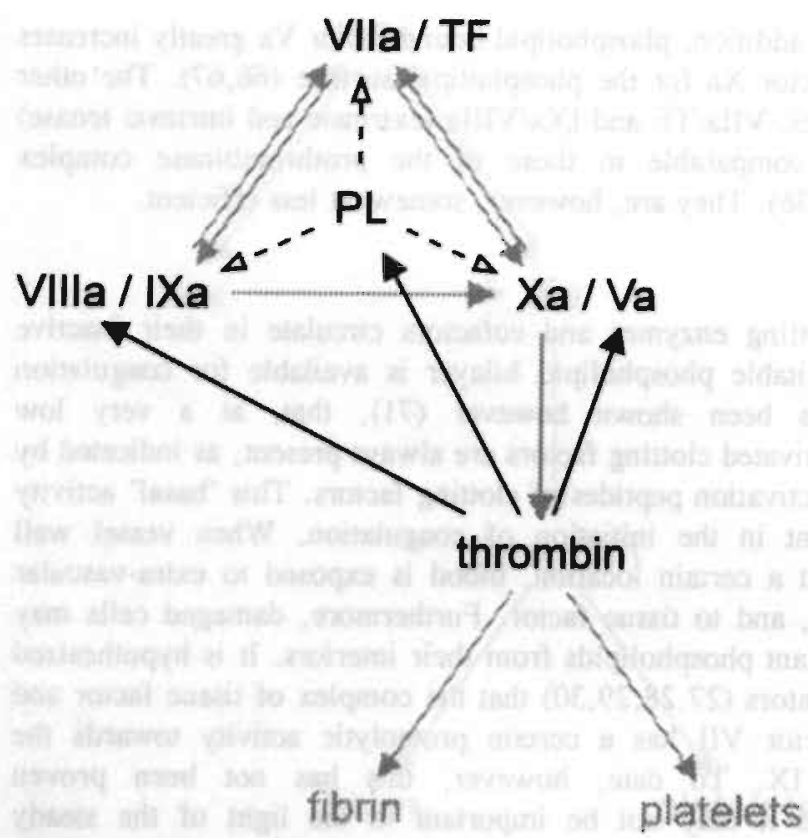

figure 2. feedback reactions

Solid arrows indicate activation, dashed arrows point at the reactions that occur on a phospholipid surface (PL).

\section{Inhlbitory reactions}

Several inhibitory reaction pathways run through the coagulation scheme as well (fig 3). Antithrombin III and several other serine protease inhibitors inhibit thrombin and factor $\mathrm{Xa}$ at a slow but concentration dependent pace. The factors IXa, Xla and VIIa are inhibited by AT III at an even lower rate. The factor VIla-TF complex falls prey to TFPI after a certain lag. The activated cofactors may be attacked by activated protein C, possibly accompanied by protein S. Perhaps less obvious, but probably at least of equal importance are several other inhibitory mechanisms. Blood flow, leading to a dilution of the active clotting factors, is an important factor $(79,80)$ which is very difficult to assess since the exact flow conditions at a site of wound may be very complicated and variable. Additionally, competition between different reactions should not be neglected. Competition may all but completely suppress reactions in vivo, that are clearly demonstrated in purified systems. This especially affects limited resources, such as procoagulant phospholipid surface, and enzymes 
with many substrates, such as thrombin. The initial complex of thrombin with serpins for example is formed rather slowly $(50,51,52)$. Therefore, they effectively do not compete for thrombin in the first stages of the clotting process when thrombin concentrations are low, so that positive feedback may proceed unhindered.

AT III

APC

TFPI

thrombin, Xa, IXa, Xla

$\mathrm{Va}, \mathrm{VIIla}$

\section{VIla/TF, Xa}

ngure 3. Inhibitery reactions

Arows designate the targets of these physiologically occurring inhibitor proteins.

\section{2. control}

The myriad of activations, complexes and inhibitions involved in the hemostatic process, may give the impression of an extremely complicated not very well organised bunch of reactions which, almost magically, seem to produce the desired effect. Things fall into place a little better when one realises that most of these reactions occur only at specific places and times. The concept of localisation, both in space and time, of the coagulation reactions may shed a different light on hemostasis.

\section{1 space localisation}

Hemostasis is needed only at a particular place, the site of vessel lesion. This space confinement is reflected in several aspects of the underlying reactions.

First, the reactions of the backbone of the coagulation system all take place with the components, enzyme, cofactor and substrate, bound to a negatively charged phospholipid membrane, which is not normally accessible. Where cells are damaged, the negatively charged inner leaflet necessary for the clotting reactions may become exposed. As mentioned before, blood platelets even provide a mechanism for transversal movement of phospholipid molecules, which is triggered when the platelets are activated. All vitamin $\mathrm{K}$ dependent clotting factors and their 
cofactors bind to a negatively charged phospholipid surface. Their activated forms also bind, with the exception of thrombin. Thrombin, however, is in part bound by fibrin, which protects it from being inactivated. Thus, thrombin is only partly confined to the site of injury, and may exert some action downstream the lesion site. Since thrombin binds thrombomodulin on intact endothelium, this downsteam action of thrombin may mainly be anticoagulant.

Second, platelets contain a number of receptors enabling them to adhere to components of the subendothelial connective tissue. This leads among other things to the release of ADP from the platelet dense bodies, which causes activation and aggregation of other platelets.

Third, intact endothelium provides a number of mechanisms for inhibiting procoagulant reactions. Active thrombin, for instance, binds to thrombomodulin which is present on the surface of endothelial cells. The complex of thrombin and thrombomodulin has an anticoagulant action by proteolytically cleaving protein $\mathrm{C}$ to form activated protein C (APC). APC is able to shut off thrombin formation by proteolytic destruction of the cofactors $\mathrm{Va}$ and VIIIa. This may help suppressing thrombin activity where it is not needed.

Fourth, blood flow keeps hemostatic reactions localised since it dilutes activated components of the hemostatic system as they drift further away from the lesion site.

It should be noted that studying spatial localisation is not an easy undertaking. Classical test tube experiments are suitable only to a limited extent.

\section{2. time localisation}

The general flavour of the concept of time localisation is that procoagulant reactions are fast but short-lived, and that anticoagulant reactions are slow but persistent. The character of hemostasis as an emergency process is reflected by the rapid increase of the reaction rates of the procoagulant reactions. This is a consequence of both the fact that coagulation is a multistep process, with the intermediate steps acting as amplifiers, and of the various positive feedback mechanisms.

It is of great importance that the hemostatic reactions at the lesion site are efficiently shut down after a while, but neither too soon nor too late. Thus, inhibitory mechanisms should initially keep a slack reign on the procoagulant reactions, but must halt them a little later on. The initial trigger of the coagulation system, the TF/VIla complex is blocked within minutes, or even seconds, by TFPI, which starts being effective as soon as sufficient factor $\mathrm{Xa}$ is present. This, however, does not stop the activation of factor $\mathrm{X}$ by the intrinsic tenase complex, or the formation of thrombin 
by the prothrombinase complex. Here ATIII and a number of other serpins, which are all present in a relatively high concentration in plasma, come into play. They have a remarkable mode of action as they first bind their target enzymes in a weak reversible manner. This initial complex is converted into a nearly irreversible one, but since the rate of inhibition is determined by the speed of the initial complex formation, it is slow, in spite of the high concentration of the inhibitor. On the other hand, the inhibition rate is also linearly dependent on the enzyme concentration, a property that eventually limits the concentration of free enzyme as the inhibitory rate starts balancing the formation rate of the enzyme. Consequently, the inhibitory capacity of the serpins is initially overpowered by the burst-like procoagulant reactions, but dominates in the end when the speed of the procoagulant reactions fades. Another phenomenon that conceivably favours, and later counteracts procoagulant reactions is impediment of blood flow inside the forming fibrin and platelet clot. Dilution of active clotting factors is diminished, which initially works procoagulant. Eventually, consumption of clotting factor zymogens, caused by insufficient supply, leads to a decreasing rate of activation.

\section{3. combination}

It is noteworthy that some of the same mechanisms that cause spatial localisation also lead to temporal localisation. An example of this is the occurrence of clotting reactions on negatively charged phospholipid surfaces. As mentioned above, this confines clotting factors to the site of vessel damage. But it also accelerates those reactions quite considerably by effectively increasing the enzyme size to include a relatively large area of phospholipid surface, thereby concomitantly increasing the collision rate. As described above, the interplay between the initially fast procoagulant and the slow anticoagulant reactions is responsible for the time characteristics of the hemostatic process. Another example is blood flow. Dilution causes spatial localisation whereas impediment of flow at the site of clot formation should ultimately limit the coagulatory respons.

\section{3. the present investigation}

This thesis describes a number of studies which deal with thrombin and the positive feedback mechanisms which it triggers. The central role of thrombin in the hemostatic mechanism is depicted in fig.4. The importance of thrombin lies in the fact that it is both the effector enzyme, being the end product of the coagulation cascade and able to clot 
fibrinogen and to activate platelets, and a central regulatory protein, being at the origin of several important positive and negative feedback loops of the coagulation system. It should, therefore, not come as a surprise that thrombin involvement has been observed in venous as well as arterial thrombosis $(81,82,83,84)$. The latter observation provides further evidence that the classical distinction between 'primary hemostasis', viewed as a platelet process, and 'secondary hemostasis' or 'coagulation', with thrombin as its main actor, is obsolete.

\section{efiect}

foedback

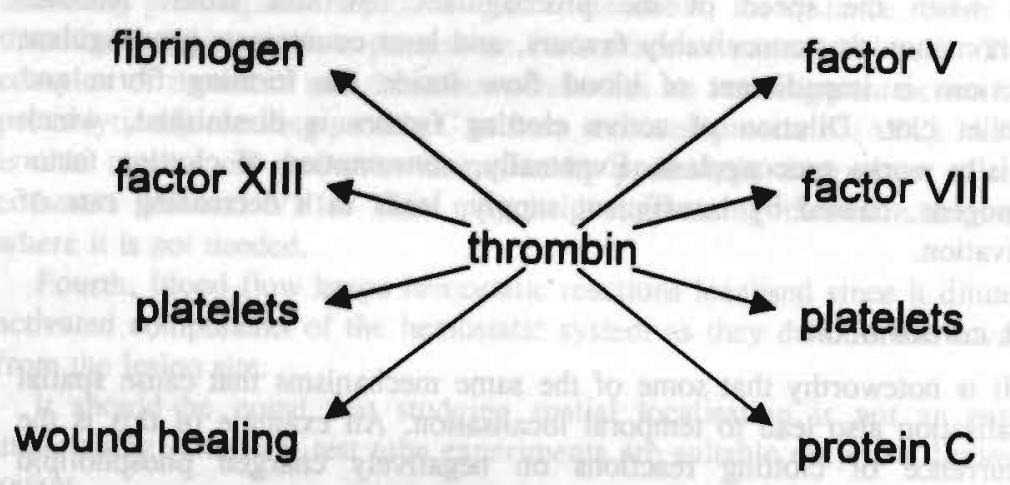

\section{ngure 4. central role of thrombin}

Platelets are both on the effoct and on the foecback side since, on the one hand, they bulld the primary hemostatic plug, and, on the other hand, provide the phospholipld surfece necessery for several of the coagulation reactions.

As thrombin is involved in so many reactions simultaneously, the task of predicting its behaviour in vivo, from experiments carried out in purified systems becomes daunting (Like looking at the climatological situation in an air conditioned building, and using the information gained in this manner to predict the weather outside). We therefore chose to stay close to the physiological milieu of the coagulation system, and set up measurements in plasma or whole blood. In doing so it was inevitable that we sacrificed, to a certain extent, the exact definition of the experimental system used. But it should be kept in mind that we could fall back on a solid base of knowledge about the proteins involved and their interactions, and that experiments in purified or partially purified systems still served us 
as valuable tools for testing hypotheses developed from the integral system.

Chapter two describes a technique we developed for measuring thrombin concentrations in clotting whole blood which has not been anticoagulated upon its collection. In this way we could study the coaguation process in an environment that more closely approximntes the physiological reaction environment. We first cornpared thrombin generation in this system with thrombin generation in whole blood that has gone through the usual procedure of citration and recalcification. Subsequently the influence of aspirin treatment on thrombin generation was investigated in an attempt to demonstrate the interdependence of coagulation and platelet reactions. Aspirin inhibits the thromboxane synthesis of platelets but has no direct effect on the coagulation system.

In Chapter three we analyse time curves of thrombin concentration in plasma, and curves of the time integral of the free thrombin concentration. The latter were measured using a new continuous measurement of thrombin activity in plasma. It is shown how the confounding influence of the $a_{2}$-macroglobulin thrombin complex can be accounted for, and how several important parameters can be obtained from the experimental data. These include the time course of prothrombin activation in plasma, and the thrombin potential. It is also shown why, even in the presence of heparin, thrombin inhibition by antithrombin III is a second order process.

Chapter four presents a technique for measuring concentrations of activated factor VIII in plasma. It deals with the extreme instability of factor VIIIa, and the ability of factor Xa to activate the non-activated factor VIII which is present in plasma samples. This method allowed us to investigate one of the thrombin induced positive feedback mechanisms of coagulation in plasma.

In chapter 5 we investigate the initial phase of the coagulation process in plasma, combining a newly developed assay of low factor Xa concentrations with the measurement of the clotting factors $\mathrm{Va}$, VIIla and thrombin. Coagulation in these experiments was triggered with physiologically low concentrations of tissue factor. The importance of Tissue Factor Pathway Inhibitor, and the role of the alternative extrinsic pathway are shown. A synthetic thrombin inhibitor was used to study positive feedback through cofactor activation. The data presented in this chapter shine a new light on the initial phase of the coagulation process in plasma. 
As mentioned before, we tried to approach the in vivo situation of the blood coagulation process by setting up measurements of clotting factors in plasma and whole blood. We attempted to go one step beyond this and extend our measurements to blood flowing from bleeding time wounds. Whether the coagulation system plays a role in bleeding time hemostasis is still a matter of debate. Many of the published experiments suggesting no influence of thrombin could also be interpreted differently, viz. thrombin being required in trace amounts. The large variability of the present day bleeding time measurements precludes obtaining convincing evidence for either possibility. Chapter six describes an attempt at minimizing bleeding time variability by using an automated bleeding time monitor.

\section{references}

1. Vu T-KH, Hund DT, Wheston VI, Coughlin SR. Molecular cloning of a functional thrombin receptor reveals a novel proteolytic mechanism of receptor activation. Cell 1991;64:1057-68.

2. Esmon NL, Owen WG, Esmon CT. Isolation of a membrane-bound cofactor for thrombin-catalyzed activation of protein C. J Biol Chem 1982;257(2):85964.

3. Comp PC, Jacocks RM, Ferrell GL, Esmon CT. Activation of protein C in vivo. J Clin Invest 1982;70:127-34.

4. Chen LB, Buchanan JM. Mitogenic activity of blood components. I. Thrombin and prothrombin. Proc Natl Acad Sci USA 1975;72:131-5.

5. Teng NNH, Chen LB. The role of surface proteins in cell proliferation as studied with thrombin and other proteases. Proc Natl Acad Sci USA 1975:72:413-7.

6. Zetter BR, Sun TT, Chen LB, Buchanan JM. Thrombin potentiates the mitogenic response of cultured fibroblasts to serum and other growth promoting agents. J Cell Physiol 1977;92:233-40.

7. Pohjanpleto P. Proteases stimulate proliferation of human fibroblasts. J Cell Physiol 1977;91:387-92.

8. Kieffer N, Phillips DR. Platelet membrane glycoproteins: Functions in cellular interactions. Annu Rev Cell Biol 1990;6:329-57.

9. O'Toole TE, Lothus JC, Du X, Glass AA, Ruggeri ZM, Shattill SJ, et al. Affinity modulation of the $\alpha_{11} \beta_{3}$ integrin (platelet GPIIb-IIIa) is an intrinsic property of the receptor. Cell Reg 1990;1:883-93.

10. Bevers E, Comfurius P, van Rijn JMML, Hemker HC, Zwaal RFA. Generation of prothrombin converting sctivity and the exposure of phosphatidylserine at the outer surface of platelets. Eur J Biochem 1982;122:429-36. 
11. Rosing J, Tans G, Govers-Riemslag JWP, Zwal RFA, Hemker HC. The role of phospholipids and Extor $V_{a}$ in the prothrombinase complex. J Biol Chem 1980:255(1):274-83.

12. Nesheim ME, Taswell JB, Mana KG. The contribution of hovine factor V and factor $\mathrm{Va}$ to the activity of prothrombinase. J Biol chem 1979;254(21): 1095262.

13. Rijn van JLML, Govers-Riemslng JW!, Zwad RFA, Rosing J. Kinetic studies on prothrombin activation: Effect of factor $\mathrm{Va}_{\mathrm{a}}$ and phospholipids on the formation of the enzyme substrate complex. Biochemistry 1984;23:4557-63.

14. Lindhout T, Govers-Riemslag JWO, Waar van de P, Hemker HC, Rosing J. Factor $V_{a}$ - factor $X_{a}$ interaction. Effects of phospholipid vesicles of varying composition. Biochemistry 1982;21:5494-502.

15. Sandberg H, Andersson L, Hoglund S. Isolation and characterization of lipidprotein particles containing platelet factor 3 released from human platelets. Biochem J 1992;203:303-11.

16. Hemker HC. Velkkamp JJ, Hensen A, Loeliger EA. Nature of prothrombin biosythesis: preprothrombinemin in vitumin $K$ deficiency. Nature 1963;200:589-90.

17. Nelsestuen GL. mole of y-carboxyglutamic acid. An unusual protein transition required for the calcium-dependent binding of prothrombin to phospholipid. J Biol Chem 1976:251(18):5648-56.

18. Suttie JW. Mechanism of action of vitamin K: Synthesis of $\gamma$-carboxyglutamic acid. CRC Crit Rev Biochem 1980;8(2): 189.

19. Suttie JW, Jackson CM. Prothrombin structure, activation and biosynthesis. Physiol Rev 1977;57:1-65.

20. Radcliffe R, Nemerson Y. Activation and control of factor VII by activated factor $\mathrm{X}$ and thrombin. Isolation and characterization of a single chain form of factor VII. J Biol Chem 1975;250:388-95.

21. Seligsohn U, Osterud B, Brown SF, Griftin JH, Rapaport SI. Activation of human factor VII in plasma and in purified systems. Roles of activated factor IX, kallikrein, and activated factor XII. J Clin lavest 1979;64:1056-65.

22. Masys DR, Bajaj SP. Rapaport SI, Activation of human factor VII by activated factor IX an X. Blood 1982;60:1143-50.

23. Nemerson $Y$, Repke D. Tissue factor accelearates the activation of coagulation factor VII. The role of a bifunctional cofactor. Thromb Res 1985;40:351-58.

24. Rao LVM, Bajaj SP, Rapaport SI. Activation of buman factor VII during clotting in vitro. Blood 1985;65:218-26.

25. Rao LVM, Rapaport SI. Activation of factor VII bound to tissue factor: A key eraly step in the tissue factor pathway of blood coagulation. Proc Natl Acad Sci USA 1988;85:6687-91.

26. Bajaj SP, Rapaport SI, Brown SF. Isolation and characterisation of human factor VII. Activation of factor VII by factor Xa. J Biol Chem 1981;256:253-9. 
27. Pujikawa K, Coan MH, Legaz ME, Davie EW. The mechanism of activation of bovine factor $X$ (Stuart factor) by intrinsic and extrinsic pathways. Biochemistry 1974;13:5290-9.

28. Kisiel W, Davie EA. Isolation and characterization of bovine factor VII. Biochemistry 1975;14(22):4928-34.

29. Zur M, Nemerson $Y$. The esterase activity of congulation factor VII. Evidence for intrinsic activity of the zymogen. J Biol Chem 1978;253(7):2203-9.

30. Nemerson Y. Regulation of the initiation of coagulation by factor VII. Heemostasis 1983;13:150-5.

31. Williams EB, Krishnaswamy S, Mann KG. Zymogen/enzyme discrimination using peptide chloromethyl ketones. J Biol Chem 1989;264:7536-45.

32. Wildgoose $\mathrm{P}$, Kisiel W. Activation of human factor VII by factors $\mathrm{XXa}$ and $\mathrm{Xa}$ on human bladder carcinoma cells. Blood 1989;73(7):1888-95.

33. Lawson JH, Butenast S, Mann KG. The evaluation of complex-dependent alterations in human factor VIIa. J Biol Chem 1992;267:4834-43.

34. Hemker HC, Kahn MJP. Reaction sequence of blood coagulation. Nature 1967;215:1201.

35. Dieijen van G, Tans G, Rosing J, Hemker HC. The role of phospholipid and factor VIIla in the activation of bovine factor X. J Biol Chem 1981;256:343342.

36. Dieijen van G, Rijn van JLML, Govers Riemslag JWP, Hemker HC, Rosing J. Assembly of the intrinsic factor $\mathrm{X}$ activation complex - Interactions between factor IXa, factor VIIla and phospholipid. Thromb Hacmost 1985;53(3):396400.

37. Fujikawn $\mathrm{K}$, Legaz ME, Davie EW. Bovise factor $\mathrm{X}_{1}$ (Stuart factor). Mechnnism of activation by a protein from Russel's viper venom. Biochemistry 1972;11(26):4892-9.

38. Fair DS, Plow EF, Edgington TS. Combined functional and immunochemical analysis of normal and abnormal factor X. J Clin Invest 1979:64:884-94.

39. Papahadjopoulos D. Hanahan DJ. Observations on the interaction of phospholipids and certain clotting factors in prothrombin activator formation. Biochim Biophys Acta 1964;90:436-9.

40. Nemerson Y. Tissue factor and hemostasis. Blood 1988;71:1-8.

41. Rapaport SI, Schiffman S, Patch MJ, Ames SB. The importance of activation of antiheamophilic globulin and proaccelerin by traces of thrombin in the generation of intrinsic prothrombinase activity. Blood 1963;21:221-36.

42. Rapapon SI, Hjort PF, Patch MJ. Further evidence that thrombin activation of factor VIII is an essential step in intrinsic clotting. Scand J Clin Lab Invest suppl 1965; 17: 84-8.

43. Biggs R, Macforlane RG, Denson WE, Ash BJ. Thrombin and the interection of factors VIII and IX. Brit J Heemat 1965; 11: 276-295. 
44. Colmnn RW. The effect of proteolytic enzymes on bovine factor V. Kinetics of activation and inactivation by bovine thrombin. Biochemistry 1969: 4: 143844.

45. Zimmermen TS, Fulcher CA. Factor VIII procoagulant protein. Clinics in Haematology 1985; 14(2):343-58.

46. Fulcher CA, Zimmerman TS. Characterization of the human factor VIII procoagulant protein with a heterologous precipitating antibody. Proc Natl Aced Sci USA 1982;79:1648.

47. Tracy PB, Eide LL, Bowie EJW, Mann KG. Radioimmunoassay of factor $V$ in human plasma and platelets. Blood 1982;60(1):59-63.

48. Carrel RW, Christey PB, Boswell DR. Serpins: antithrumbin and other inhibitors of coagulation and fibrinolysis. Evidence from amino acid sequences. In Verstraete M, Vermylen J, Lijnen R, Arnout J (eds): Thrombosis and Haemostasis 1987, Leuven University Press, Leuven pp 1.

49. Longstaff C, Gaffney PJ. Serpin-serine protease binding kinetics: $\alpha_{2}$. antiplasmin as a model inhibitor. Biochemistry 1991:30(4):979-86.

50. Olson ST, Shore JD. Demonstration of a two-step reaction mechunism for inhibiton of $\alpha$-thrombin by antithrombin III and identification of the step affected by heparin. J Biol Chem 1982;257:14891-95.

51. Olson ST, Shore JD. Transient kinetics of heparin-catalyzed protease inactivation by antithrombin III. The reaction step limiting heparin turnover in thrombin neutralization. J Biol Chem 1986;2661(28):13151-9.

52. Shore JD, Olson ST, Craig PA, Choay J, Bjork I. Kinetics of heparin action. Ann NY Acad Sci 1989;556:75-80.

53. Rao LVM, Rapaport SI. Studies of a mechanism inhibiting the initiation of the extrinsic pathway of coagulation. Blood 1987;69:645-51.

54. Broze GJ, Warren LA, Novotny WF, Higuchi DA, Girard JJ, Miletich JP. The lipoprotein-associated coagulation inhibitor that inhibits the factor VII-tissue factor complex also inhibits factor $\mathrm{Xa}$ : Insight into its possible mechrnism of action. Blood 1988:71:335-43.

55. Kisiel W, Canfield WM, Ericsson LH, Davie EW. Anticoagulant properties of bovine plasma protein C following activation by thrombin. Biochemistry 1977;16(26):5824-31.

56. Vehar GA, Davie EW. Preparation and properties of bovine factor VIII (Antihemophilic factor). Biochemistry 1980;19(3):401-10.

57. Lorand L. Interaction of thrombin and fibrinogen. Physiol Rev 1954;34:742.

58. Seegers WH, Nieft ML, Loomis EC. Note on the adsorbtion of thrombin on fibrin. Science 1945; 100:520-1.

59. Quick AJ, Favre-Gilly JE. Fibrin: A factor influencing the consumption of prothrombin in coagulation. Am J Physiol 1949;158:387.

60. Jackson CM, Nemerson Y. Blood coagulation. Ann rev biochem 1980;49:765811. 
61. Josso F, Prou-Wartelle O. Interaction of tissue factor and factor VII at the earliest phase of coagulation. Thromb Diath Hemorrt 1965;171:35-44.

62. Sterud B, Rapaport SI. Activation of factor IX by the reaction product of tissue factor and factor VII: Additional pathway for initiating blood coagulation. Proc Natl Acad Sci USA. 1977;74(12):5260-4.

63. Esterud B, Rapaport SI. Activation of ${ }^{125} 5_{\text {I-factor IX and }}{ }^{125} 5_{\text {I-factor X }}$ : Effect of tissue factor and factor VII, factor $\mathrm{Xa}_{\mathrm{a}}$ and thrombin. Scand $\mathrm{J}$ Haematol 1980;24:213-26.

64. Marlar RA, Kleiss AJ, Griffin JH. An alternative extrinsic pathway of human blood coagulation. Blood 1982;60(6): 1353-8.

65. Giesen PLA, Willems GM, Hermens WTh. Production of thrombin by the prothrombinase complex is regulated by membrane-mediated transpor of prothrombin. J Biol Chem 1991;266(3): 1379-82.

66. Krishnaswamy S, Jones KC, Mann KG. Prothrombinase complex assembly. Kinetic mechanism of enzyme assembly on phospholipid vesicles. J Biol Chem 1988; 263(8):3823-34.

67. Giesen PLA, Willems GM, Hemker HC, Hermens WTh. Membrane-mediated assembly of the prothrombinase complex. J Biol Chem 1991;266(28):18720-5.

68. Jesty J, Nemerson Y. Purification of factor VII from bovine plasma. Reaction with tissue factor and activation of factor X. J Biol Chem 1974;25:509-15.

69. Zur M, Nemerson Y. Kinetics of factor IX activation via the extrinsic pathway. J Biol Chem 1980;255(12):5703-7.

70. Silverberg SA, Nemerson Y, Zur M. Kinetics of the activation of bovine coagulation factor $\mathrm{X}$ by components of the extrinsic pathway. Kinetic behavior of two-chain factor VII in the presence and absence of tissue factor. J Biol Chem 1977;252:8481-8.

71. Bauer KA, Rosenberg RD. The pathophysiology of the prethrombotic state in humans: Insights gained from studies using markers of hemostatic system activation, Blood 1987;70(2):343-50.

72. Hemker HC, Kessels H. Feedback mechanisms in coagulation. Haemostasis 1991:21:189-96.

73. Willems GM, Lindhout T, Hermens WTh, Hemker HC. Simulation model for thrombin generation in plasma. Haemostasis 1991;21:197-207.

74. Foster WB, Nesbeim ME, Mann KG. The factor Xa-catalyzed activation of factor V. J Biol Chem 1983:258:13970.

75. Monkovic DD. Tracy PB. Activation of human factor $\mathrm{V}$ by factor $\mathrm{Xa}$ and thrombin. Biochemistry 1990;29:1118-28.

76. Hultin MB. Role of human factor VIII in factor $\mathbf{X}$ activation. I Clin Invest 1982;69:950-5.

77. Lollar P, Knutson GJ, Fass DN. Activation of porcine factor VIII by thrombin and factor Xa. Biochemistry 1985;24:8056-64. 
introduction

78. Peters J. Lindhout T, Hemker HC. In situ-generated thrombin is the only enzyme that effectively activates factor VIII and factor $V$ in thromboplastinactivated plasma. Blood 1989:74:1021-4.

79. Goldsmith HL. Turrito VT. Rheological aspects of thrombosis and haemostasis: Basic principles and applications. Thromb Haenost 1986;55:415. 35.

80. Leonard EF. Rheology of thrombosis. In: Hemostasis and thrombosis. Basic principles and clinical practice. $2^{\text {nd }}$ edition (Eds Dolman RW, Hirsh J, Murder VJ, Salesman EW) JP Lippincott Company, Philadelphia 1987, 1111-22.

81. The sixty plus reinfanction study research group. A double-blind trial to assess longterm oral anticoagulant therapy in elderly patients after myocardial infarction. Lancet 1980;2:989-94.

82. Neri-Serneri GG, Rovelli F, Gensine GF, Pirelli S, Carnovali M, Fortini A. Effectiveness of low-dose heparin prevention of myocardial reinfarction. Lancet 1987;25:937-42.

83. Hers M, Chesebro JH, Webster MWI, Mruk JS, Grill DE, Penny WJ, et al. Hirudin, heparin, and placebo during deep arterial injury in the pig. Circulation 1990;82:1476-84.

84. Badimon L, Badimon J, Lassila R, Heres M, Chesebro JH, Buster V. Thrombin isolated collagen type 1 at arterial flow conditions in a porcine model: effects of hirudins, heparin and calcium chelation. Blood 1991;78:42334.

29 


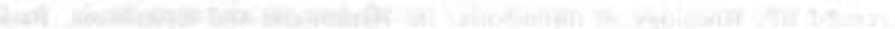

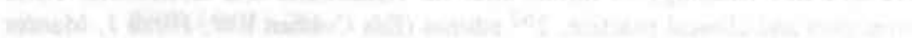

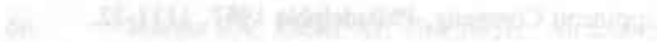

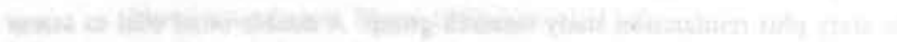

What and

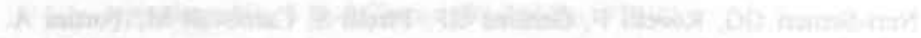

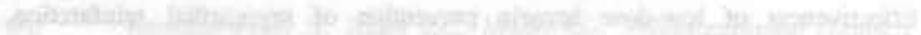

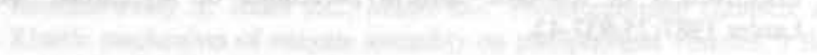

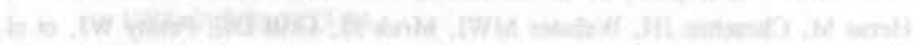

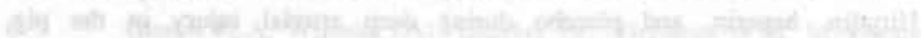

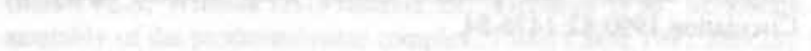

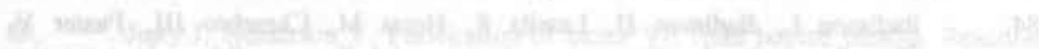

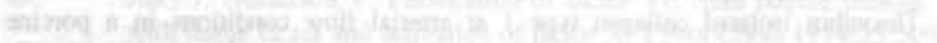

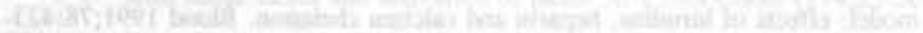

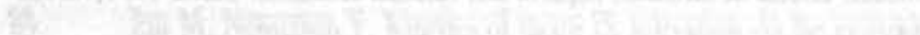

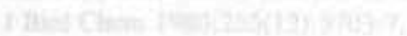

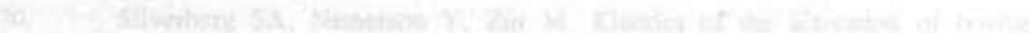

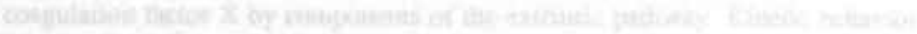

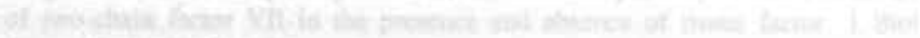

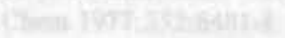

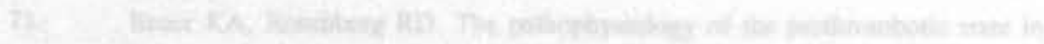

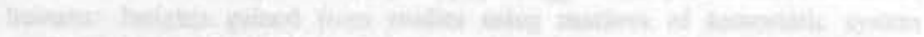

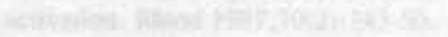

10

10

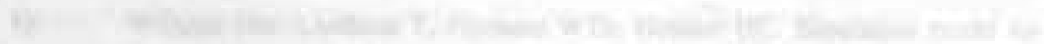

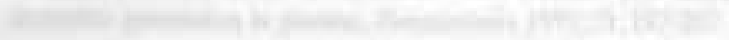

10

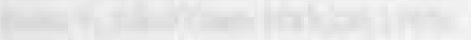

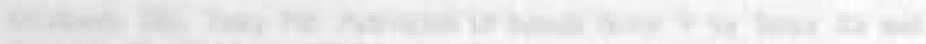

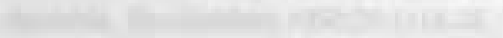

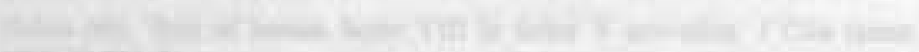
(20)

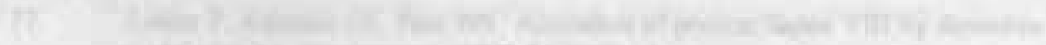

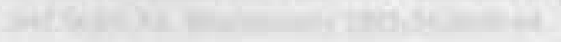




\section{measurement of thrombin generation in whole blood; the effect of heparin and aspirin."}

\section{summary}

A technique has been developed for the measurement of thrombin concentrations in freshly collected whole blood in the absence of anticoagulants. It is based on the centrifugal separation of the cellular components from subsamples of blood drawn from non-anticoagulated clotting whole blood which are diluted in buffer containing a chromogenic substrate. Using this technique it is shown that the burst of thrombin generation after triggering coagulation with trace amounts of tissue thromboplastin occurs sooner in non-anticoagulated whole blood than in citrated whole blood. This reduction of the lag time of thrombin generation is relatively larger in the presence of heparin. In addition, it is demonstrated that intake of $500 \mathrm{mg}$ of aspirin delays and inhibits thrombin generation in non-anticoagulated, thromboplastin triggered whole blood, demonstrating that platelet reactions and the coagulation system are closely linked processes. It further lends support to the hypothesis that inhibition of thrombin generation is a common denominator of antithrombotic therapy.

\section{introduction}

Thrombin is a central enzyme in the process of haemostasis, being at the cross-roads of coagulation and platelet reactions. Measurement of thrombin generation in clotting plasma has provided much insight in the mechanisms of action of the coagulation system (1). Moreover, platelet rich plasma has proven a rich source of data on the interplay of the enzymatic and the cellular pathways in a near-physiological system (2). Usually, plasma is prepared from blood which has been collected on citrate. The plasma is recalcified when coagulation is triggered. This

\footnotetext{
"based on: Kessels H, Beguin S, Henker H.C. submitted for publication
} 
process of citration and recalcification, however, may influence the function of platelets and the coagulation system.

In order to remain closer to the physiological circumstances under which hemostasis takes place, we developed a technique for measuring thrombin concentrations in non-anticoagulated whole blood. Chromogenic assays in whole blood are hampered by the preserice of hemoglobin, with a broad light absorption peak around $420 \mathrm{~nm}$. Erythrocytes were discarded by centrifugation of subsamples which were taken from clotting whole blood and diluted in buffer containing a chromogenic substrate. In order to investigate possible influences of citration on coagulation, this technique was employed to compare thrombin generation in untreated and citrated whole blood, after addition of trace amounts of human brain thromboplastin, in the presence and absence of heparin.

The coagulation system and platelet activation are closely coupled, since activated platelets provide the negatively charged phospholipid surface necessary for various reactions of the coagulation system, and since thrombin, especially in combination with collagen, is the most potent physiological activator of platelets. Therefore, inhibition of platelet function may be expected to affect thrombin generation. Acelylsalicylic acid (aspirin) inhibits platelet function by irreversibly acetylating platelet cyclooxygenase (7). It causes a prolongation of the bleeding time (8) and has been reported to reduce the incidence of thromboembolic disease in several populations at risk $(3,4,5,6)$. However, no influence of aspirin on thrombin generation was known. This has cast considerable doubts on the involvement of thrombin in primary hemostasis. It seems, furthermore, not compatible with a close linkage of coagulation and platelet reactions. To prevent obscuring influences of de- and recalcification, we investigated the possible effect of aspirin on the coagulation system by measuring thrombin generation in whole blood without added anticoagulants, triggered with trace amounts of thromboplastin.

\section{materlals and mothods}

\section{materials}

Buffers used were $50 \mathrm{mM}$ Tris- $\mathrm{HCl}, 100 \mathrm{mM} \mathrm{NaCl}$ and $0.5 \mathrm{~g} / 1$ bovine serum albumin (Sigma), pH 7.35 (buffer A), and $50 \mathrm{mM}$ Tris-HCl, 100 $\mathrm{mM} \mathrm{NaCl}, 20 \mathrm{mM}$ EDTA (ethylene dinitrilo tetra-acetic acid) and $0.5 \mathrm{~g} / 1$ bovine serum albumin, pH 7.9 (buffer B).

$4^{\text {th }}$ Internationa! standard heparin was obtained from the National Bureau of Standards and Control (London). Enoxaparin was from RhonePoulenc-Rorer (Paris). The stable synthetic prostacyclin analog Ilomedine (ZK36374) was from Schering AG (Berlin). 
Chromogenic substrate for thrombin was S2238 (H-D-Phe-Pip-ArgpNA.2HCl, from Kabi, Sweden).

Human brain thromboplastin was prepared as described by Owren (9). It was subsequently centrifuged at $1000 \mathrm{rpm}$ for $5 \mathrm{~min}$ and stored in $50 \mu \mathrm{l}$ aliquots at $-80^{\circ} \mathrm{C}$. It was thawed and diluted in buffer A containing $2 \mathrm{mM}$ $\mathrm{CaCl}_{2}$ (for untreated whole blood) or $100 \mathrm{mM} \mathrm{CaCl}_{2}$ (for blood collected on citrate). Subsequently, it was incubated at $37{ }^{\circ} \mathrm{C}$ for $30 \mathrm{~min}$ before use. Final dilution after addition was 1 in 3600 . Tenfold less diluted thromboplastin produces a clotting time of $70 \mathrm{~s}$ in platelet poor plasma.

\section{methods}

measurement of thrombin generation In non-anticoagulated whole blood

Blood was obtained by antecubital venipuncture. The first 2 to $3 \mathrm{ml}$ were discarded and then $5 \mathrm{ml}$ were collected in a plastic tube not containing an anticoagulant, and immediately transferred to a water bath at $37^{\circ} \mathrm{C}$.

1 Volume of buffer A was added to 9 volumes of whole blood, to obtain a dilution of blood equal to that of citrated blood. The active, or cell free, volume $\left(\mathrm{V}_{\text {aci }}\right)$ of this mixture is obtained by subtracting the volume occupied by the cells, as determined from a haematocrit measurement, from the total volume. $0.25 \cdot \mathrm{V}_{\text {act }}$ of buffer $\mathrm{A}$ containing any substance under investigation was added, and coagulation was triggered by addition of $0.25 \cdot \mathrm{V}_{\text {act }}$ of buffer $\mathrm{A}$ containing $1 / 600$ diluted thromboplastin (final dilution 1/3600). This last addition was at exactly $1 \mathrm{~min}$ after collection of blood. All additions contained $2 \mathrm{mM}$ of $\mathrm{CaCl}_{2}$.

At timed intervals $10 \mu \mathrm{l}$ subsamples were taken from the whole blood mixture and transferred to tubes containing $190 \mu \mathrm{l}$ buffer B with $200 \mu \mathrm{M}$ of the chromogenic substrate S2238. Within $10 \mathrm{~s}$ a second dilution was made by transferring $40 \mu \mathrm{l}$ of the obtained mixture to a microcentrifuge tube containing $760 \mu \mathrm{l}$ buffer B, again containing S2238 (final concentration $200 \mu \mathrm{M}$ ). This amounts to an overall dilution of 1 in 400 of the original subsample. In addition to providing the measurable signal, S2238 competitively inhibits inactivation of thrombin in the reaction mixture. It is for this reason that in the intermediate mixture \$2238 was included as well.

As soon as the clot tended to interfere with subsampling, it was removed. This appeared not to influence thrombin generation (data not shown). The micro centrifugation tubes were kept on ice until subsampling had finished. They were subsequently centrifuged for $1 \mathrm{~min}$ at high speed. Supernatants were transferred to disposable microcuvettes and prewarmed for at least $3 \mathrm{~min}$ at $37{ }^{\circ} \mathrm{C}$. The rate of conversion of S2238 was then determined photometrically at $405 \mathrm{~nm}$ by a two point measurement of 
optical density. This rate was converted to thrombin concentration in the whole blood sample using a conversion factor of $9.06 \mathrm{pM}$ thrombin / ( $\mathrm{mOD} / \mathrm{min}$ ), obtained using active site-titrated pure human $\alpha$-thrombin. The thrombin concentration was then corrected for the void volume occupied by the erythrocytes in the original subsample. This void volume decreases during the course of bloodclotting. This was shown (cf. fig 1) to be due only to cells getting entrapped in the clot when it is in the process of being formed. Thus, it seemed appropriate to use the initial $\mathrm{Ht}$ values for samples until clot formation, and the final $\mathrm{Ht}$ values for samples starting from clot formation.

\section{thrombin measurement in whole blood collected on citrate}

Blood was collected on $0.13 \mathrm{M}$ trisodium citrate, nine parts of blood on one part of citrate solution. It was immediately transferred to a waterbath. To this mixture were added a volume of $0.25 \cdot \mathrm{V}_{\mathrm{act}}$ of buffer $\mathrm{A}$, with or without various concentrations of standard heparin and enoxaparin, and, at 1 min after collection, $0.25 \cdot \mathrm{V}_{\text {act }}$ of thromboplastin diluted $1 / 600$ (final dilution $1 / 3600$ ) in $100 \mathrm{mM} \mathrm{CaCl}_{2}$ (final added concentration $16.7 \mathrm{mM}$ ). Further processing was carried out as described above for thrombin measurement in untreated whole blood.

\section{thrombin mosaurement in platolet rich plasma}

This was carried out as previously described (2). Briefly, platelet rich plasma (PRP) was prepared from citrated whole blood by centrifugation $(10 \mathrm{~min}, 1000 \mathrm{rpm})$. To $240 \mu \mathrm{l}$ of PRP were added $60 \mathrm{ul}$ of buffer A, and $60 \mu \mathrm{l}$ of $1 / 600$ diluted thromboplastin (final dilution $1 / 3600$ ) in $100 \mathrm{mM}$ $\mathrm{CaCl}_{2}$ (final added concentration $16.7 \mathrm{mM}$ ). Thrombin generation was then monitored by diluting timed subsamples in buffer B containing 200 $\mu \mathrm{M}$ S2238, and assessing the $\$ 2238$ conversion rate by an end-point measurement of optical density (10).

\section{determination of calclum dependency of clotting times}

Blood was collected in an empty PVC tube and immediately placed in a waterbath. At registered times within $2 \mathrm{~min}$ after collection, $500 \mu \mathrm{l}$ were added to a tube containing $55.6 \mu \mathrm{l}$ of trisodium citrate, $0.25 \cdot \mathrm{V}_{\text {act }}$ of a mixture containing one of several $\mathrm{CaCl}_{2}$ concentrations, with or without $1.2 \mathrm{U} / \mathrm{ml}$ of standard heparin (final concentration $0.2 \mathrm{U} / \mathrm{ml}$ ), and $0.25 \cdot V_{\text {act }}$ of $1 / 600$ diluted thromboplastin (final dilution $1 / 3600$ ) in buffer A. Also, $500 \mu \mathrm{l}$ of blood were added to a tube with $55.6 \mu \mathrm{l}$ of buffer $A$ containing $2 \mathrm{mM} \mathrm{CaCl}, 0.25 \cdot \mathrm{V}_{\mathrm{aca}}$ of a mixture containing $2 \mathrm{mM} \mathrm{CaCl}$, with or without $1.2 \mathrm{U} / \mathrm{ml}$ of standard heparin (final concentration 0.2 $\mathrm{U} / \mathrm{ml}$ ), and $0.25 \cdot \mathrm{V}_{\text {act }}$ of $1 / 600$ diluted thromboplastin (final dilution $1 / 3600$ ) in buffer $A$, again with $2 \mathrm{mM} \mathrm{CaCl}$. 


\section{aspirin}

The effect of intake of a single dose of $500 \mathrm{mg}$ of aspirin on thrombin generation in whole blood was investigated in 10 healthy male volunteers, none of whom had taken any medication for at least one week. Thrombin generation in non-anticoagulated whole blood, after triggering coagulation with thromboplastin (final dilution $1 / 3600$ ), was measured $5 \mathrm{~min}$ before, and $1.5 \mathrm{~h}$ after aspirin ingestion.

\section{Iag times}

Lag times of thrombin formation were defined as the time necessary to reach a level of $50 \mathrm{nM}$ of thrombin, as determined by linear interpolation.

\section{heomatocrit}

Haematocrit values were measured by centrifugation of standard heparinized haematocrit capillaries.

\section{results}

The plasma volume of a sample of whole blood can be determined as the difference between the total sample volume, and the volume occupied by cells. The latter is equal to the total sample volume multiplied by the haematocrit. To investigate whether this cell volume does not change during coagulation, we measured the haematocrit at timed intervals during a thrombin generation experiment.

Fig. 1 shows that the cell volume remains constant during the first few minutes, jumps to a lower level at the timed clot formation, and then remains constant again. For calculation of thrombin concentrations, we used the preclot value of the Ht until the moment that $10 \mathrm{nM}$ of thrombin had formed, which is roughly equal to the moment of clotting, and the postclot value afterwards.

When collected blood is not anticoagulated, a slow intrinsic initiation of the coagulation system may occur, resulting in clot formation after 15 to 20 min (when PVC tubes are used). Several precautions were taken to minimize this activation: The first 2 to $3 \mathrm{ml}$ of blood collected were discarded since traces of tissue factor might be present. Additionally, the collected blood was pipetted carefully and not mixed using vortex type mixers. 


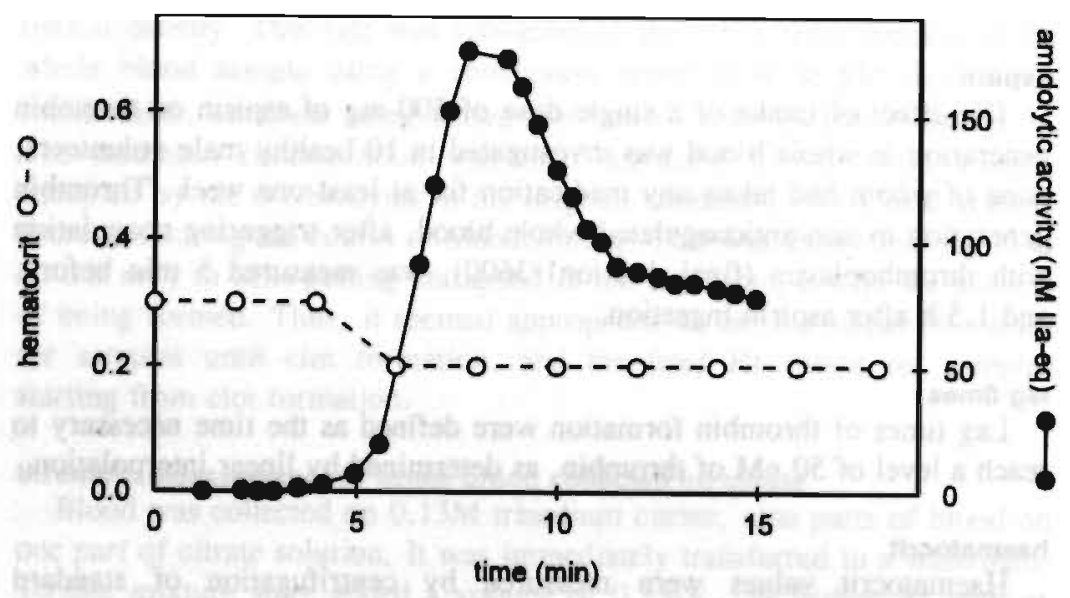

figure 1. tme couree of cell volume during clot formation.

Blood from a healthy donor was collected in a PVC tube without anticoagulant, and placed in a waterbath at $37^{\circ} \mathrm{C}$. Thromboplastin (final dilution 1 to 3600 ) was added expctly at $1 \mathrm{~min}$ after collection. Samples were drawn and processed for thrombin measurement as described in the materials and methods section. In addition, at two min intervals, $50 \mu l$ of the mixture was transferred to empty PVC tubes, from which heparinized haematocrit capillaries were filled. concentration. O… O: haematocrit.

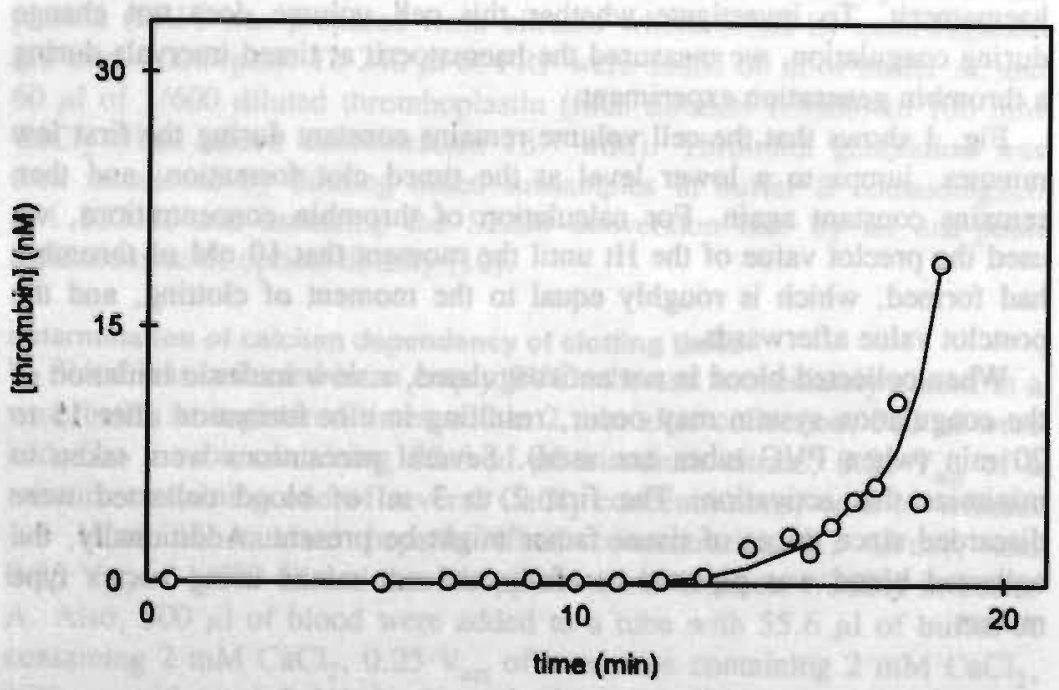

ngure 2. thrombin generation in non-triggered whole blood.

Blood from a hedthy donor was collected in an empty PVC tube at time zero and immediately placed in a waterbath at $37^{\circ} \mathrm{C}$. At timed intervals samples, were draun and assessed for thrombin as described in the materials and methods section. 


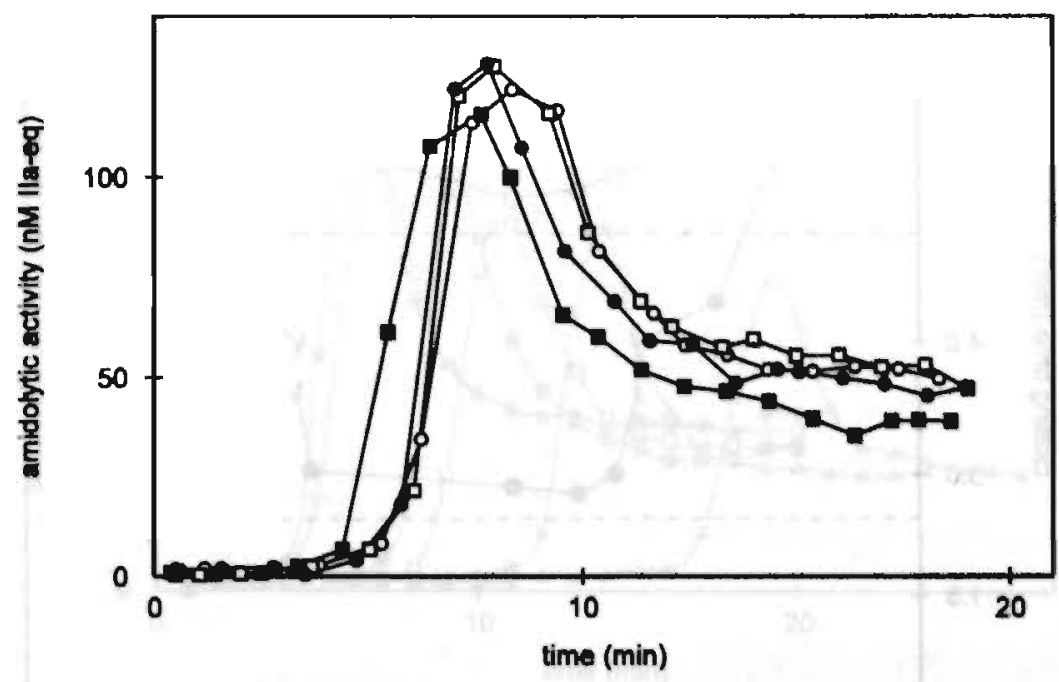

figure 3. thrombln generation in whole blood trlggered at a variable time after collection.

Blood from a healthy donor was collectecl in an emply plastic tube at time zero. and immediatefy placed in a waterbath at $37^{\circ} \mathrm{C}$. Thromboplastin (nnal dilution 1 to 3600 ) was added $1 \mathrm{~min}(\bullet), 3 \mathrm{~min}(0), 5 \mathrm{~min}(\square)$ or $7 \mathrm{~min}(\square)$ after collection. At intervals, samples were drawn and processed for thrombin measurement as described in the materials and methods section. The origin of the graph represents the moment of addition of thromboplastin.

In order to quantify the extent of activation of the coagulation system, we attempted to measure thrombin in non triggered whole blood during the first minutes after collection, but concentrations remained below our detection limit $(0.2 \mathrm{nM})$ for more than $10 \mathrm{~min}$ (fig.2). Fig. 3 shows that the time delay between blood collection and triggering coagulation with thromboplastin can be extended to $5 \mathrm{~min}$ without a detectable influence on thrombin generation. Only when thromboplastin was added at $7 \mathrm{~min}$ or more after collection, we observed a slightly accelerated thrombin generation curve. In all further experiments, blood was triggered at exactly $1 \mathrm{~min}$ after collection.

The optimal amount of $\mathrm{Ca}^{2+}$ for recalcifying citrated whole blood was determined by measuring the clotting times of citrated whole blood recalcified with different $\mathrm{Ca}^{2+}$ concentrations, in the presence and absence of standard heparin $(0.2 \mathrm{U} / \mathrm{ml}$, final concentration). fig. 4 shows the existence of a relatively broad $\mathrm{Ca}^{2+}$ optimum. The figure also shows that no citrate - calcium ratio can rival non-anticoagulated whole blood with regard to sheer speed of clotting. 


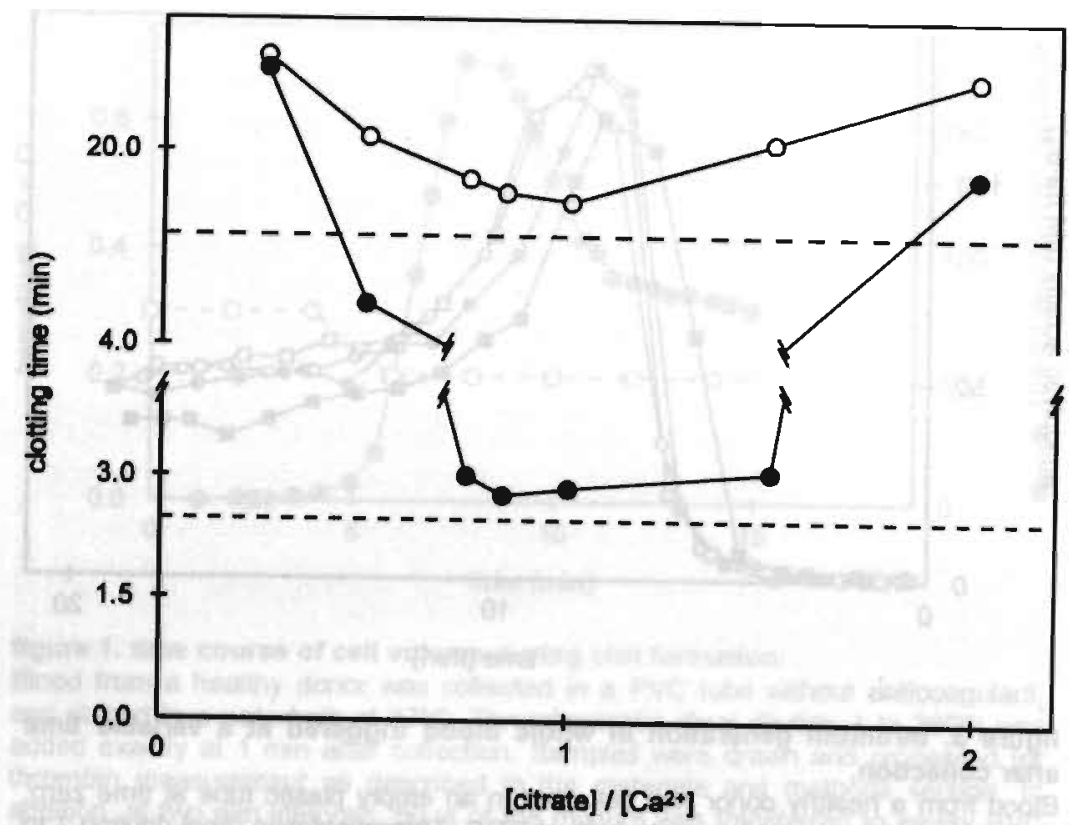

figure 4. Infinence of the cltrate/calclum ratio on the clotting times of whole blood in the presence and absence of standard heparin.

Blood from a healthy donor was collected in an empty plastic tube, and immediately transferred to a waterbath at $37^{\circ} \mathrm{C}$. Clotting times were measured as described in the materials and methods section, after addition of diluted thromboplastin (1/3800), in the presence (O) or absence $(\theta)$ of $0.2 \mathrm{U} / \mathrm{ml}$ of standard heparin. The citrate/Ca $\mathrm{Ca}^{2+}$ ratio was varied by adding different $\mathrm{Ca}^{2+}$ concentrations to one citrate concentration. Dotted line: clotting time of nonanticoagulated whole blood.

Fig.5 (upper panel) compares thrombin generation in citrated and nonanticoagulated whole blood in the presence of standard heparin. Blood was collected three times from the same volunteer, each time both on citrate and in an empty plastic tube. Thrombin generation was measured upon addition of thromboplastin $(1 / 3600)$, with or without addition of 0.1 or $0.2 \mathrm{U} / \mathrm{ml}$ of standard heparin. Measurements of thrombin generation in citrated and non-anticoagulated whole blood were always carried out in parallel, starting $1 \mathrm{~min}$ after collection. The lower panel of fig. 5 shows the same experiment, performed with and without $1 \mu \mathrm{g} / \mathrm{ml}$ of enoxaparin. The lag phase between triggering and the burst of thrombin generation was shorter in untreated whole blood than in citrated whole blood. Increasing concentrations of heparin cause a lag time that is progressively longer in citrated whole blood than in non-anticoagulated whole blood . 

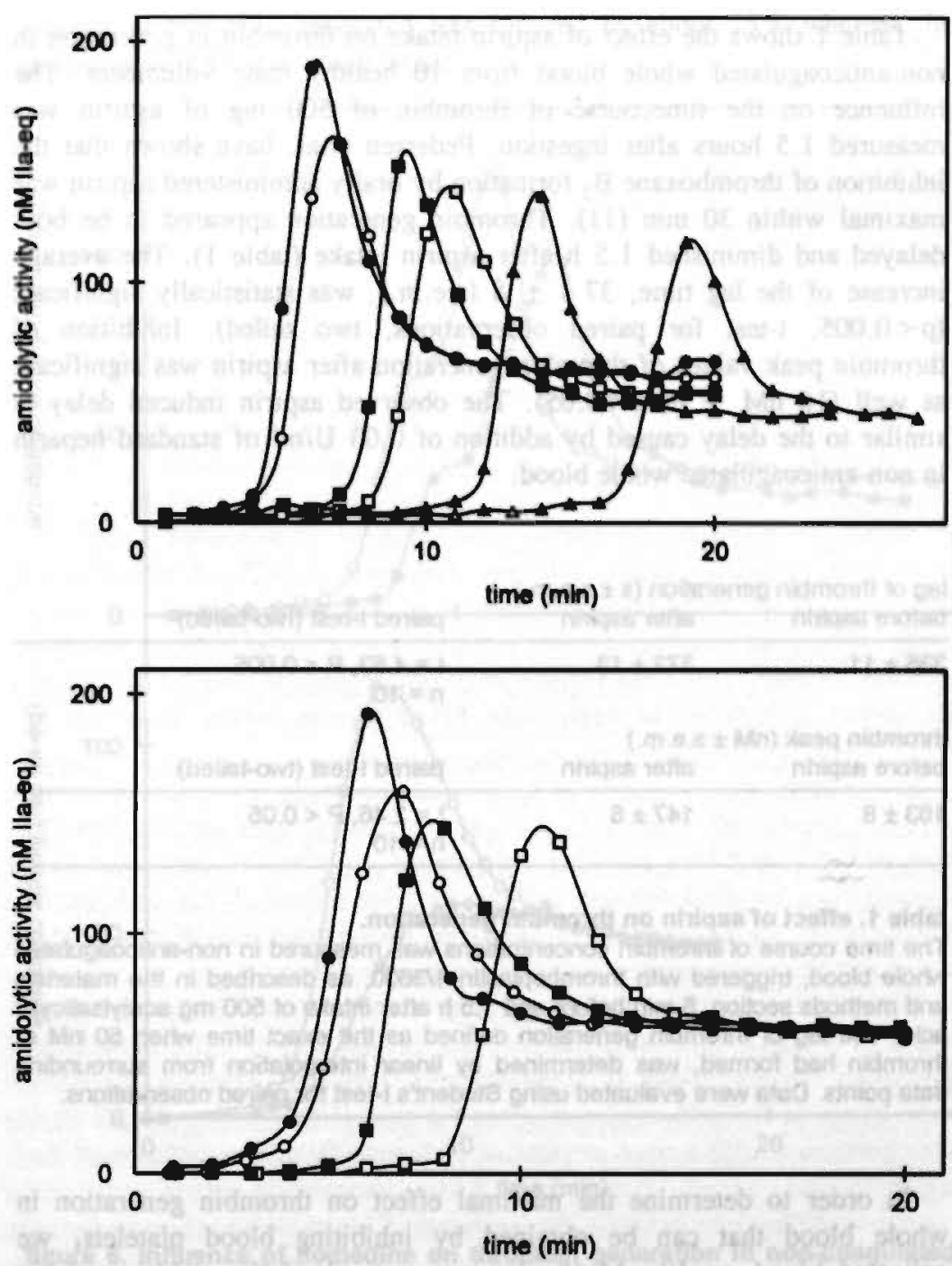

figure 5. thrombln generation in untreated and cltrated whole biood, eflect of standard heparin and the low molecular woight heparin exoxaparin.

Blood from a healthy donor was collected both on citrate, and in an empty plastic tube. Both were transferred to a waterbath at $37^{\circ} \mathrm{C}$. Stenderd heperin (upper graph, final concentrations $0(0), 0.1(\square)$ or $0.2(\Delta) \mathrm{U} / \mathrm{ml}$ ) or enoxapein (lower graph, final concentrations 0 (O) or 1 (D) $\mu \mathrm{g} / \mathrm{ml}$ ) was added. Clotting was triggered by addition of thromboplastin (1/3600 final dilution), at exactly 1 min after collection for the untreated whole blood, and at $1 \mathrm{~min} 30 \mathrm{~s}$ for the citrated whole blood. The experiment was run in separate series, one for each heperin concentration, on the same day with the same donor. Thrombin generation in untreated (closed symbols) and citrated (open symbols) whole blood wes measured in parallet. 
Table 1 shows the effect of aspirin intake on thrombin in generation in non-anticoagulated whole blood from 10 healthy male volunteers. The influence on the timecourse of thrombin of $500 \mathrm{mg}$ of aspirin was measured 1.5 hours after ingestion. Pedersen et.al. have shown that the inhibition of thromboxane $\mathrm{B}_{2}$ formation by orally administered aspirin was maximal within $30 \mathrm{~min}$ (11). Thrombin generation appeared to be both delayed and diminished $1.5 \mathrm{~h}$ after aspirin intake (table 1). The average increase of the lag time, $37 \mathrm{~s} \pm 8$ (s.e.m.), was statistically significant $(p<0.005, t$-test for paired observations, two tailed). Inhibition of thrombin peak values of thrombin generation after aspirin was significant as well $(16 \mathrm{nM} \pm 6, \mathrm{p}<0.05)$. The observed aspirin induced delay is similar to the delay caused by addition of $0.03 \mathrm{U} / \mathrm{ml}$ of standard heparin in non-anticoagulated whole blood.

leg of thrombin generation ( $\mathrm{s} \pm$ s.e.m.)

\begin{tabular}{lll}
\begin{tabular}{lll} 
before aspirin & after aspirin & paired t-test (two-tailed) \\
\hline $335 \pm 11$ & $372 \pm 13$ & $t=4.53, P<0.005$ \\
& $n=10$
\end{tabular} \\
\begin{tabular}{lll} 
thrombin peak ( $\mathrm{nM} \pm$ s.e.m.) \\
before aspirin & after aspirin & paired t-test (two-tailed) \\
\hline $163 \pm 8$ & $147 \pm 6$ & $t=2.46, P<0.05$ \\
& $n=10$
\end{tabular} \\
\hline
\end{tabular}

table 1. effect of aspirin on thrombin generation.

The time course of thrombin concentrations was measured in non-anticoagulated whole blood, triggered with thromboplastin $1 / 3600$, as described in the materials and methods section, $5 \mathrm{~min}$ before and $1.5 \mathrm{~h}$ after intake of $500 \mathrm{mg}$ acetylsalicylic acid. The lag of thrombin generation defined as the exact time when $50 \mathrm{nM}$ of thrombin had formed, was determined by linear interpolation from sumounding data points. Data were evaluated using Student's t-test for paired observations.

In order to determine the maximal effect on thrombin generation in whole blood that can be obtained by inhibiting blood platelets, we collected blood on $10 \mu \mathrm{M}$ (final concentration) of the stable synthetic prostacyclin analog llomedine (ZK36374). This substance is known to completely inhibit platelet activation by thrombin (12). Platelets from blood collected on Ilomedine did not aggregate after addition of collagen. Blood was also collected on citrate and Ilomedine in order to be able to assess the effect of llomedine in platelet rich plasma. Fig. 6 shows that both in non-anticoagulated whole blood and platelet rich plasma Ilomedine caused a small ( $2 \mathrm{~min}$ ) delay of thrombin generation. In whole blood the 
amount of thrombin generated was reduced by about $15 \%$ whereas the inhibition in PRP was much larger.

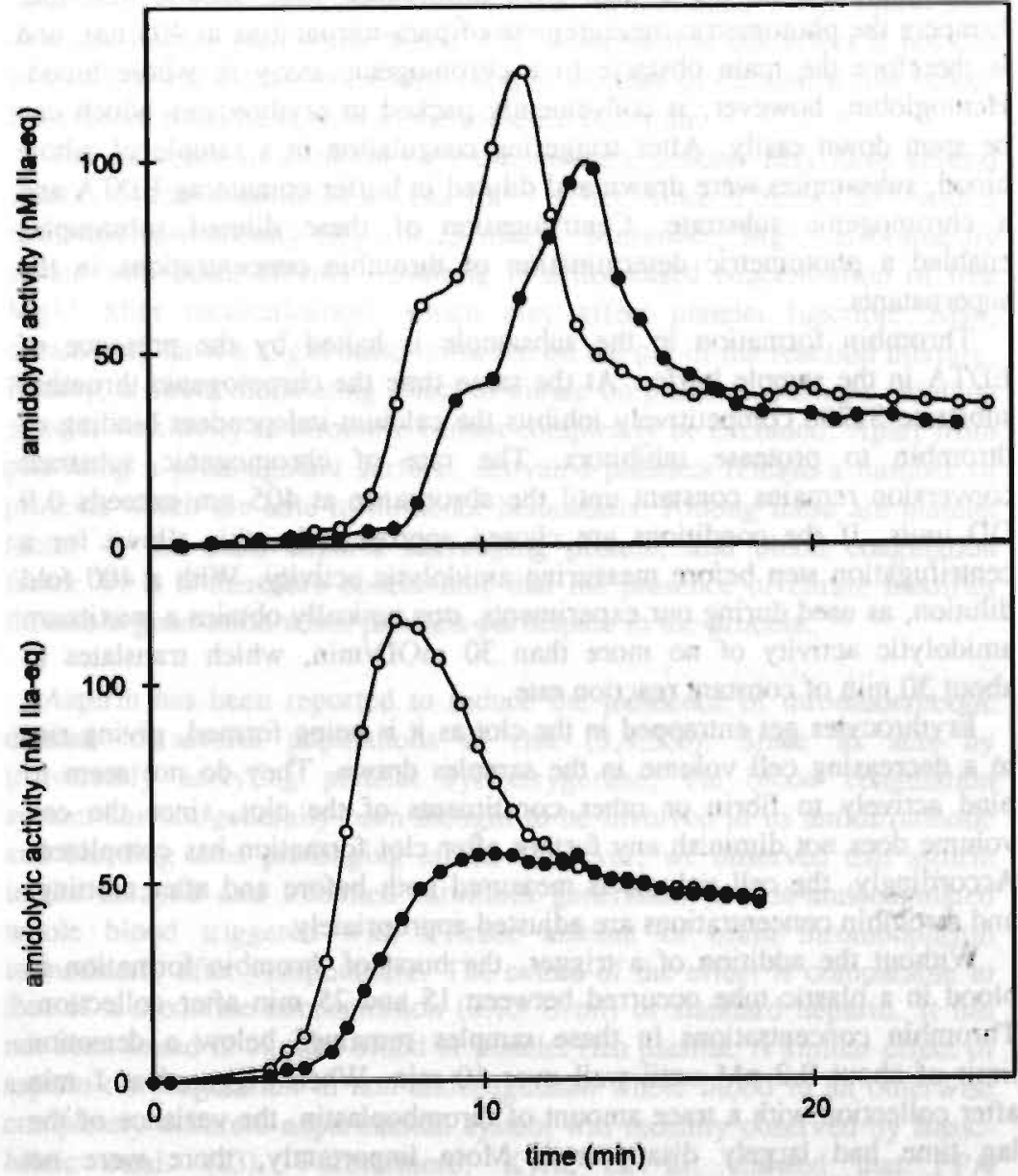

figure 6. influence of llomedine on thrombin generation in non-coagulated whole blood and platelet rich plasma.

upper panel: Whole blood. Blood from a healthy donor was collected both on llomedine (e) (100 $\mu \mathrm{M}, 9 \mathrm{vol}$ blood on $1 \mathrm{vol}$ of llomedine) and in an empty plastic tube $(O)$, and placed on a water bath at $37^{\circ} \mathrm{C}$. Clotting was triggeresd by addition of thromboplastin (1/3800 final dilution) exactly at $1 \mathrm{~min}$ after collection.

lower panel: PRP. Blood from the same donor was collected both on cltrate $(O)$, and on citrateflomedine (๑). PRP was prepared as describad in the materials and methods section, and placed in a weter bath at $37^{\circ} \mathrm{C}$. Clotting wes triggered by addition of thromboplastin (1/3800 final dilution). In both cases thrombin concentrations were measured as described in the materials and methods section. 


\section{discussion}

Hemoglobin, having a high light absorbance peak around $420 \mathrm{~nm}$, hampers the photometric measurement of para-nitroaniline at $405 \mathrm{~nm}$, and is therefore the main obstacle to a chromogenic assay in whole blood. Hemoglobin, however, is conveniently packed in erythrocytes which can be spun down easily. After triggering coagulation in a sample of whole blood, subsamples were drawn and diluted in buffer containing EDTA and a chromogenic substrate. Centrifugation of these diluted subsamples enabled a photometric determination of thrombin concentrations in the supernatants.

Thrombin formation in the subsample is halted by the presence of EDTA in the sample buffer. At the same time the chromogenic thrombin substrate S2238 competitively inhibits the calcium-independent binding of thrombin to protease inhibitors. The rate of chromogenic substrate conversion remains constant until the absorbance at $405 \mathrm{~nm}$ exceeds 0.9 $O D$ units. If the conditions are chosen appropriately, this allows for a centrifugation step before measuring amidolytic activity. With a 400 fold dilution, as used during our experiments, one typically obtains a maximum amidolytic activity of no more than $30 \mathrm{mOD} / \mathrm{min}$, which translates to about $30 \mathrm{~min}$ of constant reaction rate.

Erythrocytes get entrapped in the clot as it is being formed, giving rise to a decreasing cell volume in the samples drawn. They do not seem to bind actively to fibrin or other constituents of the clot, since the cell volume does not diminish any further after clot formation has completed. Accordingly, the cell volume is measured both before and after clotting, and thrombin concentrations are adjusted appropriately.

Without the addition of a trigger, the burst of thrombin formation in blood in a plastic tube occurred between 15 and $25 \mathrm{~min}$ after collection. Thrombin concentrations in these samples remained below a detection limit of about $0.2 \mathrm{nM}$ until well over $10 \mathrm{~min}$. When triggered at $1 \mathrm{~min}$ after collection with a trace amount of thromboplastin, the variance of the lag time had largely disappeared. More importantly, there were no consistent differences between the lag times of blood activated up to $5 \mathrm{~min}$ after collection. Thus we feel confident that no detectable degree of activation has occurred before triggering thrombin generation at $1 \mathrm{~min}$.

Comparison of thrombin generation in the absence and presence of heparin in citrated whole blood with thrombin generation in platelet rich plasma in a similar experimental system, as measured by Béguin et al. (2) showed little differences both in lag times and in peak thrombin concentrations. In contrast to this, we observed that the burst of thrombin 
generation occurs earlier after triggering in blood without added anticoagulant. Furthermore, the influence of heparin on the lag time of thrombin generatin is considerably smaller in untreated whole blood than in recalcified citrated whole blood. Fig. 4 shows that this effect is not due to a suboptimal citrate to calcium ratio in the case of citrated whole blood. It therefore must be related to the presence of citrate.

The influence of citration on the hemostatic process may have several causes. Citrate establishes a weak $\mathrm{Ca}^{2+}$ buffer, since it binds $\mathrm{Ca}^{2+}$ with a relatively low affinity $\left(\mathrm{K}_{\mathrm{d}} \approx 0.25 \mathrm{mM}\right)$. Moreover, $\mathrm{Mg}^{2+}$ is bound by citrate with equal affinity, resulting in a decreased concentration of free $\mathrm{Mg}^{2+}$ after recalcification, which may affect platelet function. Also, citrate may have a slight basic influence on the $\mathrm{pH}$ of the reaction mixture. Finally, a direct modulating effect of citrate on platelets, perhaps reducing platelet sensitivity to thrombin cannot completely be excluded. Apart from providing a procoagulant surface, activated platelets release a number of proteins which are able to influence hemostasis. Among these are platelet factor 4, the main heparin scavenging protein, and blood coagulation factor V. It is therefore conceivable that the presence of citrate modifies thrombin generation when platelets participate in the process.

Aspirin has been reported to reduce the incidence of thromboembolic disease in several populations at risk $(3,4,5,6)$. Since its acts by irreversibly acetyling platelet cyclooxygenase, the blood coagulation system has not generally been thought to be involved in its antithrombotic and bleeding time prolonging effect. However, we observed that aspirin intake delayed and inhibited thrombin generation in non-anticoagulated whole blood triggered with a trace amount of brain thromboplastin immediately after venipuncture. The extent of the effect is comparable to that of a moderate concentration $(0.03 \mathrm{U} / \mathrm{ml})$ of standard heparin. It has not been found in citrated blood or platelet rich plasma. A similar effect of aspirin on coagulation in non-anticoagulated whole blood in an otherwise completely different experimental system was recently observed by BasicMicic et.al. (13). Furthermore, Kyrle et. al. showed that FPA concentrations in blood from bleeding time wounds were decreased after aspirin treatment (14)

An estimate of the maximal effect of platelet inhibition on thrombin generation in whole blood and platelet rich plasma, as measured by the effect of $10 \mu \mathrm{M}$ of Ilomedine, shows a relatively small delay of thrombin generation (about $2 \mathrm{~min}$ ). Additionally, in PRP and, but to a much smaller extent, in whole blood, a reduction of the amount of generated thrombin was observed. This difference between PRP and whole blood can probably be attributed to the presence of erythrocytes in whole blood, as addition of 
the leucocyte fraction to PRP had no effect on thrombin generation (not shown). In the light of the modest maximal effect attainable by platelet inhibition the influence of aspirin on thrombin generation is easily overlooked. On the other hand, the llomedine experiment shows that thrombin generation in whole blood is not all that sensitive as a test of platelet inhibition, although a delay of thrombin generation may be quite important in a flowing system.

Classically a distinction is made between arterial thrombosis and primary haemostasis which are viewed as predominately platelet mediated processes, and venous thrombosis and secondary haemostasis where the coagulation system plays the major role. Yet recent insights tend to stress the importance of thrombin in the pathogenesis of arterial thrombosis $(15,16)$ and major clinical trials show that anticoagulant drugs such as heparin and oral anticoagulants, are effective anti-thrombotics not only in the venous but also in the arterial circulation $(17,18,19)$. This suggests that affecting the concentration of free thrombin may be a shared mechanism of action of anti-thrombotic drugs. The observation that inhibitors of platelet function, like aspirin, do affect thrombin generation in non-anticoagulated whole blood, lends support to this notion of a common pathway for the various sorts of anti-thrombotic therapy. Reduction of thrombin concentrations, then, may be achieved by inhibition of thrombin formation (oral anticoagulation), by increase of thrombin inactivation (heparin) or by inhibition of platelet function (aspirin).

In conclusion, a precise chromogenic thrombin measurement in whole blood samples is feasible using the technique described in this chapter. Using this technique, it has been shown that collection of blood on citrate causes thrombin formation to be delayed, and the effect of heparin to be overestimated. In addition a delaying and inhibiting effect of aspirin on thromboplastin triggered thrombin generation in non-anticoagulated whole blood has been demonstrated, stressing the linkage between platelet reactions and coagulation.

The technique described in this chapter enables the measurement of thrombin, and thereby investigation of the effect of a variety of anticoagulant drugs on thrombin generation in blood without the necessity of additional processing. This property of the assay may permit measurement of thrombin generation in physiological haemostasis, e.g. in blood flowing from a wound. 


\section{acknowledgements}

We thank 'De Broeders van Den Beijaard' for their generous donations of blood.

\section{references}

1. Biggs R, Macfarlane RG. Human blood coagulation and its disorders. Blackwell Scientific Publications, Oxford 1953.

2. Beguin S, Lindhout MT, Hemker HC. The effect of trace amounts of tissue thromboplastin on thrombin generation in platelet rich plasma, its inhibition by heparin. Thromb Haenwost 1989;60:25-9.

3. Chesebro JH, Clements IP. Fuster V. Eiveback LR, Smith HC, Bardsley WT, et al. A platelet-inhibitor-drug trial in coronary-artery bypass operations. N Engl J Med 1982;307:73-8.

4. Lewis DH, Davis J, Archibald DG, Steinke WE, Smitherman TC, Doherry EJ, et al. Protective effects of aspirin against acute myocardial infarction and death in men with unstable angina. N Engl J Med 1983;309:396-403.

5. Cairns JA, Gent M, Singer J, Finnie KJ, Froggatt GM, Holder DA, et all, Aspirin, sulfinpyrazone, or both in unstable angin. N Engl J Med 1985:313:1369-75.

6. UK TIA Study Group. United Kingdom transient ischaenuic attack (UK-TIA) aspirin trial: interim results. Br Med J 1988;296;316-20.

7. Roth GJ, Majerus PW. The mechanism of the effect of aspirin on human platelets. J Clin Invest 1975;56:624-32.

8. Rodgers RPC, Levin J. A critical reappraisal of the bleeding time. Semin Thromb Hemost 1990;16:1-20

9. Owren PA, Aas K. The control of dicumarol therapy and the quantitative determination of prothrombin and proconvertin. Scand J Clin Lab Invest 1951;3:201-18.

10. Hemker HC, Willems GM, Béguin SA. A computer assisted method to obtain the prothrombin activation velocity in whole plasma independent of thrombin decay processes. Thromb Haemostas 1986;56:9-17.

11. Pedersen AK, Fitzgerald GA. Dose-related kinetics of aspirin. New Engl J Med 1984;311(19):1206-11.

12. Baruch D, Hemker HC, Lindhout T. Kinetics of thrombin-induced release and activation of platelet factor V. Eur J Bioch 1986;154:213-18.

13. Basic-Micic M, Broddin HK. PITT and detection of a risk of venous and arterial thrombosis. Abstract, XIIth congress ISTH, Amsterdam. Thromb Haemostas 1991;65(6): 1318. 
14. Kyrle PA, Westwick J, Scully MF, Kakkax VV, Lewis GP. Investigation of the interaction of blood platelets with the coagulation system at the site of plug formation in vivo in man - Effect of low-dose aspirin. Thromb Hacmostas 1987;57(1):62-6.

15. Weiss HJ, Lages B. Evidence for tissue factor-dependent activation of the classic extrinsic coagulation mechanism in blood obtained from bleeding time wounds. Blood 1988;71:629-35.

16. Heras M, Chesebro JH, Webster MWI, Mruk JS, Grill DE, Penny WJ, et al. Hirudin, heparin, and placebo during deep arterial injury in the pig. Circulation 1990;82:1476-84.

17. The sixty plus reinfarction study research group. A double-blind trial to assess longterm oral anticoagulant therapy in elderly patients after myocardial infarction. Lancet 1980;2:989-94.

18. Turpie AG, Levine MN, Hirsh J, Carter CJ, Jay RM, Powers PJ, et al. A radomized controlled trial of a low-molecular-weight heparin (enoxaparin) to prevent deep-vein thrombosis in patients undergoing elective hip surgery. $\mathbf{N}$ Engl J Med 1986;315:925-9.

19. Theroux P, Ouimet H, McCans J, Latour JG, Joly P, Levy G, et al. Aspirin, heparin, or both to treat acute unstable angina. N Engl J Med 1988;319:110511. 


\section{chapter 3}

\section{analysis of thrombin generation curves.}

\section{summary}

Measurement of thrombin generation in plasma using small oligopeptide chromogenic substrates gives rise to a signal that is not only a measure of the concentration of free thrombin, but also a reflection of the presence of the complex of thrombin with $\alpha_{2}$-macroglobulin. This chapter describes a mathematical procedure to extract from the obtained curves the signal due to free thrombin only. In addition, it is described how the time course of prothrombin conversion can be obtained from thrombin generation curves when the constants governing thrombin decay are known. The thrombin potential, a parameter conveying much useful information about the state of the coagulation system can also be calculated from thrombin generation curves.

Pseudo-continuous measurement of the time integral of the thrombin concentration promises clinical applicability of thrombin generation tests. It is shown how the curves produced by these tests can be analysed analogously to curves measured by subsampling from clotting plasma.

\section{Introduction}

Thrombin is the central enzyme of the coagulation system. Its adequate production at the site of a vascular lesion is pivotal in arresting bleeding. Initial traces of thrombin are formed upon the exposure to blood or plasma of tissue factor from damaged tissue. These traces trigger the activation of much larger amounts of thrombin by feedback activating platelets, and the cofactors V and VIII. The generation of thrombin is influenced by every type of antithrombotic therapy, as well as by most coagulation disorders

\footnotetext{
- based on: - Kessels H, Willems G, Hemker HC. submitted for publication

- Béguin S, Kessels H, Dol F, Hemker HC. Thromb Heemostas 1992;68(2):136-42.

- Hemker HC, Wielders S, Kessels H, Beguin S. Thromb Haemostas, in press.
} 
(1). Measurement of the time course of thrombin concentrations in clotting plasma, giving a rise to a so called thrombin generation curve, therefore yields important information about the functioning of the coagulation system. One of the parameters which condenses much information of a thrombin generation curve is the thrombin potential (2). It is defined as the surface under the time curve of the free thrombin concentration.

The time course of free thrombin is the result of prothrombin conversion on the one hand, and thrombin breakdown on the other. It is often useful to be able to differentiate between these possibilities when thrombin generation is abnormal. This chapter describes how both the thrombin potential and the time course of prothrombin conversion can be obtained from thrombin generation curves. It also describes how these parameters can be distilled from curves of the time integral of the thrombin concentration.

Measurement of thrombin concentrations using chromogenic substrates is based on the amidolytic liberation by thrombin of the para-nitroaniline (pNA) group of the substrate, altering its light absorption spectrum. The thrombin concentration then determines the rate of change of optical density at $405 \mathrm{~nm}$ (3). Using this method, thrombin concentrations are measured in subsamples drawn from clotting plasma at timed intervals.

This method to measure thrombin generation in clotting plasma is not a routine undertaking, as it takes an experienced technician more than an hours work. We recently described a technique to measure the integral of the thrombin concentration pseudo-continuously in a cuvette (4). Since no subsampling is required, the technique has the potential of being automated and used routinely in a hospital laboratory. It is based on the presence of a chromogenic substrate in clotting plasma. Thrombin being generated in the plasma converts the chromogenic substrate. The rate of conversion of chromogenic substrate at any moment indicates the amount of enzyme, so that the optical density vs. time curve represents the time integral of the enzyme concentration. The thrombin potential, in this case, is equal to the steady endlevel of the resulting integral free thrombin curve, and can easily be obtained.

Chromogenic substrates are not as specific for thrombin as fibrinogen is. In particular, the physiologically inactive complex of thrombin with one of its minor inhibitors, $a_{2}$-macroglobulin proteolyses small chromogenic substrates almost as well as free thrombin does $(5,6,7)$. This is because $\alpha_{2}$-macroglobulin does not bind the active centre of thrombin, but still impedes the binding and conversion of large (protein) substrates. Therefore, the conversion of chromogenic substrate is due to both free 
thrombin and the $\alpha_{2}$-macroglobulin-thrombin complex. This chapter describes a mathematical procedure to reduce a time curve of chromogenic substrate converting activity to a true thrombin generation curve. Analogously, time curves of optical density, measured using the pseudo continuous method, can be transformed into a time curves of the integral of the free thrombin concentration.

In order to be able to calculate the time course of prothrombin conversion, information is needed about thrombin breakdown in plasma. Thrombin is not only inhibited by $\alpha_{2}$-macroglobulin, but also, and mainly, by antithrombin III. Several other inhibitors, such as $\alpha_{1}$-antitrypsin are active as well, but their contribution is relatively minor. One inhibitor, heparin cofactor II, is only active if a potentiating compound, dermatan sulphate or one of its derivatives, or a very high concentration of heparin is present (8). These inhibitors all operate according to the same principle. They bind thrombin to form an essentially irreversible, inactive complex.

The concentration of antithrombin III is not in a large excess over the prothrombin concentration. Thus, a considerable amount of antithrombin III is consumed during, blood clotting in a plasma sample $(9,10,11)$. Since the rate of complex formation between thrombin and antithrombin III is dependent on both the concentration of free thrombin and the concentration of antithrombin III, this rate decreases as the concentration of antithrombin III decreases (11). A procedure is delineated to calculate the velocity of thrombin breakdown at any time during the clotting process. This information is then used to calculate the time course of prothrombin conversion, or the prothrombinase activity, in plasma during the process of haemostasis.

\section{thrombin generation measured by chromogenic assay of subsamples from clotting plasma.}

\section{experimental method}

This method is described in full detail in ref. 3. Briefly, to $240 \mu \mathrm{l}$ of plasma are added $60 \mu \mathrm{l}$ of a buffer (buffer A, $50 \mathrm{mM}$ Tris-HCl, 100 $\mathrm{mM} \mathrm{NaCl}, 0.5 \mathrm{mg} / \mathrm{ml}$ bovine albumin, $\mathrm{pH} 7.35$ ), containing any substance under investigation. Clotting is initiated by addition of $60 \mu \mathrm{l}$ of a solution containing $100 \mathrm{mM} \mathrm{CaCl} 2$ and human brain thromboplastin in as suitable dilution. At timed intervals, $10 \mu \mathrm{l}$ subsamples are diluted into a cuvette with $490 \mu \mathrm{l}$ of a buffer (buffer B, $50 \mathrm{mM}$ Tris-HCl, $175 \mathrm{mM}$ $\mathrm{NaCl}, 20 \mathrm{mM}$ EDTA, $0.5 \mathrm{mg} / \mathrm{ml}$ bovine albumin, pH 7.90) containing $200 \mu \mathrm{M}$ of the chromogenic substrate $\mathbf{S 2 2 3 8}$ (Kabi, Sweden). Amidolysis 
of the chromogenic substrate in the cuvette is allowed to proceed for approximately 2 minutes. This reaction is then halted by the addition of $300 \mu \mathrm{l}$ of $1 \mathrm{M}$ citric acid. The precise moments of subsampling and stopping are recorded on a personal computer by means of push-button equipped pipettes. Optical densities are measured at $405 \mathrm{~nm}$ and converted into amidolytic activities ( $\mathrm{mOD} / \mathrm{min}$ ) by dividing by the reaction times. Thus, the result of such a thrombin generation experiment is a series of amidolytic activities with corresponding time points. Fig. 1 shows a typical curve of amidolytic activity obtained in pooled normal plasma. The steady endlevel of this curve is caused by the activity of the $\alpha_{2} \mathrm{M}$-thrombin complex.

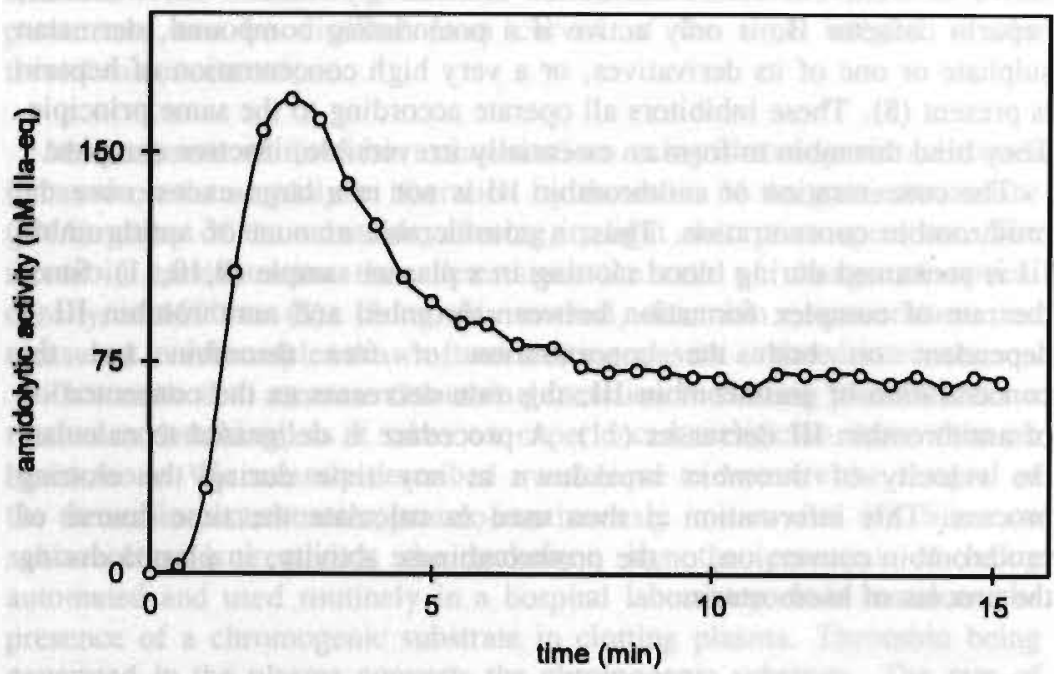

figure 1. the time course of the amidolytic activity.

This was measured in a subsampled thrombin generation experiment carried out as described in normal pooled plasma. Coagulation was triggered at time zero with human brain thromboplastin diluted 240 fold and $\mathrm{Ca}^{2+}(16.7 \mathrm{mM})$.

\section{calculation of the free thrombin concentration}

The experimentally determined amidolytic activity $E$ at time point $t$ is the result of both the thrombin concentration $T$ and the concentration of the $\alpha_{2}$-macroglobulin-thrombin complex MT at time t. Since the $K_{m}$ values of thrombin and the $\alpha_{2} \mathrm{M}$-thrombin complex for conversion of S2238 are very much lower than the actual concentration of S2238, the reaction velocity is linear with the thrombin and $\alpha_{2} \mathrm{M}$-thrombin concentrations. 


$$
E(t)=\gamma(T(t)+f \cdot M T(t)), \gamma \approx k_{\text {cat }}
$$

with $k_{\text {cat1 }}$ and $k_{\text {car }}$ being the catalytic constants for conversion of $\$ 2238$ of thrombin and $a_{2} \mathrm{M}$-thrombin respectively, and $f$ being the reaction rate of substrate conversion by $\alpha_{2} \mathrm{M}$-thrombin relative to the reaction rate of an equal concentration of thrombin, i.e. $f=k_{\text {cat2 }} / k_{\text {cal1 }}$. The value of $f$ has been determined at 0.556 (3).

Thrombin breakdown by $a_{2} M$ is a first order process (3) so that the rate at which the complex of thrombin and $\alpha_{2} \mathrm{M}$ forms is linearly dependent on the thrombin concentration:

$$
\frac{d M T}{d t}=k_{2} \cdot T(t)
$$

When the time between two subsequent samples is not too long (less than about $45 \mathrm{~s}$ for a usual thrombin generation curve), it can be adequately approximated by the discrete case:

$$
\operatorname{MT}\left(t_{i}\right)=\operatorname{MT}\left(t_{1-1}\right)+k_{2} \cdot T\left(t_{-1}\right)
$$

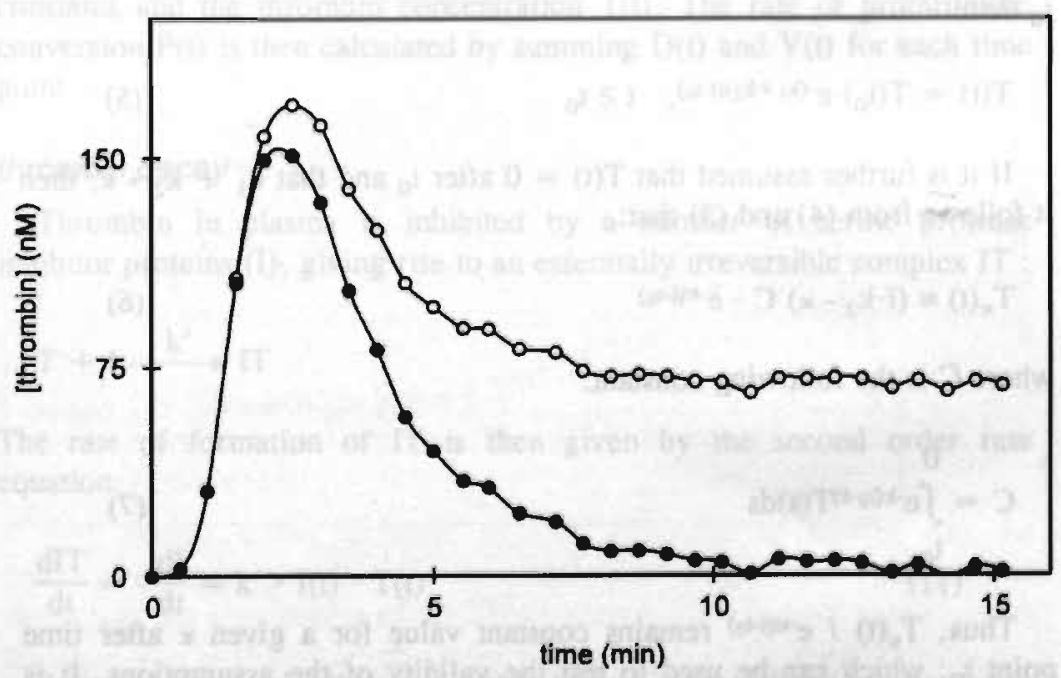

figure 2. a thrombin generation curve and the calculated time course of the free thrombin concentration.

O: The experimentally determined amidolytic activity - Free thrombin as calculated form the amidolytic activity and the $\alpha_{2} \mathrm{M}$ dependent decay constant $\left(k_{2}\right)$. 
Once the value of the first order decay constant for $\alpha_{2} M\left(k_{2}\right)$ is known, the time curve of the free thrombin concentration can be obtained by applying equations (3) and (1) to the series of amidolytic activities. Fig. 2 shows a measured time curve of optical density, and the thrombin vs. time curve derived from it.

\section{estimation of the $\alpha_{2}$-macroglobulin dependent decay constant}

Since the complex of $\alpha_{2} \mathrm{M}$ and thrombin has residual amidolytic activity, the $\alpha_{2} M$ dependent decay constant $k_{2}$ can be estimated directly from curves of amidolytic activity vs. time. First, time courses of the free thrombin concentration are calculated from the amidolytic activity values as described above, using a range of values $\kappa$ for $f \cdot k_{2}$. These calculated thrombin concentrations $T_{K}$ are related to the real (but unknown) thrombin concentrations $T$ in the following manner:

$$
T_{x}(t)=T(t)+\left(f \cdot k_{2}-k\right) \int_{t}^{0} e^{-k(t-s)} T(s) d s
$$

If it is assumed that prothrombin conversion has stopped at a time point to then:

$$
T(t)=T\left(t_{0}\right) \cdot e^{-\left(k_{1}+k_{2}\right)\left(\left(-t_{0}\right)\right.}, \quad t \geq t_{0}
$$

If it is further assumed that $T(t)=0$ after $t_{0}$ and that $k_{1}+k_{2} * x$, then it follows from (4) and (5) that:

$$
T_{k}(t) \approx\left(f \cdot k_{2}-k\right) C \cdot e^{-k\left(t-t_{0}\right)}
$$

where $\mathrm{C}$ is the following constant:

$$
C=\int_{t_{0}}^{0} e^{-k\left(t_{0}-s\right)} T(s) d s
$$

Thus, $T_{k}(t) / e^{-k\left(t-t_{0}\right)}$ remains constant value for a given $k$ after time point $t_{0}$, which can be used to test the validity of the assumptions. It is equal to zero when $x$ is equal to $f \cdot k_{2} . T_{x}(t) / e^{-k\left(t-t_{0}\right)}$ is then plotted as a function of $\kappa$, and $k_{2}$ is determined from the intersection of this function with the horizontal axis. It proved practical to estimate this intersect by fitting the function to the following exponential: 


$$
T_{x}(t) / e^{-k\left(t-t_{0}\right)}=a \cdot e^{b \cdot k}+c
$$

so that:

$$
f \cdot k_{2}=\frac{\ln (-c)-\ln (a)}{b}
$$

calculation of the rate of prothrombin conversion from time curves of the froe thrombin concentration

The rate of change (V) of the thrombin concentration $(\mathrm{T})$ in plasma is the difference of the rate of prothrombin conversion (prothrombinase activity, $\mathrm{P}$ ) and the rate of thrombin breakdown (D):

$$
V(t)=d T / d t=P(t)-D(t)
$$

$V(t)$ can be obtained from the series of thrombin concentrations $T(t)$ which are calculated from the measured course of the amidolytic activity $E(t) . D(t)$ is determined from the independently measured thrombin decay constants and the thrombin concentration $T(t)$. The rate of prothrombin conversion $P(t)$ is then calculated by summing $D(t)$ and $V(t)$ for each time point

\section{thrombin decay}

Thrombin in plasma is inhibited by a number of serine protease inhibitor proteins (I), giving rise to an essentially irreversible complex IT:

$$
\mathrm{T}+\mathrm{I} \stackrel{\mathrm{k}^{\prime}}{\longrightarrow} \mathrm{IT}
$$

The rate of formation of IT is then given by the second order rate equation:

$$
\frac{d I T}{d t}=-\frac{d I}{d t}=k^{\prime} \cdot I(t) \cdot T(t)
$$

Serine protease inhibitors relevant to thrombin breakdown in plasma are antithrombin III (AT III), $\alpha_{2}$-macroglobulin $\left(\alpha_{2} M\right)$, heparin cofactor II (HC II), and a number of serpins with a relatively unimportant anti-thrombin activity (R). The concentration of the most important physiological thrombin inhibitor AT III is not much higher than the 
prothrombin concentration, so that during the course of coagulation the concentration of AT III decreases considerably $(9,10,11)$. The rate of thrombin breakdown due to AT III decreases to the same extent, since the it is linearly proportional to the AT III concentration. In the presence of dermatan sulphate, consumption of the inhibitor plays an even bigger role in the decay of thrombin due to heparin cofactor II, since the plasma concentration of HC II is about two thirds the plasma concentration of prothrombin. If no dermatan sulphate is present, no inhibitory action of $\mathrm{HC}$ II can be detected. The plasma concentration of $\alpha_{2} \mathrm{M}$ is relatively high $(3.5 \mu \mathrm{M})$ and does not decrease significantly during coagulation, nor does the concentration of the group of inhibitors of secondary importance. Therefore, it is reasonable to assume first order kinetics for the inactivation of thrombin by these inhibitors:

$$
-\frac{d T}{d t}=D(t)=\left(k_{1}^{\prime} \cdot \operatorname{ATIII}(t)+k_{4}^{\prime} \cdot \operatorname{HCII}(t)+k_{2}+k_{3}\right) \cdot T(t)
$$

with $k_{2}=k_{2}^{\prime} \cdot \alpha_{2} M$ and $k_{3}=k_{3}^{\prime} \cdot R$

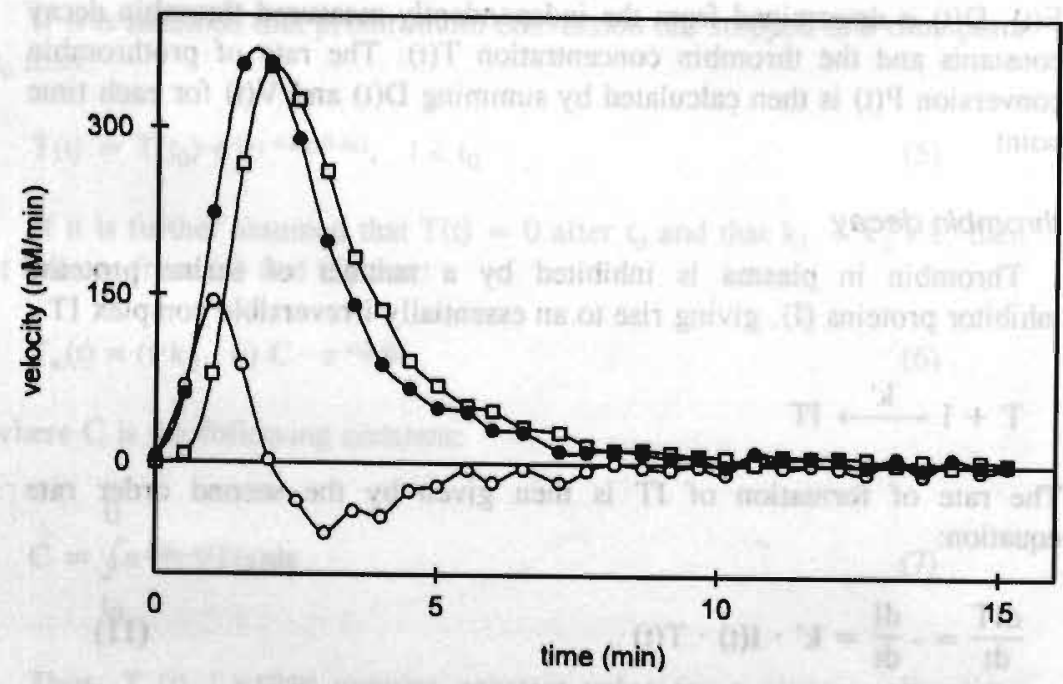

figure 3. velocities of decay and formation of thrombin

The velocity of thrombin decay $(\square)$ was determined from the thrombin generation curve of figure 2 and the independently measured thrombin decay constants. Together with the first derivative of the thrombin concentration in time $(O)$, this determines the velocity of prothrombin conversion, also known as the prothrombinase activity (0). 


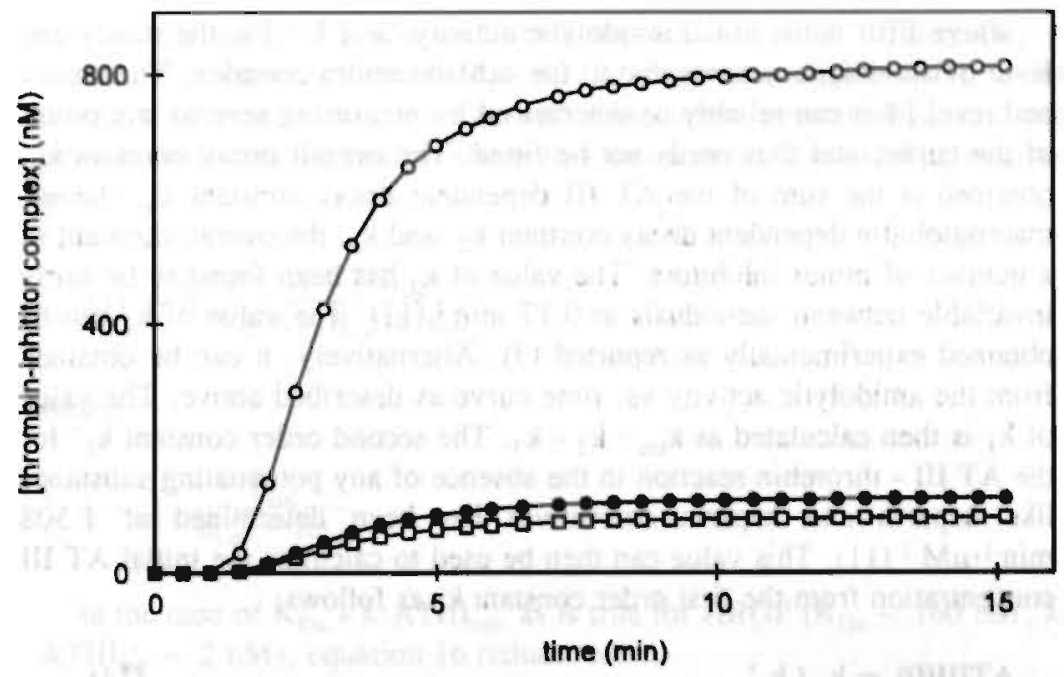

figure 4. thrombin Inhibitor complexes

The time course of the concentrations of various thrombin inhibitor complexes as calculated from thrombin generation curve of fig. 2 and the measured thrombin decay constents. O: Thrombin-AT III; -: Thrombin- $\alpha_{2} M$; $\square$ : the complex of thrombin with other minor thrombin inhibitors

The series of values for $D$ and the concentrations of the thrombin inhibitor complexes can be calculated iteratively from curves of the free thrombin concentration once the decay constants and the initial AT III concentration are known, using the discrete forms of equations 11 and 12. Figure 3 shows $D(t), V(t)$ and $P(t)$ for a typical thrombin generation experiment. Figure 4 shows the time course of the thrombin-inhibitor complexes.

experimental determination of the decay constants of thrombin and the AT III concentration

The overall decay constant $k_{\text {to }}$ of thrombin in plasma can be determined experimentally (3) by addition of thrombin to plasma and measuring the time course of its disappearance. This is done essentially in the same way as described above for measurement of thrombin generation. The amidolytic activities $\mathrm{E}(\mathrm{t})$ as obtained in the experiment can be fitted to the following exponential:

$$
E(t)=E(\infty)+(E(0)-E(\infty)) e^{-k_{\operatorname{cox}} t}
$$


where $E(0)$ is the initial amidolytic activity, and $E(\infty)$ is the steady end level of amidolytic activity due to the $\alpha_{2} \mathrm{M}$-thrombin complex. The steady end level $E(\infty)$ can reliably be determined by measuring several late points of the curve, and thus needs not be fitted. The overall decay constant $k_{\text {tot }}$ obtained is the sum of the AT III dependent decay constant $k_{1}$, the $\alpha_{2}$ macroglobulin dependent decay constant $k_{2}$, and $k_{3}$, the overall constant of a number of minor inhibitors. The value of $k_{3}$ has been found to be fairly invariable between individuals at $0.17 \mathrm{~min}^{-1}(11)$. The value of $\mathrm{k}_{2}$ can be obtained experimentally as reported (3). Alternatively, it can be obtained from the amidolytic activity vs. time curve as described above. The value of $k_{1}$ is then calculated as $k_{t o t}-k_{2}-k_{3}$. The second order constant $k_{1}{ }^{\prime}$ for the AT III - thrombin reaction in the absence of any potentiating substance like heparin and heparin derivatives has been determined at 1.508 $\min ^{-1} \cdot \mu \mathrm{M}^{-1}(11)$. This value can then be used to calculate the initial AT III concentration from the first order constant $k_{1}$ as follows:

$$
\operatorname{ATIII}(0)=k_{1} / k_{1}{ }^{\prime}
$$

If, in subsequent experiments with the same plasma, heparin or one of its derivates is added, its influence on the second order decay constant $k_{1}$ ' can be inferred as follows:

$$
k_{1 \text { hep }}{ }^{\prime}=k_{\text {1hep }} / \operatorname{ATIII}(0)
$$

Heparin increases the inhibitory capacity of AT III for thrombin. It acts as a catalyst, since it associates reversibly with AT III and it is liberated upon formation of the irreversible AT III - thrombin complex. The affinity for thrombin of the AT III-heparin complex is several orders of magnitude higher than the affinity of AT III alone, but the rate constant for the formation of the irreversible AT III-thrombin complex from the initial reversible AT III-thrombin complex is not altered (12). Heparin binds to AT III with a $K_{d}$ of about $160 \mathrm{nM}$, and is normally present in concentrations much less than the concentration of AT III which is about ten times this $K_{d}$. This would mean that essentially all heparin would be bound to AT III so that an increase or decrease in the AT III concentration would not have a significant influence on the decay rate of thrombin. It therefore may come as a surprise that the thrombin decay velocity in the presence of heparin is still linearly proportional to the AT III concentration. However, heparin is known to bind many plasma proteins and competition between these proteins for heparin easily explains the AT III dependence of thrombin decay (11). One example of a heparin binding protein is Histidin Rich Glycoprotein (HRGP), which has a plasma 
concentration of $\sim 5 \mu \mathrm{M}$ and binds heparin with high affinity $\left(\mathrm{K}_{\mathrm{d}}=\right.$ $7 \mathrm{nM}$ ). The concentration of the AT III heparin complex (AH) in the presence of heparin $(H)$, AT III, with dissociation constant $K_{D_{A}}$, and one other heparin binding protein $(\mathrm{B})$ with a dissociation constant $\mathrm{K}_{\mathrm{Db}}$ is given by:

$$
\mathrm{AH}=\mathrm{H}_{\mathrm{tox}} \frac{\lambda \cdot \mathrm{ATIII}_{\mathrm{tos}}}{\lambda \cdot \mathrm{ATII}}
$$

where

$$
\lambda=1-\frac{\mathrm{B}_{10 \mathrm{~s}}}{\mathrm{~B}_{\mathrm{tox}}+\mathrm{K}_{\mathrm{Db}}}
$$

in the case of $\mathrm{K}_{\mathrm{Da}} \cdot \lambda \cdot \mathrm{ATIII}_{\mathrm{tot}}$, as is true for HRGP $\left(\mathrm{K}_{\mathrm{Da}_{\mathrm{a}}}-160 \mathrm{nM}, \lambda\right.$. ATIII $\left._{\text {tox }} \sim 2 \mathrm{nM}\right)$, equation 16 reduces to:

$$
\mathrm{AH}=\frac{\lambda}{\mathrm{K}_{\mathrm{Da}}} \mathrm{H}_{\mathrm{tot}} \cdot \mathrm{ATIII}_{\mathrm{tot}}
$$

which shows that AH, and therefore the AT III dependent thrombin decay velocity, is indeed linearly proportional to the AT III concentration in the presence of heparin under the above conditions. The presence of more heparin binding proteins does not affect this property. Equation 17 is the basis for the definition of the specific antithrombin activity of a heparin. This is defined as the increase of $k_{1}$ caused by $1 \mu \mathrm{g}$ of heparin per $\mathrm{ml}$ plasma normalised to an AT III level of $1 \mu \mathrm{M}$.

The decay of thrombin brought about by heparin cofactor II is normally of no importance. If, however, dermatan sulphate or a related substance is present in plasma, it has to be considered (8). In such a case, the initial concentration of HC II has to be determined in plasma devoid of AT III.

\section{thrombin generation measured by pseudo-continuous recording of the time integral of thrombin}

\section{experimental method}

The method for measuring thrombin generation pseudo-continuously is described in detail in ref. 4 . In brief, $400 \mu \mathrm{l}$ of reptilase defibrinated plasma, $100 \mu \mathrm{l}$ of buffer A containing any substance under investigation, 
and $60 \mu \mathrm{l}$ of the chromogenic substrate SQ 68 (methylmalonylmethylalanyl-arginyl-pNA, from Serbio, France) are added to a cuvette at $37^{\circ} \mathrm{C}$. The chromogenic substrate SQ 68 is used in these experiments instead of S2238, because of its more suitable kinetic properties, as discussed further below. Clotting is triggered by addition of $40 \mu \mathrm{l}$ of tissue factor in $0.25 \mathrm{M} \mathrm{CaCl}_{2}$. The time course of optical density at $405 \mathrm{~nm}$ is then recorded pseudo-continuously at a rate of two optical density readings per second. Fig 5 shows an example of a typical time course of optical density in pooled normal plasma.

The chromogenic substrate in the cuvette is continuously converted by the thrombin being generated and broken down. The resulting optical density vs. time curve is the integral of the thrombin generation curve. The final slope of this curve is the consequence of the end level of $\alpha_{2} \mathrm{M}$ thrombin.

Using this approach it is inevitable that the presence of the chromogenic substrate influences the reactions of thrombin in plasma. SQ 68 will compete with both the thrombin breakdown reactions by AT III, $\alpha_{2} \mathrm{M}$ and others, and the positive feedback reactions exerted by thrombin, i.e.

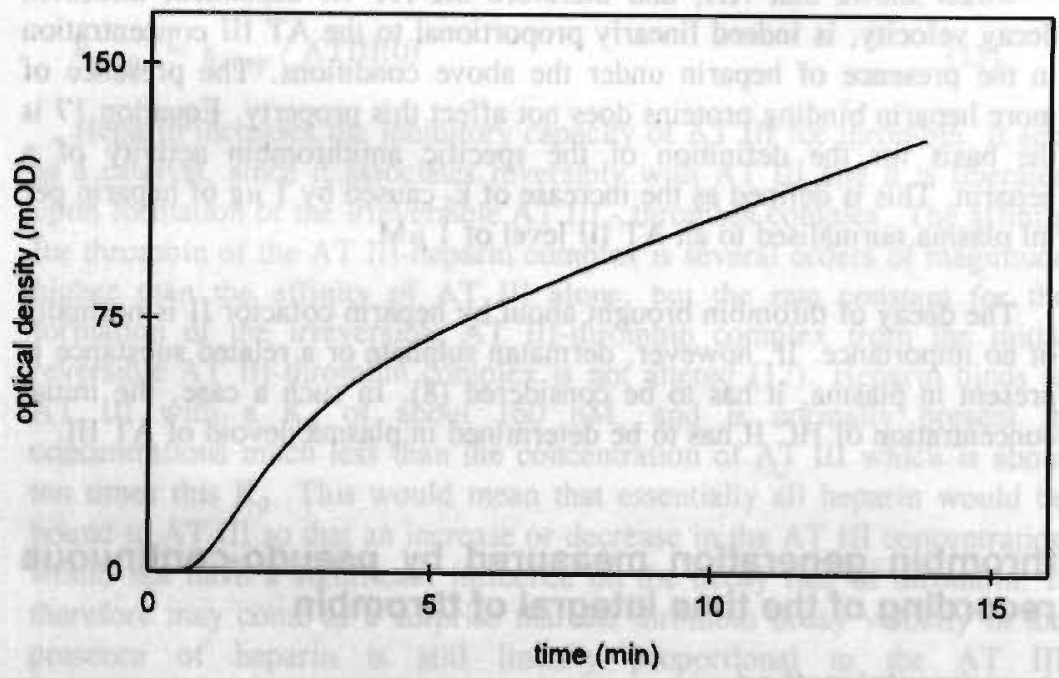

ngure 5. continuous measurement of enzyme activity

The time course of the optical density (in mOD) as measured with a pseudecontinuous thrombin generation experiment carried out as described, in nomal pooled plasma. Coagulation was triggered at time zero with human brain thromboplastin diluted 240 fold and $\mathrm{Ca}^{2+}(16.7 \mathrm{mM})$. The SQ 68 concentration was $500 \mu \mathrm{M}$. 
activation of the cofactors V and VIII. The ideal chromogenic substrate, the one with the least influence on the reactions of thrombin, would have a very high $\mathrm{K}_{\mathrm{m}}$, so that only a very limited amount is in complex with thrombin, and a relatively high $k_{\text {cat }}$, so that its high $K_{m}$ still results in a measurable signal. The substrate SQ 68 , comes closest to the ideal kinetic properties of the substrates available to date (table 1), but might be improved upon.

\begin{tabular}{llcc} 
enzyme & conditions & $K_{m}(\mu M) \pm$ s.e. & $K_{\text {cat }}\left(s^{-1}\right) \pm$ s.e. \\
\hline thrombin & heated plasma & $819 \pm 19$ & $0.38 \pm 0.002$ \\
thrombin & buffer $A$ & $830 \pm 48$ & $0.46 \pm 0.04$ \\
$\alpha_{2} M$-thrombin & serum & $788 \pm 11$ & $0.29 \pm 0.01$ \\
\hline
\end{tabular}

table 1. kinetic parameters of SQ 68.

The kinetic parameters for thrombin conversion of the chromogenic substrate SQ 68 were measured by measuring the rate of hydrolysis of a $S Q 68$ values in the renge of 0 to $2000 \mu \mathrm{M}$ by thrombin in a concentration of $100 \mathrm{nM}$, at $37^{\circ} \mathrm{C}$. The $k_{\text {cat }}$ and $K_{m}$ values were extracted from the substrate vs. reaction rate curves using a non-linear fit procedure.

\section{influence of SQ 68 on thrombin decay.}

The reaction of thrombin with its serine protease inhibitors goes through an initial, low affinity complex, which can then be converted to a tight, nearly irreversible complex (13). The $\mathrm{K}_{\mathrm{d}}$ of the initial complex between thrombin and AT III is very high (1.4 mM, ref. 14) compared to the plasma AT III concentration, so that the presence of SQ 68 (S), in spite of its own relatively high $\mathrm{K}_{\mathrm{m}}$, effectively competes with the serine proteases for thrombin. Therefore the rate of thrombin inhibition by serine proteases (I) is decreased:

$$
I T(t)=T_{\text {tod }}\left(1-e^{-I \cdot k_{\text {spp }} \cdot t}\right)
$$

with

$$
k_{\text {app }}=k_{\text {dec }}\left(\frac{K_{m}}{S+K_{r a}}\right)
$$

Thus, the apparent AT III dependent decay constant of thrombin is reduced by a factor $K_{m} /\left(S+K_{m}\right)$. For a concentration of chromogenic substrate of $1 \mathrm{mM}$ the apparent decay of thrombin inactivation by AT III would be about $40 \%$ of $k_{\text {dec }}$. The situation is somewhat different for $\mathrm{c}_{2}$ macroglobulin. While this protein is also a member of the serpin family, and might therefore be expected to exhibit the same kind of behaviour as 
AT III, there is one important difference in its mode of action: it does not bind thrombin at the active site. Thus, a molecule of SQ 68 bound to thrombin may hinder the formation of a complex between $\alpha_{2} M$ and thrombin, it does not necessarily prevent it.

\section{influence of SQ 68 on thrombin formation}

Theoretically, the presence of SQ 68 might also affect prothrombinase activity, by competing with feedback activation of the cofactors $\mathrm{V}$ and VIII by thrombin. However, there are several reasons why this effect can be expected to be much less important. First, the affinity of thrombin for these cofactors is high with $\mathrm{K}_{\mathrm{d}}$ values in the nanomolar range, so that it takes higher substrate concentrations to produce appreciable inhibition. Second, thrombin concentrations soon rise above the concentrations of its natural substrates ([VIII] $<1 \mathrm{nM},[\mathrm{V}] \approx 25 \mathrm{nM}$ ) so that complexing of a part of the thrombin with chromogenic substrate has relatively little effect.

\section{meesurement of the influence of SQ 68}

Thrombin decay in the presence of various concentrations of SQ 68 was measured. Table 2 shows that indeed there is a dependence of the $k_{\text {dec }}$ of thrombin on the SQ 68 concentration. The decay constants as function of the SQ 68 concentration were fitted to equation 18. The resulting $K_{m}(600$ $\mu \mathrm{M} \pm 60$ ) was in good agreement with the value of $\mathrm{K}_{\mathrm{m}}$ obtained by direct measurement of reaction rates $(660 \mu \mathrm{M} \pm 100)(4)$.

Measurement of thrombin generation curves in the presence of SQ 68 allows for estimation of the $k_{\text {dec }}$ values for $\alpha_{2} M$ mediated thrombin decay

\begin{tabular}{cccc} 
[SQ 68] $(\mu \mathrm{M})$ & $k_{\operatorname{dec}}\left(\mathrm{min}^{-1}\right)$ & $k_{1}\left(\mathrm{~min}^{-1}\right)$ & $k_{2}\left(\mathrm{~min}^{-1}\right)$ \\
\hline 0 & 2.446 & 2.223 & 0.223 \\
100 & 2.072 & 1.858 & 0.214 \\
200 & 1.863 & 1.669 & 0.194 \\
500 & 1.425 & 1.254 & 0.171 \\
1000 & 0.885 & 0.758 & 0.127 \\
1500 & 0.578 & 0.477 & 0.101 \\
2000 & 0.478 & 0.399 & 0.079 \\
\hline
\end{tabular}

table 2. Influence of SQ 68 on thrombin decay constants

Decay constants of thrombin were measured after addition of $100 \mathrm{nM}$ of thrombin to plasma containing the indicated concentrations of SQ 68. Timed subsamples from this plasma were diluted in buffer containing the chromogenic substrate \$2238 for measurement of the thrombin concentrations as described (3). Contribution of the SQ 68 in the plasma to the optical density in the dilution was not measurable. Values for the $k_{2}$ were extracted from thrombin generation curves as described in this chapter. 


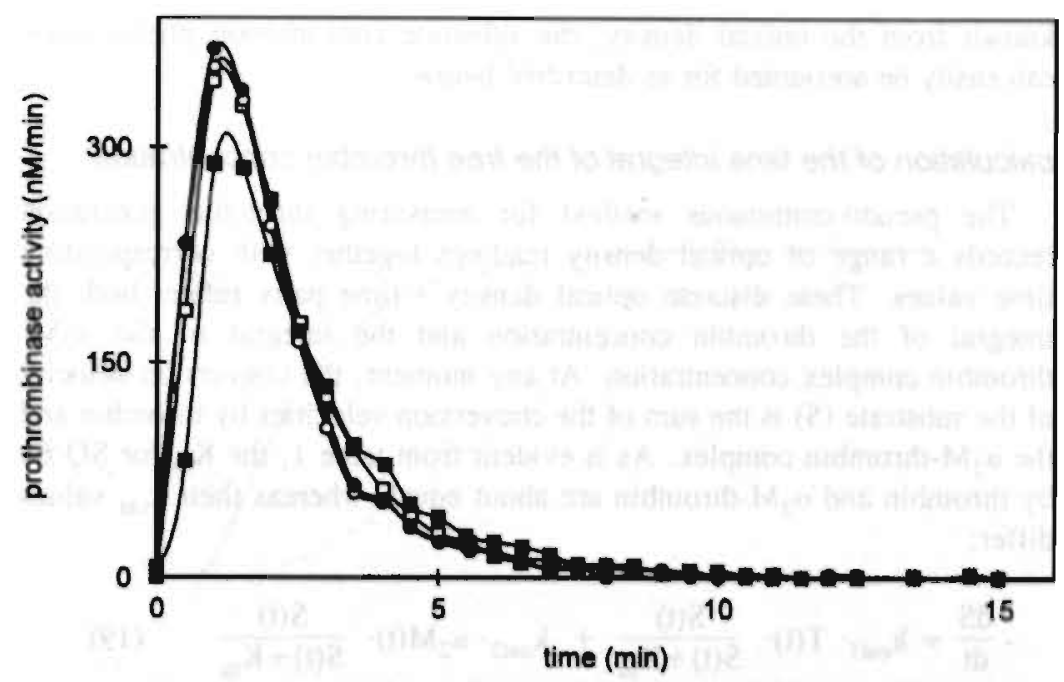

figure 6. Influence of SQ 68 on the prothrombinase actlvity In plasma.

Prothrombinase activities were calculated from thrombin generation curves measured using the subsempled method in the presence of various concentrations of SQ 68, and the decay constants of table 2. O: no SQ 68; $\bullet: 200 \mu \mathrm{M} ; \square: 500$ $\mu \mathrm{M} ; \mathbf{a}: 1 \mathrm{mM}$.

$\left(\mathrm{k}_{2}\right)$, as described above. The $\mathrm{K}_{\mathrm{m}}$ obtained by fitting to equation 18 is much higher now $(1400 \mu \mathrm{M})$, which probably reflects the fact that $\alpha_{2} \mathrm{M}$ bound to thrombin leaves the active site of thrombin still accessible.

Knowledge of the decay constants of thrombin for AT III and $\alpha_{2} \mathrm{M}$ makes it possible to calculate the prothrombinase activity from the thrombin generation curves as described in this chapter. Fig 6 shows that up to $500 \mu \mathrm{M}$ of SQ 68 may be present without inhibiting prothrombinase activity (data from ref. 4 ).

\section{consumption of SQ 68}

Since the concentration of SQ 68 is at or below the $K_{m}$ value, the concentration of SQ 68 should not drop very much, as the conversion rate of SQ 68 by thrombin is almost linearly dependent on the SQ 68 in this concentration range. Simulation of a measured integral thrombin curve, starting from a known (measured) normal thrombin generation curve, showed that the reaction rate at 15 minutes was still above $94 \%$ of the reaction rate at time zero when the SQ 68 concentration was $500 \mu \mathrm{M}$. Since the amount of SQ 68 that is converted at any given moment is 
known from the optical density, the substrate consumption phenomenon can easily be accounted for as described below.

\section{calculation of the time integral of the free thrombin concentration}

The pseudo-continuous method for measuring thrombin generation records a range of optical density readings together with corresponding time values. These discrete optical density - time pairs reflect both the integral of the thrombin concentration and the integral of the $\alpha_{2} \mathrm{M}$ thrombin complex concentration. At any moment, the conversion velocity of the substrate (S) is the sum of the conversion velocities by thrombin and the $a_{2}$ M-thrombin complex. As is evident from table 1, the $K_{m}$ for SQ 68 by thrombin and $\alpha_{2} \mathrm{M}$-thrombin are about equal, whereas their $\mathrm{k}_{\text {cat }}$ values differ:

$$
-\frac{d S}{d t}=k_{\text {call }} \cdot T(t) \cdot \frac{S(t)}{S(t)+K_{m}}+k_{c a t 2} \cdot \alpha_{2} M(t) \cdot \frac{S(t)}{S(t)+K_{m}}
$$

which resolves into:

$$
\int_{0}^{t} T(\tau) d \tau=\frac{S(0)-S(t)+K_{m}(\ln S(0)-\ln S(t))}{k_{\text {cat1 }}}-f \cdot \int_{0}^{t} \alpha_{2} M(\tau) d \tau
$$

with $f$ again equal to $k_{\text {cat } 2} / k_{\text {cat1 }}$. This equation accounts for the consumption of chromogenic substrate during the measurement.

$S(t)$ can be obtained from the measured optical density (OD) value at time $t$ as follows:

$$
S(t)=S(0)-O D(t) / \varepsilon
$$

$\varepsilon$ being the molar absorption coefficient of para-nitroaniline at a wavelength of $405 \mathrm{~nm}$.

Integration of equation 2 gives the relationship between the time integral of the $\alpha_{2} \mathrm{M}$ concentration and the time integral of the thrombin concentration. Since optical density is monitored continuously in a cuvette. the time interval between 2 optical density readings can be made almost arbitrarily small. It is sufficient, however, to have readings at $30 \mathrm{~s}$ intervals. Now, the discrete form of the differential equation can again safely be used: 


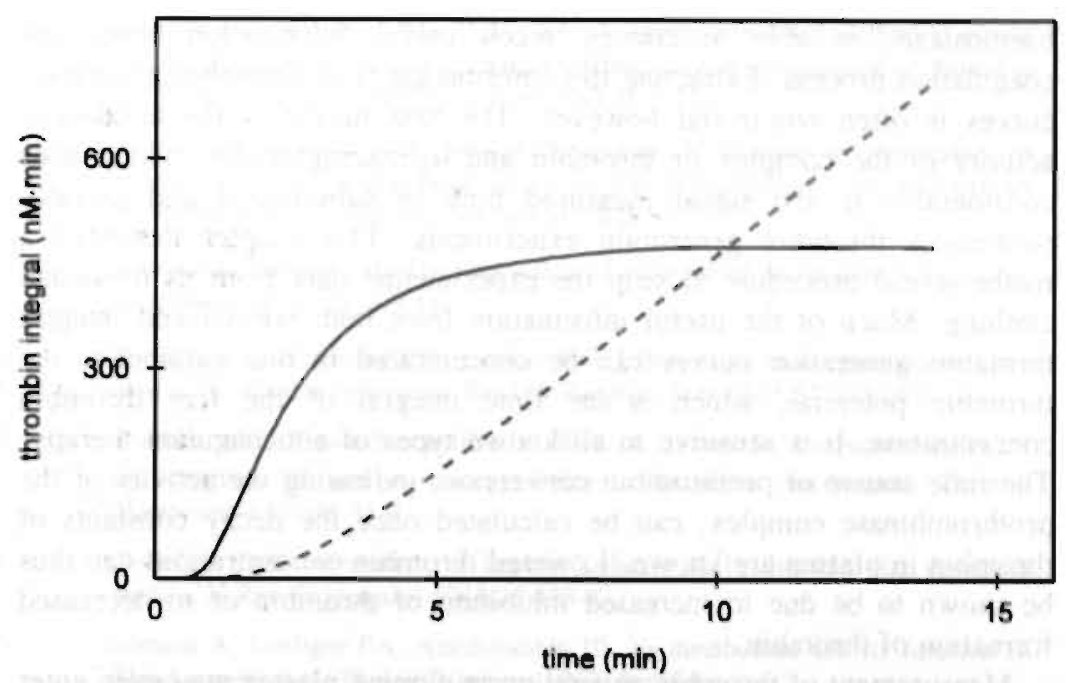

ngure 7. the time integral of the free thrombin concentration

The time course of the time integral of the thrombin concentration (-) as. calculated from the time course of optical density measured during a pseudocontinuous thrombin generation experiment. The dashed line $(-\cdots)$ shows the time course of the integral of the $\alpha_{2}$-macroglobulin thrombin concentration.

$$
\int_{0}^{4} \alpha_{2} M(\tau) d \tau=\int_{0}^{4-1} \alpha_{2} M(\tau) d \tau+k_{2} \cdot \int_{0}^{4-1} T(\tau) d \tau
$$

By applying equations 20,21 and 22 to the array of optical density values constituting the result of a continuous measurement of thrombin generation, the time course of the integral of the thrombin concentration can be calculated, provided $k_{2}$ is known. The value of $k_{2}$ can be determined directly from an experimental curve as delineated above. Figure 7 shows an integral thrombin curve derived from a time curve of optical density.

\section{conclusions}

Measurement of thrombin generation in clotting plasma has undergone a revival during the last decade spurred by the invention of chromogenic substrates in the mid seventies. Thrombin, being the central enzyme in 
haemostasis, is able to convey much useful information about the coagulation process. Extracting this information from thrombin generation curves is often non-trivial however. The first hurdle is the amidolytic activity of the complex of thrombin and $\alpha_{2}$-macroglobulin, which adds considerably to the signal measured both in subsampled and pseudocontinuous thrombin generation experiments. This chapter describes a mathematical procedure to strip the experimental data from its unwanted clothing. Much of the useful information from both normal and integral thrombin generation curves can be concentrated in one parameter, the thrombin potential, which is the time integral of the free thrombin concentration. It is sensitive to all known types of anticoagulant therapy. The time course of prothrombin conversion, indicating the activity of the prothrombinase complex, can be calculated once the decay constants of thrombin in plasma are known. Lowered thrombin concentrations can thus be shown to be due to increased inhibition of thrombin or to decreased formation of thrombin.

Measurement of thrombin generation in clotting plasma may even enter into the realm of clinical laboratory analysis. The impetus for this has been given by the development of a pseudo-continuous, automatable, thrombin generation test. Since a chromogenic substrate is present during thrombin generation and decay in plasma, what really is recorded, after subtracting the signal brought about by $\alpha_{2}$-macroglobulin, is the time integral of free thrombin during clotting. It is shown that the presence of the chromogenic substrate SQ 68 in concentrations of $500 \mu \mathrm{M}$ or thereabouts does not interfere too much with the coagulation process while still retaining a signal that is well measurable. The inevitable consumption of the substrate during the clotting process is accounted for.

All calculations presented in this article have been implemented in several computer programs (for IBM compatibles) which can be obtained from the authors.

\section{references}

1. Henker HC. Thrombin generation, an essential step in haemostasis and thrombosis. In: Haemostasis and thrombosis. Ed. Bloom et. al. Churchill Livingstone, Edinburgh 1993.

2. Henker HC, Wielders S, Beguin S. The thrombin potential. A parameter to assess the effect of antithrombotic drugs on thrombin generation. Fraxiparine, second international symposium. Recent pharmacological and clinical data. Eds Bounameaux H, Samama M, ten Cate J. 1990;89-101. Schattauer, StuttgartNew York. 
3. Hemker HC. Willems GM, Beguin SA. A computer assisted method to obtain the prothrombin activation velocity in whole plasm independent of thrombin decay processes. Thromb Hacmostas 1986;56:9-17.

4. Hemker HC. Wielders S, Kessels H, Béguin S. Continuous registration of thrombin generation in plasma, its use for the determination of the endogenous thrombin potential. Thromb Haemostess, in press.

5. Barret AJ, Starkey PM. The interection of $\alpha_{2}$-macroglobulin with proteinases. Biochem J 1973:133:709-15.

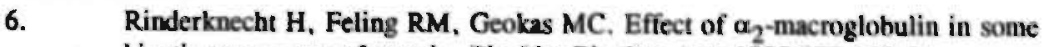
kinetic parameters of trypsin. Biochim Biophys Acta 1975:377:150-65.

7. Fischer AM, Tapon-Bretaudiere J, Bros A, Josso F. Respective roles of antithrombin III and $\alpha_{2}$-macroglobulin in thrombin inactivation. Thromb Haemostas 1981:45:51-4.

8. Tollefsen DM. Activation of heparin cofactor II by heparin and dermatan sulfate. N Rev Fr Hematol 1984;26:233-7.

9. Hensen A, Loeliger EA. Antithrombin III, its metabolism and its function in blood coagulation. Thromb Haemost 1963; Suppl 1.

10. Fagerhol MK, Abilgaard U. Immunological studies on human antithrombin III. Influence of age, sex and use of oral anticonceptives on serum concentration. Scand J Haematol 1970;7:10-7.

11. Béguin S, Kessels H, Dol F, Hemker HC. The consumption of antithrombin III during coagulation, its consequences for the calculation of prothrombinase activity and the standardisation of heparin activity. Thromb Haemostas $1992 ; 68(2): 136-42$.

12. Olson ST, Shore JD. Transient kinetics of heparin-catalyzed protease inactivation by antithrombin III. The reaction step limiting heparin turnover in thrombin neutralization. J Biol Chem 1986;2661(28):13151-9.

13. Longstaff $C$, Gaffney PJ. Serpin-serine protease binding kinetics: $\alpha_{2}$ antiplasmin as a model inhibitor. Biochemistry 1991;30(4):979-86.

14. Olson ST, Shore JD. Demonstration of a two-step reaction mechanism for inhibiton of $\alpha$-thrombin by antithrombin III and identification of the step affected by heparin. J Biol Chem 1982;257:14891-95. 


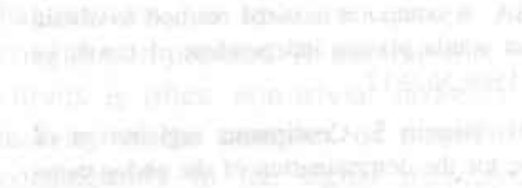

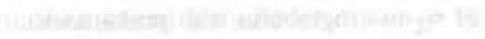

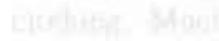

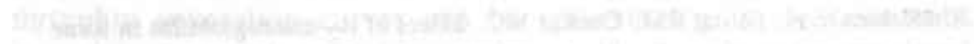

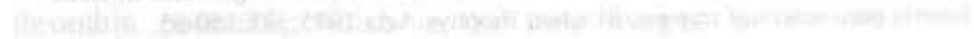

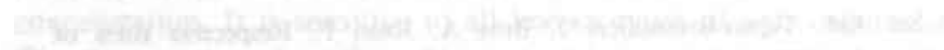

T/8,

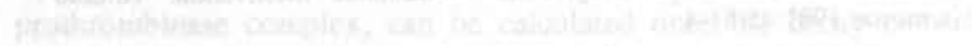

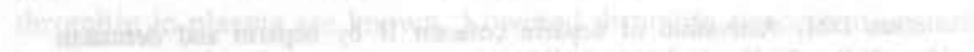

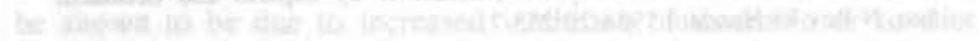

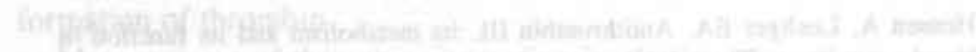

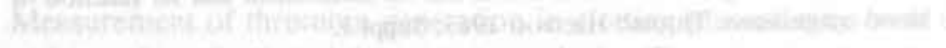

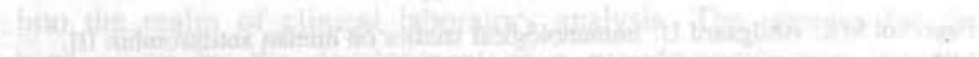

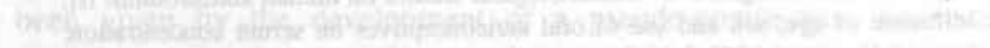

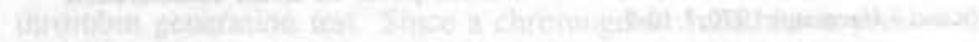

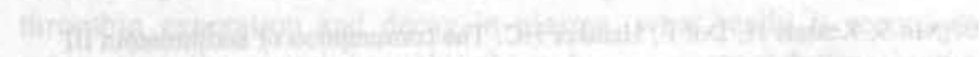

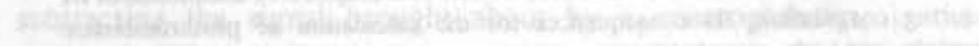

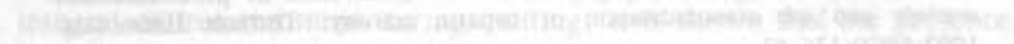

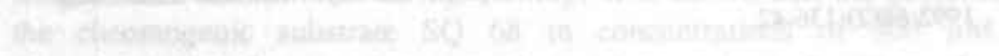

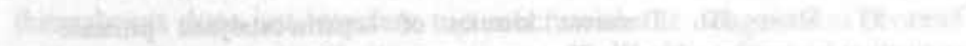

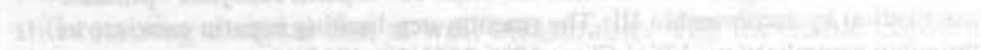

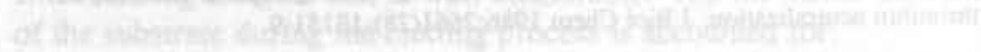

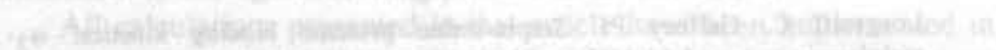

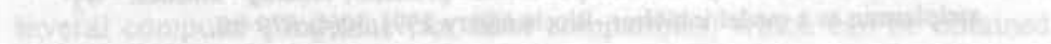

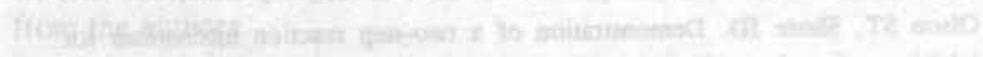

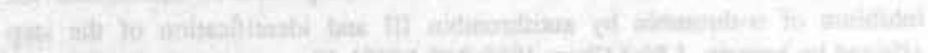

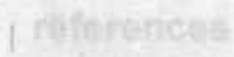

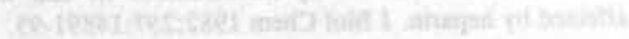

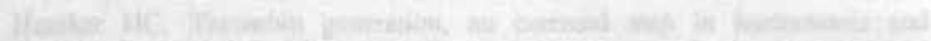

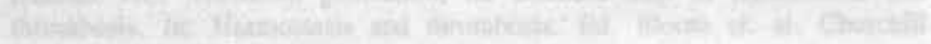

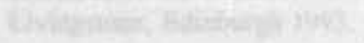

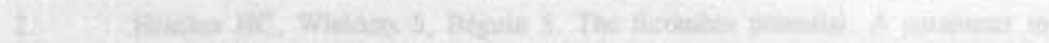

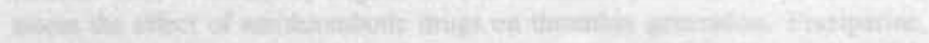

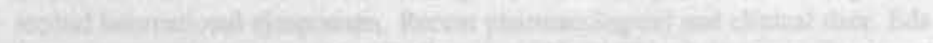

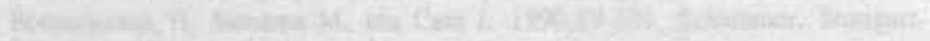

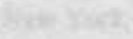




\section{chapter 4}

\section{measurement of actlvated factor VIII in plasma*}

\section{summary}

A method is described which enables an accurate quantitative measurement of the concentration of activated factor VIII (VIIla) in plasma. Based on the ability of factor VIlla to accelerate the activation of factor $\mathrm{X}$ by factor IXa, phospholipid and calcium ions, the course of factor $\mathrm{X}$ activation in time is measured using a chromogenic substrate. Free factor $\mathrm{Xa}$ is able to activate non-activated factor VIII present in a plasma sample, which increases the factor $\mathrm{X}$ activation velocity, and thus disturbs the measurement of factor VIlla. Furthermore, factor $\mathrm{Xa}$ was found to be inactivated by serine protease inhibitors from the plasma sample. By adding surplus chromogenic substrate these reactions of factor $\mathrm{Xa}$ are inhibited and at the same time the rate of substrate conversion is a measure of the amount of factor $\mathrm{Xa}$ present. Factor $\mathrm{X}$ activation and amidolysis of chromogenic substrate then take place simultaneously. It is shown that under proper conditions the factor $\mathrm{X}$ activation velocity is linearly proportional to the factor VIIla concentration. This causes the optical density to increase as a parabolic function of time. The concentration of factor VIIla can be obtained from the quadratic coefficient of the equation describing the parabola. The method is specific for factor VIIIa in that the extrinsic factor $\mathrm{X}$ activator, the factor VIla . tissue factor complex, is shown to have no influence on the measurement of factor VIIIa in thromboplastin activated plasma. We conclude that a sensitive and reliable method for assessing factor VIIla concentrations in plasma has been developed on the basis of simultaneous inhibition and measurement of factor $\mathrm{Xa}$ by $\mathrm{a}$ high concentration of chromogenic substrate.

\section{introduction}

Clot formation in plasma is initiated by the serial enzymatic activation of clotting factors, which results in the appearance of small traces of

- Based on: Kessels H, Beguin S, Wagenvoord R, Hemker HC. Thromb Haemost $1990 ; 66(4): 430-4$. 
thrombin (1). The explosive nature of the coagulation process is a consequence of the positive feedback reactions that these thrombin traces exert on the cofactors V $(2,3,4)$ and VIII $(4,5,6,7,8,9)$, and on platelets (10). Activated factors V and VIII boost the performance of factors $\mathrm{Xa}$ and IXa, whereas activated platelets provide, among other things, the negatively charged surface necessary for most coagulation reactions (11).

As the line separating thrombosis and bleeding seems to be thin, the importance of control mechanisms that steer the hemostatic process is obvious. In spite of the enormous progress that has been made by studies in systems with purified clotting factors, the fine tuning of hemostasis in vivo still remains a largely unsolved riddle. The initial traces of thrombin and the feedback reactions they provoke, are likely to play a crucial role in the overall process of hemostasis. Therefore, we set out to develop a method to directly assess one of those feedback reactions in plasma, viz. the activation of factor VIII.

Traditionally, factor VIII concentrations, and also factor VIII activation in plasma were measured using coagulation assays, involving factor VIII deficient plasma $(12,13,14)$. The occurrence of various feedback reactions made it impossible to relate, in a quantitatively reliable way, obtained values to amounts of factor VIII activated. The advent of a chromogenic substrate for factor $\mathrm{Xa}$ made a more direct way of determining functional factor VIIIa conceivable. The property of activated factor VIII, to accelerate the activation of factor $\mathrm{X}$ by factor IXa, phospholipid and calcium ions, by several orders of magnitude, was molded into a sensitive assay procedure for VIIIa $(15,16)$. However, feedback reactions of factor Xa on factor VIII $(17,18,19,20)$ and factor $X(21)$, and the inactivation of factor $\mathrm{Xa}$ by the antithrombin III and al-antitrypsin present in plasma can seriously hamper the feasibility of using the same type of assay for the measurement of factor VIIIa in plasma. On the basis of a method by Pieters et.al.(4) we developed a scheme for measuring factor VIIIa in plasma, that circumvents these difficulties.

\section{materials and mothods}

\section{materials}

Factor Xa chromogenic substrate ( $\mathrm{CH}_{3} \mathrm{OCO}$-D-Chg-Gly-Arg-pNA.AcOH) and the competitive thrombin inhibitor $\alpha$-NAPAP $(\mathrm{N}-\alpha-$ (2-Naphtylsulfonyl) - glycyl - D,L-amidino - phenylalanine-piperidine. $\mathrm{HCl}$ ) were obtained from Pentapharm (Basel, Switzerland). The factor Xa 
chromogenic substrate has $K_{m}$ and $V_{\max }$ values of $142 \mu \mathrm{M}$ and 230 $\mathrm{mA} / \mathrm{min} / \mathrm{nM}$ for bovine factor Xa (22). $\alpha$-NAPAP has a $K_{\mathrm{i}}$ for thrombin of $6.6 \mathrm{nM}$ and a $\mathrm{K}_{\mathrm{i}}$ for factor $\mathrm{Xa}$ of $7.2 \mu \mathrm{M}$ (23). Buffer used was $50 \mathrm{mM}$ Tris, $175 \mathrm{mM} \mathrm{NaCl}, 0.5 \mathrm{~g} / \mathrm{l}$ ovalbumin, $\mathrm{pH}$ 7.9. All chemicals were the highest grade commercially available.

\section{proteins}

Bovine factors $\mathrm{X}, \mathrm{Xa}, \mathrm{IX} \mathrm{a}$ and Ila were purified as previously described $(24,25,30,26)$.

\section{phospholipid}

phospholipid vesicles (PL) used were 80 mole-\% egg phosphatidyl choline and 20 mole-\% brain phosphatidyl serine (Sigma). They were prepared as described (27).

\section{plasma and euglobulins}

Plasma was prepared (28) from blood from 12 healthy male donors, 9 volumes collected on one volume of trisodium citrate $(0.13 \mathrm{M})$. Plasma was defibrinated by mixing an aliquot of plasma with $1 / 50$ volume of reptilase reagent (Boehringer Mannheim), letting a clot form for $5 \mathrm{~min}$ at $37^{\circ} \mathrm{C}$ and keeping the clotted plasma at $0^{\circ} \mathrm{C}$ for $10 \mathrm{~min}$ The fibrin formed was discarded by winding on a small plastic spatula. Euglobulins were prepared from plasma by precipitation at low ionic strength, pH $\mathbf{5 . 2}$ (plasma diluted 1 in 20 in a 0.016 vol-\% acetic acid solution), on ice for $30 \mathrm{~min}$. After centrifugation $\left(10 \mathrm{~min}, 4000 \mathrm{rpm}, 4^{\circ} \mathrm{C}\right)$, they were resuspended in 5 volumes $\mathrm{NaCl}$-aq $(9 \mathrm{~g} / \mathrm{l})$ and 1 volume trisodium citrate $(0.13 \mathrm{M})$, so as to contain a concentration of factor VIII that was not lower than $75 \%$ of the plasma concentration. $10 \mathrm{nM}$ Factor Xa remains stable in this solution for over 1 hour, in the presence of $0.1 \mathrm{U} / \mathrm{ml}$ heparin. Hemophilia A plasma was obtained from a single donor and it contained less than $1 \%$ factor VIII activity.

\section{thromboplastin}

Human brain thromboplastin was prepared as described (29). It was subsequently centrifuged at $1000 \mathrm{rpm}$ for $5 \mathrm{~min}$ and stored in $50 \mu \mathrm{l}$ aliquots at $-80{ }^{\circ} \mathrm{C}$. It was thawed and diluted 1 in 18 with buffer containing $167 \mathrm{mM} \mathrm{CaCl}$, then incubated at $37^{\circ} \mathrm{C}$ for one hour, and kept at room temperature.

\section{methods}

\section{experimental conditions}

Final concentrations of the reactants used were: factor IXa: $100 \mathrm{nM}$, PL: $20 \mu \mathrm{M}, \mathrm{Ca}^{2+}: 5 \mathrm{mM}$ and factor X: $330 \mathrm{nM}$. These are reported (30) 
to be optimal for factor $\mathrm{X}$ activation in a bovine system with human factor VIIla. The same holds for $\mathrm{pH}$ (7.9) and PS:PC ratio of the phospholipid vesicles $(20 / 80 \mathrm{~mole} / \mathrm{mole})$. All experiments were performed at $37^{\circ} \mathrm{C}$.

\section{factor Xa ascay}

$300 \mu \mathrm{l}$ from a factor $\mathrm{X}$ activation mixture was subsampled in $372 \mu \mathrm{l}$ buffer containing $20 \mathrm{mM}$ EDTA. This can be shown to stop factor $X$ activation instantaneously. After addition of $28 \mu \mathrm{l}$ of the chromogenic substrate for factor $\mathrm{Xa}$, to a final concentration of $80 \mu \mathrm{M}$, absorbance was read kinetically for $2 \mathrm{~min}$. The factor $\mathrm{Xa}$ concentration could be inferred from the initial linear increase in absorbance, using a linear least squares fit procedure. All mixtures that were assayed for factor $\mathrm{X}_{\mathrm{a}}$, contained $2.33 \mu \mathrm{M} \alpha$-NAPAP, resulting in a final concentration of $1 \mu \mathrm{M}$.

\section{measurement of absorbance}

All photometry was carried out at $405 \mathrm{~nm}$ in a sensitive dual wavelength photometer.

\section{results}

Since factor VIIIa is not an enzyme, its functional concentration cannot be measured directly by way of a chromogenic substrate. Instead, the ability of factor VIIla to enhance factor $\mathrm{X}$ activation by factor IXa, phospholipid, and $\mathrm{Ca}^{2+}$, must be exploited. The concentration of factor $\mathrm{Xa}$ can be determined chromogenically, which permits an estimation of the factor VIIla level.

\section{activation of factor VIII by factor Xa}

It is well known $(17,18,19)$ that factor $\mathrm{Xa}$ is able to activate factor VIII, be it less effectively than thrombin. Since in plasma, the intended medium for the factor VIIIla assay, both activated and non-activated factor VIII may be present, this feature of factor $\mathrm{Xa}$ is a potential hazard to the reliability of the assay.

The effect of factor $\mathrm{Xa}$ on the time course of factor $\mathrm{X}$ activation was investigated by adding a small quantity of factor $\mathrm{Xa}$ to a mixture containing factors $\mathrm{IXa}$ and $\mathrm{X}, \mathrm{PS}: \mathrm{PC}$ vesicles, $\mathrm{Ca}^{2+}$ and non-activated plasina. Thrombin mediated activation of factor VIII was prevented by the presence the thrombin inhibitor $\alpha$-NAPAP. If the added factor Xa would activate factor VIII by the added factor $\mathrm{Xa}$, complete tenase would be formed, the complex of the factors IXa and VIIla on a phospholipid surface, leading to an increase of the factor $\mathrm{Xa}$ concentration. If, on the 
other hand, factor Xa would not activate factor VIII, the factor Xa concentration would remain unaltered.

Rather surprisingly, fig. 1 (upper panel) shows an initial drop of the factor $\mathrm{Xa}$ concentration which is followed by an increase. When the experiment was repeated with hemophilia A plasma instead of normal plasma, the initial decrease of the factor Xa concentration was absent. Using the euglobulin fraction of normal plasma (no serine protease inhibitors), the upward bend of the curve was found to disappear. Using buffer instead of plasma causes the factor $\mathrm{Xa}$ concentration to remain constant.

Thus it seems likely that factor $\mathrm{Xa}$ indirectly causes factor $\mathrm{X}$ activation by activating factor VIII, and also that factor $\mathrm{Xa}$ is subject to inactivation by inhibitors (probably ATIII or al-antitrypsin) present in the diluted plasma. When the experiments were repeated with a high concentration of the highly specific potent thrombin inhibitor hirudin $(1.25 \mu \mathrm{M})$ instead of o-NAPAP, a similar course of $\mathbf{X}$ activation was obtained (results not shown).

Both activation of factor VIII by factor Xa, and inactivation of factor $X$ a directly affect the signal used for the determination of factur VIIla. Because the measurement is based on the ability of factor $\mathrm{Xa}$ to split a chromogenic substrate, adding a factor $\mathrm{Xa}$ inhibitor will effectively inhibit these undesired reactions, as well as the factor Xa measurement itself.

\section{inhibition of factor $X a$ by chromogenic substrato}

The only 'inhibitor' that can slow down the side reactions without interfering with signal generation is the chromogenic substrate for factor $\mathrm{X}_{\mathrm{a}}$, at a concentration sufficiently above $\mathrm{K}_{\mathrm{m}}$. This would prevent all reactions of factor $\mathrm{Xa}$ but amidolysis of chromogenic substrate. It means that factor $\mathrm{X}$ activation by the tenase complex and chromogenic substrate conversion by factor $\mathrm{Xa}$ are two concurrent processes.

The following equations describe these simultaneous reactions in the mixture:

$$
\begin{aligned}
& d[X a] / d t=f([V I I I a]) \\
& d A / d t=k_{2} \cdot[X a]
\end{aligned}
$$

' $\mathrm{A}$ ' being absorbance, and $\mathrm{f}$ ( [VIIIa] ), a function of the factor VIIla concentration. 


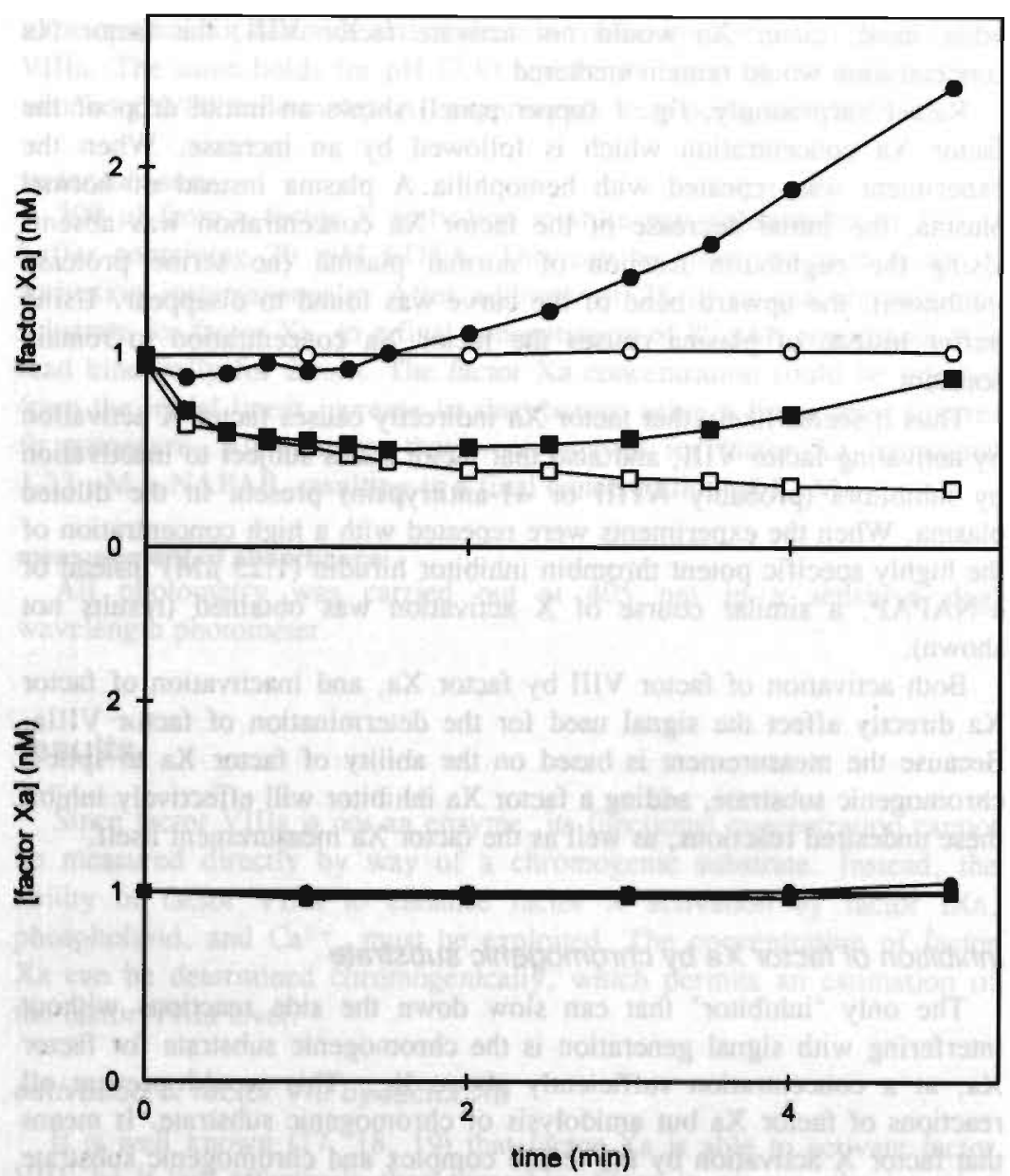

figure 1. Influence of factor $X a$ on factor $X$ activation.

upper panel: without chromogenic substrate for factor $X_{a}$ in the tenase mixture.

Factor $X$ (final concentration $0.33 \mu \mathrm{M}$ was added to a mixture of factor IXa (100 $\mathrm{nM}), \mathrm{PL}(20 \mu \mathrm{M}), \mathrm{Ca}^{2+}(5 \mathrm{mM})$ and $\alpha$-NAPAP $(2.33 \mu \mathrm{M})$. At one minute, plasma (D), hemophilia A plasma (D), euglobulin fraction ( $\bullet$ ) or buffer (O) were diluted 1 in 30 in this mixture. Ono minute later. factor Xa was added to a final concentration of $1 \mathrm{nM}$. At intervals $300 \mu \mathrm{l}$ were taken from this mixture for assay of factor $\mathrm{Xa}_{\mathrm{a}}$ as described in the materials and methods section.

lower panel: with chromogenic substrate for factor $X a$ in the tenase mixture.

Factor $X$ (final concentration $0.33 \mu \mathrm{M}$ ) was added to a mixture of factor IXa (100 $n M), P L(20 \mu M), \mathrm{Ca}^{2+}(5 \mathrm{mM}), \alpha$-NAPAP $(1 \mu \mathrm{M})$, chromogenic substrate $(400 \mu \mathrm{M})$

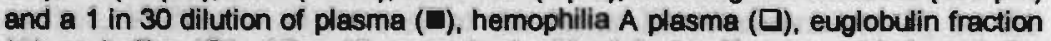
(ब) or buffer (O). After 10 seconds $1 \mathrm{nM}$ of factor $\mathrm{Xa}$ was added, and the amidolytic activity was measured every $\min$ at $405 \mathrm{nM}$. 
These equations resolve in:

$$
A(t)=A_{0}+k_{2} \cdot[X a]_{0} \cdot t+1 / 2 \cdot k_{2} \cdot f([\text { VIIla }]) \cdot t^{2}
$$

' $\mathrm{A}_{0}$ ' and ' $[\mathrm{Xa}]_{0}$ ' being 'absorbance at time zero' and 'factor $\mathrm{Xa}$ concentration at time zero' respectively.

The quadratic coefficient $\left(1 / 2 \cdot k_{2} \cdot f(\right.$ [VIIIa] $\left.)\right)$ which is a function of the factor VIIla concentration can easily be obtained from the absorbance-time curve using a simple linear least squares fit to a second order polynomial. The value of $k_{2}$ (equation II) was found to be $170 \mathrm{~mA} / \mathrm{nM}$. This is in accordance with the $\mathrm{K}_{\mathrm{m}}$ and $\mathrm{V}_{\max }$ of the chromogenic substrate, and a substrate concentration of $400 \mu \mathrm{M}$.

In practice, the course of absorbance in time was determined using the following scheme: A sample from the mixture being assayed, usually a plasma subsample, was diluted in a cuvette containing IXa (100 nM), PL $(20 \mu \mathrm{M}), \mathrm{Ca}^{2+}(5 \mathrm{mM})$ and $\alpha$-NAPAP $(1 \mu \mathrm{M})$. After 10 seconds, chromogenic substrate for factor $\mathrm{Xa}$ was added, to a concentration of 400 $\mu \mathrm{M}$. Factor $\mathrm{X}$ activation was started after another 10 seconds by addition of factor $\mathrm{X}$ to a concentration of $0.33 \mu \mathrm{M}$ (all concentrations are final concentrations). The course of the absorbance in time was then measured at $405 \mathrm{~nm}$.

The influence of factor $\mathrm{Xa}$ in this system was again investigated by adding a small quantity $(1 \mathrm{nM})$ of factor $\mathrm{Xa}$ to the factor $\mathrm{X}$ activating mixture. This was carried out essentially as described in the general scheme above, but with factor $\mathrm{Xa}(1 \mathrm{nM})$ added 10 seconds after the addition of factor $\mathrm{X}$. The experiment was performed with pooled normal plasma, hemophilia A plasma, euglobulin solution or buffer. The lower panel of fig. 1 shows that indeed all reactions of factor $\mathrm{Xa}$, except for the amidolysis of the chromogenic substrate, were effectively inhibited.

\section{standard curve}

For the concentrations used, i.e. factor IXa: $100 \mathrm{nM}$, PL: $20 \mu \mathrm{M}$ and factor VIIla: $<50 \mathrm{pM}$, the amount of complete tenase that is formed is expected to depend linearly on the concentration of factor VIIIa, since published apparent $K_{d}$ values for factor IXa in a mixture of phospholipid and factor VIIIa are below $10 \mathrm{nM}(20,26)$. To establish this linearity, the concentration of factor VIII in plasma was varied by mixing normal plasma with Hemophilia A plasma. Then all factor VIII could be activated by addition of a high concentration of thrombin. However, factor VIIla is very unstable in plasma. Therefore, we first had to find a way to stabilize 


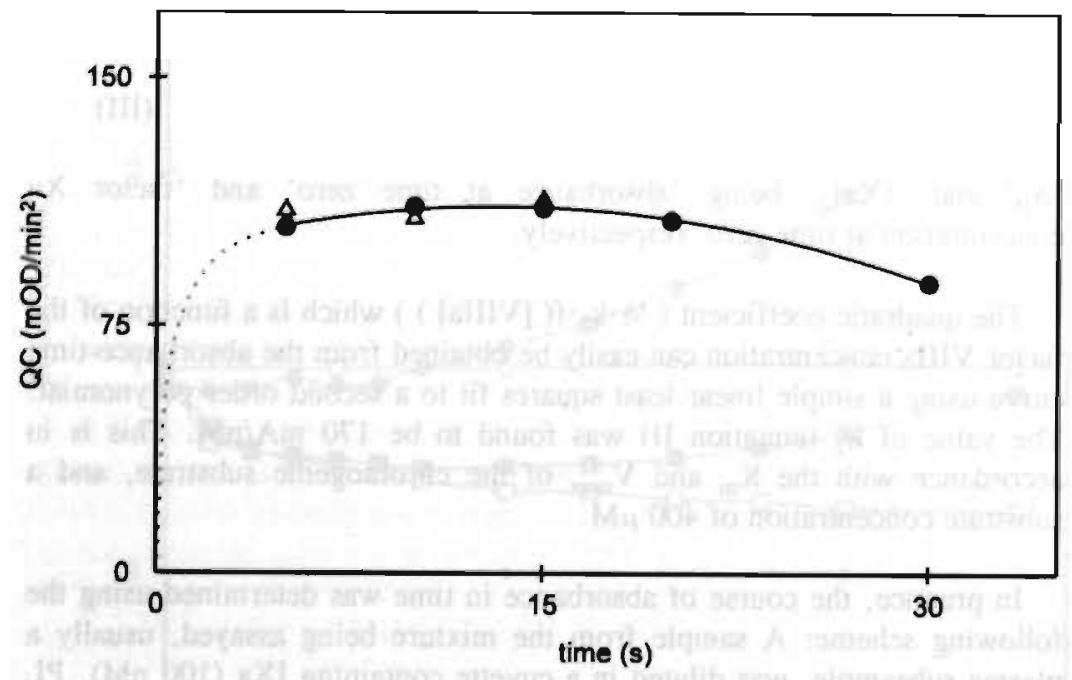

figure 2. stabillzation of factor Villa.

Plasma was diluted 100 fold in a cuvette containing IXa (100 nM), PL $(20 \mu \mathrm{M})$ and $\mathrm{Ca}^{24}(5 \mathrm{mM})$. At 30 seconds thrombin was added to concentrations of $100 \mathrm{nM}$ ( $\bullet$, mean of 3 experiments) or $200 \mathrm{nM}(\Delta)$. After a variable time, chromogenic substrate for factor $\mathrm{Xa}(400 \mu \mathrm{M})$ and $\alpha$-NAPAP $(1 \mu \mathrm{M})$ were added. The course of absorbance in tIme was measured upon addition of factor $X(0.33 \mu \mathrm{M}), 10$ seconds later. On the vertical axis are the values of the quadratic coefficient (QC) of the equation describing the absorbance time curves ( $1 / 2 \cdot k 2 \cdot f([V I I l a])$, see eq. III).

factor VIIla, so that all factor VIII in a plasma sample could be activated without inactivation going on simultaneously.

Purified factor VIIla has been found to be stabilized by complex formation with factor IXa on a negatively charged phospholipid surface in the presence of $\mathrm{Ca}^{2+}$ (31). It turned out that stability of plasma factor VIIla was achieved for about 20 seconds when the plasma was diluted first in a mixture of factor $\mathrm{IXa}, \mathrm{PL}$, and $\mathrm{Ca}^{2+}$, and then activated with a large amount of thrombin (100 $\mathrm{nM}$ ) (fig 2).

Fig. 2 also shows that the value of the quadratic coefficient did not increase when the double amount (200 nM) of thrombin was used, indicating that all factor VIII had indeed been activated.

Plasma samples with different factor VIIl concentrations were obtained by mixing pooled norma! plasma and hemophilia A plasma in various ratios. The factor VIII in these samples was completely activated as described above. Chromogenic substrate for factor Xa and $\alpha$-NAPAP were added at 45 seconds, that is 15 seconds after thrombin addition. 


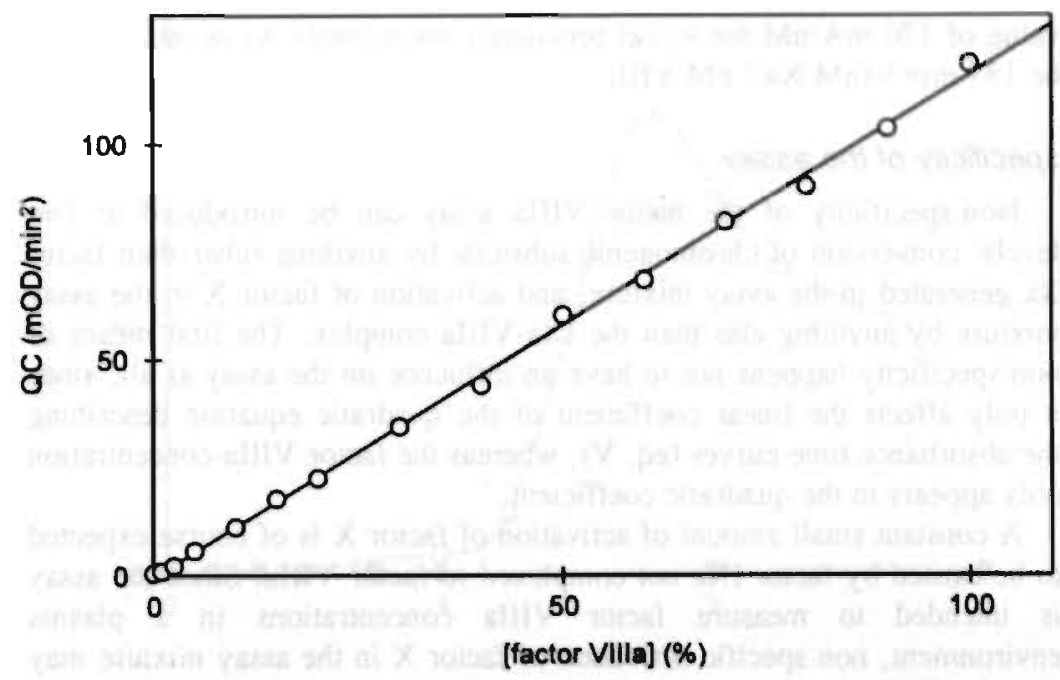

figure 3. proportionallty of the factor $X$ activation velocity to the concentration of factor Villa.

At time zero, plasma, containing various concentrations of factor VIII, was diluted 100 fold in a cuvette containing $\mathrm{Xa}(100 \mathrm{nM})$, PL $(20 \mu \mathrm{M})$ and $\mathrm{Ca}^{2+}(5 \mathrm{mM})$. At 30 seconds thrombin was added, to a concentration of $100 \mathrm{nM}$. It was allowed to activate factor VIII for 15 seconds, when chromogenic substrate for factor $\mathrm{Xa}_{\mathrm{B}}$ (400 $\mu \mathrm{M})$ and $\alpha$-NAPAP $(1 \mu \mathrm{M})$ were added. The course of absorbance in time was measured upon addition of factor $X(0.33 \mu \mathrm{M})$ after another 10 seconds. On the vertical axis are the values of the quadratic coefficient ( $Q C)$ of the equation describing the absorbance time curves (1/2-k2.f([VIIIa]), see eq. III). The concentration of factor VIII in the plasma was varled by mixing pooled normal plasma with hemophilia A plasma.

Fig. 3 shows that the quadratic coefficient, and therefore also $\mathrm{f}$ ( [VIIIa]) is linearly proportional to factor VIIla concentrations ranging from 0 to $100 \%$ in pooled normal plasma. This reduces equation (I) to

$$
f([\text { VIIla }])=k_{1} \cdot[\text { VIIIa }]
$$

so that equation (III) becomes:

$$
A(t)=A_{0}+k_{2} \cdot\left[X_{a}\right]_{0} \cdot t+1 / 2 \cdot k_{1} \cdot k_{2} \cdot[\text { VIIIa }] \cdot t^{2}
$$

The value of $1 / 2 \cdot k_{1} \cdot k_{2}$ was found to be $1.164 \pm 0.011$ (S.E.) $\mathrm{mA} / \mathrm{min}^{2} / \%$ VIIIa. Assuming $100 \%$ VIII to be $1 \mathrm{nM}(32,33)$, and using a 
value of $170 \mathrm{~mA} / \mathrm{nM}$ for $k_{2}$ (as previously mentioned), $k_{1}$ is estimated to be $137 \mathrm{~min}^{-1}$. (nM Xa / nM VIIIa).

\section{specificity of the assay}

Non-specificity of the factor VIIla assay can be introduced at two levels: conversion of chromogenic substrate by anything other than factor $\mathrm{Xa}$ generated in the assay mixture, and activation of factor $\mathrm{X}$ in the assay mixture by anything else than the IXa-VIIIa complex. The first means of non-specificity happens not to have an influence on the assay at all, since it only affects the linear coefficient of the quadratic equation describing the absorbance time curves (eq. V), whereas the factor VIIIa concentration only appears in the quadratic coefficient.

A constant small amount of activation of factor $\mathrm{X}$ is of course expected to be caused by factor IXa not complexed to factor VIIIa. Since the assay is intended to measure factor VIIIa concentrations in a plasma environment, non-specific activation of factor $\mathrm{X}$ in the assay mixture may also come from the extrinsic factor $\mathrm{X}$ activator, the complex of tissue factor with factor VIla.

The specificity of the factor VIIIa assay scheme was tested using buffer, non-activated plasma and thromboplastin (final dilution 1 in 180) activated plasma. This dilution of thromboplastin clotted uninhibited plasma in 70 seconds. When we employed the general scheme described above to measure factor VIIla activity in buffer and non-activated plasma, identical control values for the quadratic coefficient of $0.6 \mathrm{~mA} / \mathrm{min}^{2}$ were found. As already mentioned, this value is the result of the slow activation of factor $\mathrm{X}$ by IXa in the presence of phospholipid and $\mathrm{Ca}^{2+}$, but without factor VIIla.

In order to be able to determine any non-specificity from thromboplastin activated plasma, we suppressed the factor VIIla based acceleration of factor $\mathrm{X}$ activation. This was done by excluding factor IXa from the factor $X$ activating mixture, so that factor $X$ activation, if any, would be caused by constituents from the thromboplastin activated plasma, most likely the tissue factor - VIla complex. Fig. 4 shows that very little factor $\mathrm{X}$ activation could be detected. The absorbance values obtained in the absence of factor IXa were so low, that a quadratic curve could not reliably be fitted to the experimental absorbance-time data. Instead, we made an estimation of the maximal values of the quadratic coefficient by assuming the constant and linear coefficient to be zero, and calculating the quadratic coefficient from $1 / 2 \cdot k_{1} \cdot k_{2} \cdot$ [VIIIa] $=A(t) / t^{2}$ at $t=2$ min. 


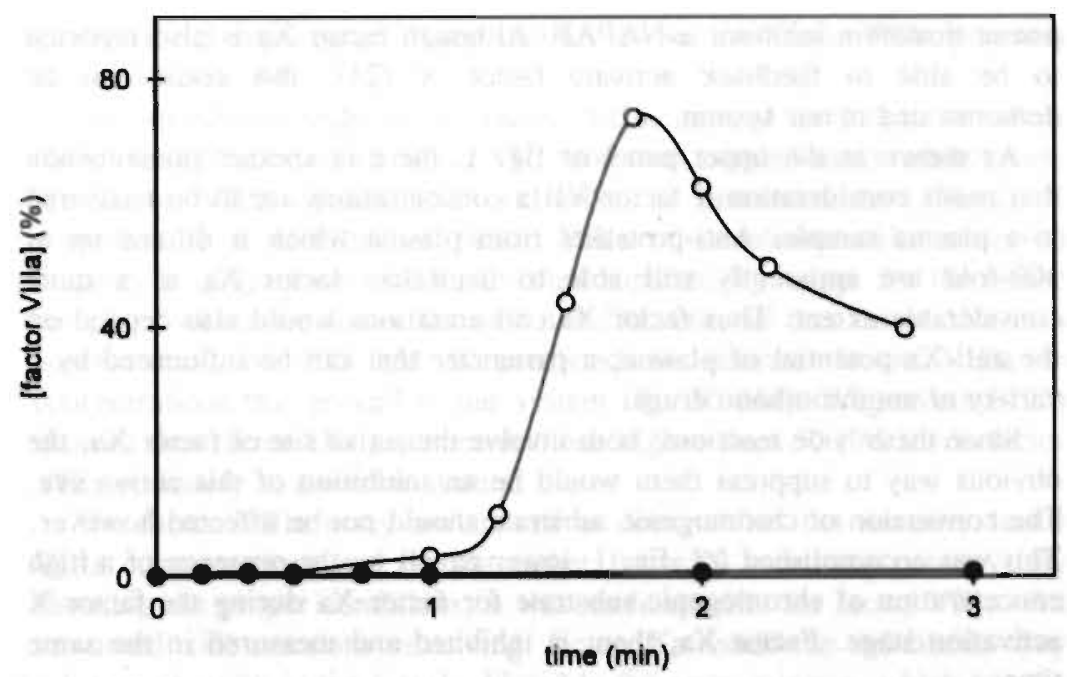

figure 4. specificity of the factor Villa asay In thromboplastin activated plasma.

$10 \mu \mathrm{J}$ of a 1 in 18 dilution of thromboplastin in a $167 \mathrm{mM} \mathrm{CaCl} 2$ solution were added $1090 \mu$ l of defibrinated plasma (final dilution of 1 in 180). At various times, a sample of this mixture was diluted 1 in 90 in a cuvette containing factor IXa (100 $n M)(0)$ or no factor IXa (๑). PL $(20 \mu \mathrm{M}), \mathrm{Ca}^{2+}(5 \mathrm{mM})$ and $\alpha$-NAPAP $(1 \mu \mathrm{M})$ in buffer, so as to obtain a final dilution of the plasma of 1 in 100. After 10 seconds, factor Xa chromogenic substrate was added, to a concentration of $400 \mu \mathrm{M}$. After another 10 seconds, factor $X(0.33 \mu \mathrm{M})$ was added to initiate the activation reaction, and absorbance was measured during $2 \mathrm{~min}$. Factor VIlla concentrations are plotted as a percentage of the total factor VIII level.

\section{discussion}

Although thrombin appears to be the only physiological activator (4), factor Xa was shown to be able to activate factor VIII in purified systems $(17,18,19,20)$. Factor $X$ activated in a system containing factor IXa, factor VIII, phospholipid and $\mathrm{Ca}^{2+}$ causes generation of factor VIIIa that in turn will accelerate the activation of factor $X$. In a method used for determining factor VIIIa concentrations this effect has to be carefully avoided, since it renders factor $\mathrm{Xa}$ concentrations not solely dependent on factor VIIIa but also on non-activated factor VIII (fig 1). The possibility that thrombin activates factor VIII in our experiments was excluded by replacing hirudin, in a large excess over thrombin, for the somewhat less 
potent thrombin inhibitor $\alpha$-NAPAP. Although factor $\mathrm{Xa}$ is also reported to be able to feedback activate factor $X$ (21), this could not be demonstrated in our system.

As shown in the upper panel of fig. 1, there is another phenomenon that needs consideration if factor VIIIla concentrations are to be measured in a plasma sample. Anti-proteases from plasma which is diluted up to 100 -fold are apparently still able to neutralize factor $\mathrm{Xa}$ to a quite considerable extent. Thus factor $\mathrm{Xa}$ concentrations would also depend on the anti-Xa potential of plasma, a parameter that can be influenced by a variety of antithrombotic drugs.

Since these 'side reactions' both involve the active site of factor $\mathrm{Xa}$, the obvious way to suppress them would be an inhibition of this active site. The conversion of chromogenic substrate should not be affected however. This was accomplished (cf, fig. 1, lower panel) by the presence of a high concentration of chromogenic substrate for factor $\mathrm{Xa}$ during the factor $\mathrm{X}$ activation stage. Factor $\mathrm{Xa}$, then, is inhibited and measured in the same time.

Then, the course of absorbance in time is the result of two simultaneous reactions: the activation of factor $\mathrm{X}$, and the amidolysis by factor $\mathrm{Xa}$ of chromogenic substrate. The latter reaction can initially be considered to be of first order, until an absorbance value of about 0.4 O.D. units.

In case of linearity between amidolysis and factor $\mathrm{Xa}$ concentration, the first derivative of the absorbance-time curve, $\mathrm{dA} / \mathrm{dt}$, is a function only of the factor $\mathrm{X}$ activation in time by the tenase complex (equation I). In all experiments performed, with activated factor VIII ranging from 0 to $100 \%$, factor $\mathrm{X}$ activation was linear in time for at least $1 \mathrm{~min}$. Care was taken to use only this part of the absorbance-time curve for parameter estimation (eq. III and V).

Lollar et.al. have shown that purified porcine factor VIIla is markedly stabilized by factor IXa, PC:PS vesicles, and $\mathrm{Ca}^{2+}$, which prolong the halflife time from $7 \mathrm{~min}$ to about 1 hour (31). As thrombin-activated factor VIII in plasma is much more unstable than its purified counterpart, so is factor VIIla in plasma that is diluted 1 in 100 in a mixture containing factor IXa, phospholipid and $\mathrm{Ca}^{2+}$. Stability is achieved for about 20 seconds, but this is followed by a rapid decrease of the factor VIIla concentration, with a $50 \%$ reduction in less than $3 \mathrm{~min}$. The question about the cause of this difference in stability of native compared to purified VIIla remains unanswered. It seems unlikely that protein $C$ is activated in our system, as we found that factor $\mathrm{Va}$ is quite stable under similar conditions (chapter 5). Furthermore, it is reported that loss of cofactor activity of factor VIIla does not have to be concomitant with a major alteration of its primary structure (31). Perhaps the recently 
published pH dependence of the stability of porcine factor VIlla provides an explanation (34).

The shortlived stability of factor VIIla proved sufficient to allow complete activation of all factor VIII, and thus enabled us to reliably vary the factor VIIla concentration in order to determine how factor $\mathrm{X}$ activation is a function of factor VIIla concentration. The observed linearity is in agreement with published apparent $\mathrm{K}_{\mathrm{d}}$ values for the tenase complex, which are lower than $10 \mathrm{nM}(20,26)$, so that factor IXa in a concentration of $100 \mathrm{nM}$ is predicted to saturate factor VIIIa in concentrations that prevail in our system (0 - $50 \mathrm{pM})$. Wagenvoord (22) showed that factor IXa at concentrations higher than $50 \mathrm{nM}$ binds factor VIlla optimally in a similar system.

The factor VIIla assay we arrived at does in fact not measure factor VIIIa concentrations per se, but rather factor $\mathrm{X}$ activating potency. By choosing the proper conditions, it was made specific for factor VIIla. All unwanted side-reactions involving factor $\mathrm{Xa}$ could be inhibited. Any substance present in the sample diluted in the assay mixture, which has the capability to split the chromogenic substrate (e.g. Xa that would be present in plasma) will only change the linear coefficient in the quadratic equation describing the course of absorbance in time, and will therefore not influence the estimation of the factor VIIla concentration. Factor IXa in the presence of PS/PC vesicles and $\mathrm{Ca}^{2+}$ ions, slowly activates factor $X$. As the concentration of IXa is fixed at $100 \mathrm{nM}$ this will always produce the same small (control) value of the quadratic coefficient. Furthermore, factor $\mathrm{X}$ activation by everything but factor VIIla from thromboplastin activated plasma, notably the extrinsic factor $\mathrm{X}$ activator, the complex of factor VIla with tissue factor, appeared to be negligible (fig. 4).

A number of reports have appeared describing assay systems of activated factor VIII in purified systems $(16,18,19,20)$. In all of those systems extreme care should be taken to avoid activation of factor VIII by factor $\mathrm{Xa}$. This could be done by careful selection of the concentration of the reactants and by limiting the time the reaction is allowed to proceed. However, when attempting to measure factor VIII activation in plasma an additional problem pops up, i.e. factor $\mathrm{Xa}$ inactivation by protease inhibitors. This is a phenomenon that cannot be dealt with by adaptation of concentrations and reaction times. It is all the more dangerous because it will not affect the calibration curve, where the large quantity of thrombin, added to the diluted plasma in order to activate the factor VIII present in that sample, will also titrate all available antiproteases, so that factor $\mathrm{Xa}$ 
inactivation is precluded. As shown, the present method effectively deals with both side reactions in a relatively simple way.

Because the factor VIIIa assay is specific, sensitive and has a well defined theoretical base, it should make possible a thorough investigatation of the physiology of factor VIII activation and inactivation, and its role in the overall process of coagulation in a close to physiological environment.

\section{references}

1. Hurlet-Birk Jensen A, Beguin S, Josso F. Factor V and VIII activation in vivo. during bleeding. Evidence of thrombin formation at the early stage of hemostasis. Path Biol 1976;24:6-10.

2. Colman RW. The effect of proteolytic enzymes on bovine factor V. Kinetics of activation and inactivation by bovine thrombin. Biochemistry 1969; 4: 143844.

3. Lindhout MJ. Activation of bovine factor $\mathrm{V}$ by thrombin and a protease from Russell's viper venom (RVV). Thromb Haemostas 1979;42:491.

4. Pieters J, Lindhout T, Hemker HC. In situ-generated thrombin is the only enzyme that effectively activates factor VIII and factor $\mathrm{V}$ in thromboplastinactivated plasma. Blood 1989;74:1021-4.

5. Rapaport SI, Hjort PF, Patch MJ. Further evidence that thrombin activation of factor VIII is an essential step in intrinsic clotting. Scand J Clin Lab Invest suppl 1965; 17: 84-8.

6. Biggs R, Macfarlane RG, Denson WE, Ash BJ. Thrombin and the interaction of factors VIII and IX. Brit J Haemat 1965; 11: 276-295.

7. Hemker HC, Kahn MJP. Reaction sequence of blood coagulation. Nature 1967;215:1201

8. Osterud B, Rapaport SI, Schiffman S, Chong MMY. Formation of intrinsic factor $\mathrm{X}$ activator with special reference to the role of thrombin. Br J Haematol 1971:21:643-60.

9. Hultin MB, Nemerson Y. Activation of factor X by factors IXa and VIII; a specific assay for factor IXa in the presence of thrombin-activated factor VIII. Blood 1978:52:928-40.

10. Davey MG. Luscher EF. Actions of thrombin and other proteolytic enzymes on blood platelets. Nature 1967:216:857-8.

11. Bevers E, Comfurius P, van Rijn JMML, Hemker HC, Zwaal RFA. Generation of prothrombin converting activity and the exposure of phospluatidylserine at the outer surface of platelets. Eur J Biochem 1982; 122:429-36.

12. Rapaport SI, Schiffman S, Patch MJ, Ware AG. A simple, specific one-stage assay for plasna thromboplastin antecedent activity. J Lab clin Med $1961: 57: 771-80$. 
13. Hardisty RM. Macpherson JC. A one-stage factor VII (antihemophilic globulin) assay and its use on venous and capillary plasma. Thrombos Diathes Haemorth 1962;7:215-29.

14. Veltkamp JJ, Drion EF, Loeliger EA. Detection of the carrier state in hereditary coagulation disorders. Thrombos Diathes haemorth 1968;19;279. 303 and 403-22.

15. Sucmela $\mathrm{H}$, Blotnback $\mathrm{B}$. The activation of factor $\mathrm{X}$ evaluated by using synthetic substrates. Thromb Res 1977;1:267-81.

16. Dieijen van G. Tans G. Rosing J. Hemker HC. The role of phospholipid and factor VIIla in the activation of bovine factor X. J Biol Chem 1981;256:343342.

17. Vebar GA, Davie EW. Preparation and properties of bovine factor VIII (Antihemophilic factor). Biochemistry 1980;19(3):401-10.

18. Hultin MB. Role of human factor VIII in factor $\mathrm{X}$ activation. J Clin Invest 1982;69:950-5.

19. Lollar P, Knutson GJ, Fass DN. Activation of porcine factor VIII by thrombin and factor Xa. Biochemistry 1985;24:8056-64.

20. Neuenschwander P, Jesty J. A comparison of phospholipid and platelets in the activation of human factor VIII by thrombin and factor $\mathrm{X}_{\mathbf{3}}$, and in the activation of factor X. Blood 1988; 72:1761-70.

21. Jesty J, Nemerson Y. Purification of factor VII from bovine plasms. Reaction with tissue factor and activation of factor X. J Biol Chem 1974;25:509-15.

22. Wagenvoord R, Hendrix H, Hemker HC. Development of a simple chromogenic factor VIII-assay for clinical use. Haemostasis 1989;19:196-204.

23. Hauptmann J, Kaiser B, Nowak G, Stürzebecher J, Markwardt F. Comparison of the anticoagulant and antithrombotic effects of synthetic thrombin and factor Xa inhibitors. Thromb Haemostas 1990;63(2):220-3.

24. Fujikawa $K$, Legaz ME, Davie EW. Bovine factor $X_{1}$ (Stuan factor), Mechanism of activation by a protein from Russel's viper venom. Biochemistry 1972;11(26):4892-9.

25. Fujikawa $\mathrm{K}$, Legaz ME, Davie EW. Bovine factor $\mathrm{X}_{1}$ and $\mathrm{X}_{2}$ (Stuart factor), Isolation and characterization. Biochemistry 1972;11:4882-91.

26. Dieijen van G, Rijn van JLML, Govers Riemslag JWP, Hemker HC, Rosing J. Assembly of the intrinsic factor $\mathrm{X}$ activation complex - Interactions between factor IXa, factor VIIIa and phospholipid. Thromb Haemost 1985;53(3):396400.

27. Rosing J, Tans G, Govers-Riemslag JWP, Zwaal RFA, Hemker HC. The role of phospholipids and factor $\mathrm{Va}$ in the prothrombinase complex. J Biol Chem 1980;255(1):274-83.

28. Hemker HC, Willems GM, Beguin SA. A computer assisted method to obtain the prothrombin activation velocity in whole plasma independent of thrombin decay processes. Thromb Haemostas 1986:56:9-17. 
29. Owren PA, Aas $\mathrm{K}$. The control of dicumarol therapy and the quantitative determination of prothrombin and proconvertin. Scand J Clin Lab Invest 1951:3:201-18.

30. Wagenvoord R, Hendrix H, Soria C. Hemker HC. Localization of the inhibitory site(s) of pentosan polysulphate in blood coagulation. Tromb Haemostas 1988:60:220-5.

31. Lollar P, Knutson GJ, Fass DN. Stabilization of thrombin-activated porcine factor VIII by factor IXa and phospholipid. Blood 1984:63:1303-8.

32. Kane WH, Davie EW. Blood coagulation factors V and VIII: Structural and functional similarities and thier relationsship to hemonthagic and thrombotic disorders. Blood 1988:71:539-55.

33. Hoyer LW. The factor VIII complex. Structure and function. Blood 1981;58:113.

34. Lollar P, Parker CG. pH-dependent denaturation of thrombin-activated porcine factor VIII. J Biol Chem 1990;265:1688-92. 


\section{chapter 5}

\section{the role of thrombin feedback reactions and factor Xa during clotting of human plasma.}

\section{summary}

Minute amounts of tissue factor are sufficient to start an efficient procoagulant response. After a short lag, this results in the explosive formation of thrombin. Development of a sensitive assay, which enables, to measure factor $\mathrm{Xa}$, and is not hindered by the presence of thrombin at concentrations of up to 4 orders of magnitude higher, made it possible to investigate the time course of factor $\mathrm{Xa}$ in plasma after triggering coagulation with physiologically low concentrations of tissue factor. It was observed that the peak concentration of factor $\mathrm{Xa}$, which was dependent on the tissue factor concentration, was reached within 20 seconds after triggering. This early peak value was shown to be a consequence of the presence of Tissue Factor Pathway Inhibitor (TFPI), which shuts down factor Xa generation by the complex of VIIa and tissue factor. The decrease of the factor Xa concentration in plasma was observed to be relatively slow so that a considerable amount was still present at the moment of factor $\mathrm{V}$ activation, even when this was artificially delayed quite considerably by the presence of a thrombin inhibitor. Part of the slow decrease seems to be due to enduring activation of factor $X$ by intrinsic tenase, since factor $\mathrm{Xa}$ concentrations fall considerably faster in plasma containing no factor VIII.

A synthetic tight binding inhibitor of thrombin was used to uncouple thrombin and factor Xa generation in order to investigate the role of the feedback activation of the cofactors V and VIII. Cofactor activation was observed to be concomitant with thrombin generation and not with factor $\mathrm{Xa}$ generation. The kinetic behaviour of the cofactors $\mathrm{Va}$ and VIIla after slow activation differed markedly due to the large difference in their stability. The minimal first order rate constant necessary for complete inhibition of cofactor activation could be estimated at approximately $2 \mathrm{~s}^{-1}$.

\footnotetext{
- based on: Kessels H, Beguin S. Hemker HC. submitted for publication
} 


\section{Introduction}

Qualitatively, the course of events during coagulation in plasma is largely known. Mostly, the reactions involved and their consequences have been deduced from observations in systems of purified proteins. Plasma, however, contains a large number of proteins, among which, presumably, a considerable number still unknown. As the number of reactions that has to be taken into account grows bigger, the effort of analysis increases rapidly. Thus, making reliable quantitative predictions about reactions in plasma is extremely difficult. Even a qualitative deduction involves significant uncertainty. Therefore, the measurement of the time course of the concentrations of coagulation enzymes in plasma during clotting may yield important clues.

Techniques for accurately measuring concentrations of activated clotting factors in plasma are the sine qua non of this type of experiment. This is not always a triviality. Complicating factors in general include the interference of other clotting factors that are present in plasma, the low prevailing concentrations of several coagulation enzymes, and the instability of some of these proteins. Methods for measuring the factors thrombin and $\mathrm{Va}$ were known beforehand $(1,2)$. A technique for measuring the very unstable, low concentration cofactor VIIIa has been described ( 3 , chapter 4$)$. This chapter introduces a novel technique to measure the apparently very low concentrations of factor $\mathrm{Xa}$ that occur in plasma when clotting is triggered with physiologically low concentrations of tissue factor. These low concentrations, in combination with the concomitant high concentrations of thrombin that occur simultaneously in clotting plasma, made existing assays of factor $\mathrm{Xa}$ unusable. The main asset of this new technique is that it separates the signals due to thrombin and factor Xa.

We used the measurements of the factors Xa, Va, VIIIa and thrombin to investigate the roles they play during coagulation after triggering with relatively low concentrations of tissue factor. Although it is difficult to appoint certain concentrations of tissue factor 'in the physiological range', we feel that the concentrations we used, $(0.2$ to $1 \mathrm{pM})$ are more appropriate than the ones used in many standard clinical coagulation assays such as the PT. As an example, full endotoxin induced expression of tissue factor in monocytes leads to an average of about $1.7 \cdot 10^{4}$ molecules per monocyte (4), which is equivalent to an overall concentration of roughly 5 to $10 \mathrm{pM}$ of tissue factor, assuming $200-400$ monocytes per $\mu \mathrm{l}$. This, however, is an extreme situation which would very likely be incompatible with life as it would give rise to a massive diffuse intravascular 
coagulation. We tried to be in the important concentration domain where it is 'decided' whether or not coagulation is going to ensue.

The effect of the synthetic reversible boro-arginin type thrombin inhibitor BIBG 64 BF on clotting in human plasma was investigated as well. Its kinetic parameters are such that activation of the feedback activation of the cofactors is not completely inhibited at lower inhibitor concentrations, thus allowing for an estimation of the minimum inhibitory potency necessary to completely prevent these reactions. We further used this inhibitor to investigate the process of feedback activation of the cofactors V and VIII in greater detail.

\section{materials and methods}

\section{materials}

\section{proteins}

Bovine factors $\mathrm{V}$ and $\mathrm{Va}(5), X(6), \mathrm{Xa}(7)$, and $\mathrm{IXa}(8)$ were purified as previously described. Human prothrombin and $\alpha$-thrombin were purified according to (9) and (10). Human factor $\mathrm{Xa}$ was prepared by activation of purified factor $\mathrm{X}$ (11) with the factor $\mathrm{X}$ activating protein from Russell's Viper Venom (KabiVitrum, Stockholm, Sweden) and isolated as described for the bovine protein (12). Polyclonal rabbit antiTFPI antibodies were a kind gift of dr. Valentin from Novo Nordisk (Denmark). Purified human factor VIII was kindly provided by dr. Spaargaren of the Central Laboratory for Blood transfusion (CLB) of Amsterdam. It contained Von Willebrand factor in a concentration about equimolar to the factor VIII concentration ( $40 \mathrm{nM})$.

\section{substrates}

Chromogenic substrates for thrombin were S2238 ( H-D-Phe-Pip-ArgpNA.2HCl, from Kabi Diagnostica Sweden) and SQ76 (isobutyloxycarbonyl-Pro-Arg-pNA.AcOH, from Serbio France). Factor Xa chromogenic substrate ( $\mathrm{CH}_{3} \mathrm{OCO}-\mathrm{D}-\mathrm{Chg}-\mathrm{Gly}$-Arg-pNA.AcOH) and thrombin inhibitor $\alpha$-NAPAP (N- $\alpha$-(2-Naphtylsulfonyl)-glycyl$\mathrm{D}, \mathrm{L}$-amidinophenylalanine-piperidine. $\mathrm{HCl}$ ) were obtained from Pentapharm (Basel, Switzerland).

\section{BIBG 64 BF}

The boroarginin type thrombin inhibitor BIBG 64 BF was a kind gift of dr. Th. Müller of Thomae, Biberach Germany. 
buffers

Buffers used were A: $50 \mathrm{mM}$ Tris- $\mathrm{HCl}, 100 \mathrm{mM} \mathrm{NaCl}$ and $0.5 \mathrm{~g} / \mathrm{l}$ bovine serum albumin (Sigma), pH 7.35, B: $50 \mathrm{mM}$ Tris- $\mathrm{HCl}, 100 \mathrm{mM}$ $\mathrm{NaCl}, 20 \mathrm{mM}$ EDTA and $0.5 \mathrm{~g} / \mathrm{l}$ bovine serum albumin, $\mathrm{pH} 7.9$ and $\mathrm{C}$ : $50 \mathrm{mM}$ Tris- $\mathrm{HCl}, 175 \mathrm{mM} \mathrm{NaCl}, 0.5 \mathrm{~g} / \mathrm{l}$ bovine serum albumin, $\mathrm{pH} 7.9$, except where indicated otherwise $\left(\mathrm{pH}\right.$ values set at $\left.20^{\circ} \mathrm{C}\right)$. All chemicals were the highest grade commercially available.

\section{phospholipld}

Phospholipids used were dioleoyl phosphatidyl choline (DOPC) and dioleoyl phosphatidyl serine (DOPS). They were purchased from Avanti Polar Lipids. Suspensions of small unilamellar vesicles were prepared by sonication of a $20 \%$ DOPS / $80 \%$ DOPC mixture in $50 \mathrm{mM}$ Tris- $\mathrm{HCl}$ (pH 7.9) containing $175 \mathrm{mM} \mathrm{NaCl}$, as described (13).

\section{plasma}

Plasma was prepared (14) from blood from 10 healthy male donors, 9 volumes collected on one volume of trisodium citrate $(0.13 \mathrm{M})$. Hemophilia A plasma was obtained from a single donor and it did not contain detectable factor VIII activity.

\section{tiesue factor \\ Recombinant tissue factor (recomboplastin) was from Baxter-Dade (Düdingen, Switzerland).}

\section{mothods}

\section{triggering of coagulation}

$20 \mu \mathrm{l}$ of buffer A, containing any substance under investigation, was added to $340 \mu \mathrm{l}$ of fibrinogen containing human plasma, incubated for at least $3 \mathrm{~min}$ at $37^{\circ} \mathrm{C}$. Coagulation was triggered by addition of $40 \mu \mathrm{l}$ of a mixture of recombinant tissue factor ( in dilutions ranging from $1 / 45$ to $1 / 225$, final dilutions $1 / 450$ to $1 / 2250$, which corresponds to concentrations of approx. 1 to $0.2 \mathrm{pM}), \mathrm{CaCl}_{2}$ (167 mM, final added concentration $16.7 \mathrm{mM}$ ), and a $20 \% / 80 \%$ PS/PC vesicle suspension (15 $\mu \mathrm{M}$, final concentration $1.5 \mu \mathrm{M}$ ) in buffer $\mathrm{A}$.

\section{measurement of thrombin concentrations in plasma}

Thrombin concentrations were measured as described before (1). Briefly, $10 \mu \mathrm{l}$ subsamples were drawn from clotting plasma, and diluted 50 fold in buffer B containing $200 \mu \mathrm{M}$ of S2238. Thrombin concentrations were inferred from the rate of change of optical density at $405 \mathrm{~nm}$. 


\section{measurement of factor Va concentrations in plasma}

Measurement of factor Va was carried out essentially as reported (2). In short, $10 \mu \mathrm{l}$ bovine factor Va containing subsamples were diluted 200 fold in buffer $\mathrm{C}$ containing $0.1 \mathrm{U} / \mathrm{ml}$ of standard heparin and $5 \mathrm{mM} \mathrm{CaCl}$ on ice. $10 \mu \mathrm{l}$ of this solution was diluted in $105 \mu \mathrm{l}$ of a mixture containing human factor $\mathrm{Xa}(20 \mathrm{pM}$ final concentration in $125 \mu \mathrm{l}), \mathrm{CaCl}_{2}$ (final concentration $5 \mathrm{mM}$ ) and phospholipid in the form of vesicles of $20 \%$ PS and $80 \% \mathrm{PC}$ (final concentration $10 \mu \mathrm{M}$ ). After 1 minute incubation, the prothrombinase reaction was, started by addition of $10 \mu \mathrm{l}$ of hurnan prothrombin to a final concentration of $200 \mathrm{nM}$. After 2 minutes, thrombin generation was halted by addition of $350 \mu$ l buffer $\mathrm{C}$ containing $20 \mathrm{mM}$ EDTA. The rate of change of optical density at $405 \mathrm{~nm}$ was recorded after addition of $25 \mu$ l of $\$ 2238$ (final concentration $200 \mu \mathrm{M}$ ).

\section{measurement of factor Villa concentrations in plasma}

Factor VIIla concentrations were measured as described (3, and chapter 5). This measurement is based on the ability of factor VIIla to accelerate factor Xa generation by factor IXa, PS/PC vesicles and $\mathrm{Ca}^{2+}$. Chromogenic substrate for factor $\mathrm{Xa}$ is present during factor $\mathrm{X}$ activation in the assay mixture, in order to competitively inhibit activation of remaining factor VIII by the generated factor Xa. Briefly, factor VIIIa containing subsamples of $5.6 \mu \mathrm{l}$ were added to $387.8 \mu \mathrm{l}$ of a mixture of $\mathrm{CaCl}_{2}$ (final concentration $5 \mathrm{mM}$ ), thrombin inhibitor $\alpha$-NAPAP (final concentration $1 \mu \mathrm{M}$ ), PS/PC (20/80) vesicles (final concentration $20 \mu \mathrm{M}$ ). and bovine factor IXa (final concentration $100 \mathrm{nM}$ ). After 10 seconds, 100 $\mu \mathrm{l}$ of chromogenic substrate for factor $\mathrm{Xa}$ is added to a final concentration of $400 \mu \mathrm{M}$. After another 10 seconds $6.7 \mu \mathrm{l}$ of bovine factor $\mathrm{X}$ are added (final concentration $333 \mathrm{nM}$ ) and an optical density vs. time curve is measured at $405 \mathrm{~nm}$. Optical density follows a parabolic path in time. From the quadratic coefficient of the equation describing this parabola, the factor VIIla concentration is inferred.

\section{measurement of factor $X a$ concentration in plasma}

The concentration of factor $\mathrm{Xa}$ in plasma cannot be determined using a chromogenic substrate since all available substrates for factor $\mathrm{Xa}$ show cross-reactivity with thrombin, which is present in much higher concentrations in clotting plasma. Instead its concentration can be measured using a prothrombinase assay, in which factor $\mathrm{Xa}$ is the rate limiting component. The factor $\mathrm{Xa}$ concentration then determines the rate of formation of thrombin. However, we could not make use of this approach because the factor $\mathrm{Xa}$ concentrations in plasma after triggering with dilute tissue factor remained so low that interference of thrombin from the plasma sample was much too high for a reliable measurement. 
However, when a chromogenic substrate for thrombin is present during thrombin generation in the prothrombinase assay, the optical density at $405 \mathrm{~nm}$ increases parabolically in time. Equation I describes this parabola:

$$
A(t)=A_{0}+k_{1} \cdot[I I a]_{0} \cdot t+1 / 2 \cdot k_{2} \cdot k_{1} \cdot[X a] \cdot t^{2}
$$

where [Ila $]_{0}$ is the thrombin concentration at time zero, and [Xa] is the factor Xa concentration.

$k_{1}$ and $k_{2}$ are the proportionality constants of optical density formation with thrombin, and thrombin formation with $\mathrm{Xa}$, respectively. The factor $\mathrm{Xa}$ concentration is responsible for the 'acceleration' of the increase of optical density, and the thrombin concentration for the initial velocity of the optical density vs. time curve. Thus, the presence of thrombin in a plasma sample should not interfere with the measurement of factor Xa. That indeed the quadratic parameter is linear with the $\mathrm{Xa}$ concentration and the linear parameter proportional to the thrombin concentration is evident from the standard lines in fig 1.

In practice, $10 \mu \mathrm{l}$ subsamples were drawn from the triggered plasma and diluted 20 fold in buffer $\mathrm{C}$ on ice. $420 \mu \mathrm{l}$ of a mixture of bovine factor $\mathrm{Va}$ (final concentration $0.6 \mathrm{nM}$ ), PS/PC (20/80) vesicles (final concentration $20 \mu \mathrm{M}$ phospholipid) and $\mathrm{CaCl}_{2}$ (final concentration $5 \mathrm{mM}$ ) in buffer $\mathrm{C}$ in a disposable microcuvette were incubated at $37^{\circ} \mathrm{C}$ for at least 3 mininiuitês. To this minixtuifê wêfê added $25 \mu \mathrm{l}$ of prewarmed $\$ 2238$ (final concentration $200 \mu \mathrm{M}$ ) and $50 \mu \mathrm{l}$ of the diluted plasma sample (final plasma dilution 1 in 200). After an incubation of 1 minute, the prothrombinase reaction was started by the addition of $5 \mu \mathrm{l}$ of human prothrombin (final concentration $1.5 \mu \mathrm{M}$ ). The time course of optical density formation at $405 \mathrm{~nm}$ was then recorded in a thermostated dual wavelength photometer. The optical density vs. time curves were fitted to equation I using a least squares fit procedure to a quadratic curve.

In this way, thrombin and factor Xa concentrations can be measured simultaneously, whereas thrombin concentrations of up to 4 orders of magnitude higher than factor $\mathrm{Xa}$ concentrations do not significantly influence the obtained factor $\mathrm{Xa}$ concentrations.

\section{measurement of the kinetic constants of BIBG 64 BF}

Progress curves for BIBG $64 \mathrm{BF}$ with thrombin and factor $\mathrm{Xa}$ were recorded as follows: Thrombin or factor $\mathrm{Xa}$ were diluted in buffer $\mathrm{C}$ to final concentrations of $50 \mathrm{pM}$, and warmed at $37^{\circ} \mathrm{C}$. After 5 minutes, chromogenic substrate was added, 15 seconds later followed by inhibitor. Both chromogenic substrate and inhibitor concentrations were varied. Optical density at $405 \mathrm{~nm}$ was then recorded as a function of time. For 
thrombin we used the chromogenic substrate SQ76 for which thrombin has a lower $k_{\text {cat }}\left(8.65 \mathrm{~s}^{-1}, \mathrm{Km}=26.6 \mu \mathrm{M}\right)$ compared to $\$ 2238\left(128 \mathrm{~s}^{-1}, \mathrm{Km}\right.$ $=5.1 \mu \mathrm{M}$ ), so that progress curves could continue for a longer time period without a significant decrease in substrate concentration.

The recorded optical density vs. time curves were fitted to the equation (15):

$$
P(t)=v_{s} \cdot t+\left(v_{0}-v\right)\left(1-e^{-k t}\right) / k
$$

where $P(t)$ is the product (PNA) formation in time, and $v_{0}, v_{s}$ and $k$ represent the initial velocity, the steady-state velocity and the apparent first-order rate constant respectively. Values for $k_{\text {on }}$ were estimated by fitting to

$$
k(S, I)=k_{\text {off }}+\frac{k_{o n} \cdot I}{1+S / K_{m}}
$$

$(15,16)$ with $S$ being the concentration of chromogenic substrate, and I the inhibitor concentration.

In case of thrombin inhibition, the $k_{\text {off }}$ values were too low to be reliably obtained in this manner. Instead $k_{\text {off }}$ was obtained from the following relationship between $v_{s}$ and $v_{0}(16)$ :

$$
v_{s}=v_{0} \cdot \frac{k_{\text {off }}}{k}
$$

$\mathrm{K}_{\mathrm{i}}$ can then be calculated as:

$$
K_{i}=k_{\text {off }} / k_{\text {on }}
$$

Additionally, the steady state velocity was determined by linear regression on a late part of the optical density time curve, and $\mathrm{K}_{\mathrm{i}}$ was also estimated from:

$$
v_{s}(S, I)=v_{\max } \cdot \frac{S}{S+K_{m}\left(1+I / K_{i}\right)}
$$



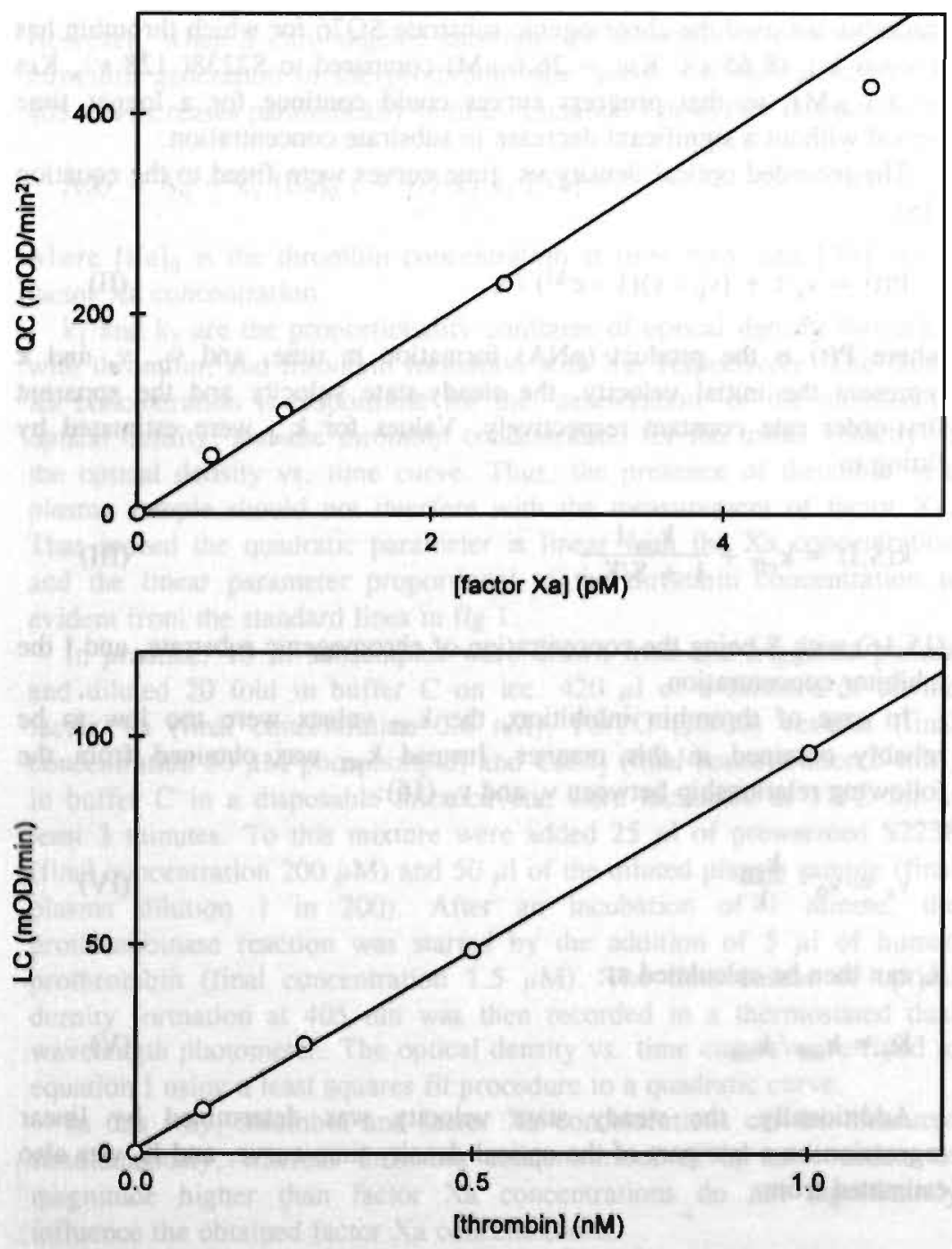

figure 1. standard lines for the measurement of factor $X a$ in plasma.

upper graph: The quadratic coefficient of the parabola describing the measured time curves of optical density, plotted as a function of the concentration of pure human factor $X a$ added to the prothrombinase assay.

lower graph: The linear coefficient of the parabola describing the measured time curves of optical density vs. the concentration of human $\alpha$-thrombin added to the prothrombinase assay. 


\section{results}

\section{factor Xa assay in plasma}

Fig. 1 shows the standard lines for the factor $\mathrm{Xa}$ assay as described in the materials and methods section with purified hurnan thrombin and factor $\mathrm{Xa}$. Clearly, the fitted linear coefficient of the parabola describing, the optical density vs. time curve is linearly proportional with thrombin concentrations up to $2 \mathrm{nM}$ in the cuvette. The quadratic coefficient is linear with factor $\mathrm{Xa}$ concentrations in the range of 0 to $2.5 \mathrm{pM}$. Pure

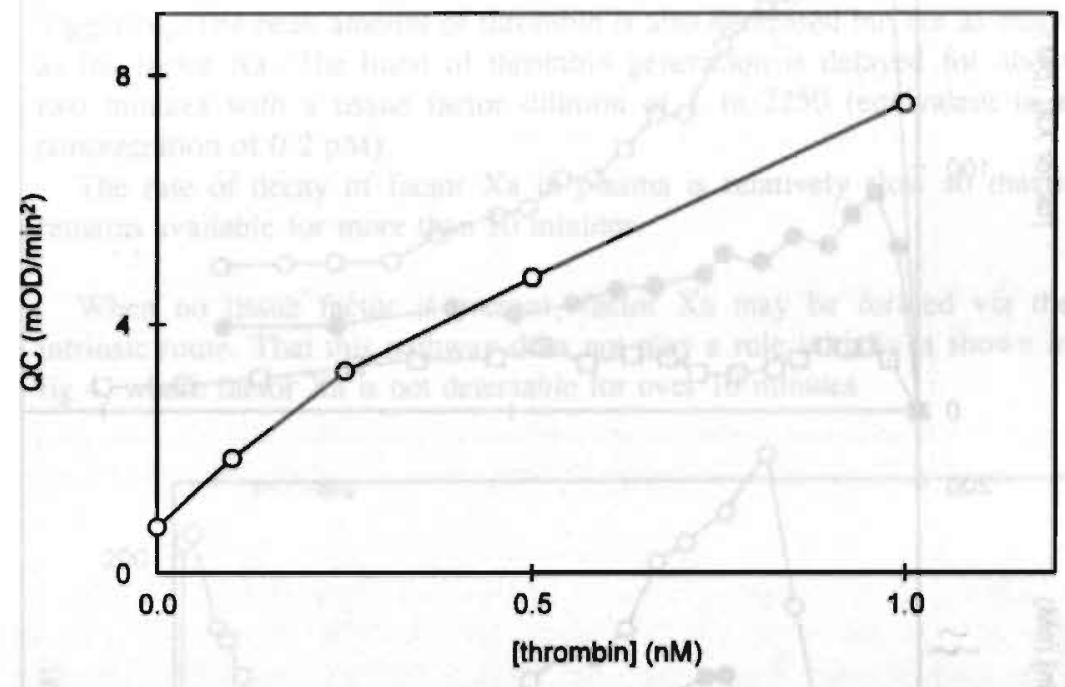

figure 2. the effect of thrombin on the 'acceleration' of optlcal density in time.

The quadratic coefficient of the parabola describing the measured time curves of optical density as a function of the concentration of pure human $\alpha$-thrombin added to the prothrombinase assay.

human thrombin has a small, as yet unexplained effect on the quadratic coefficient as well, as shown in fig. 2. When measuring factor Xa concentrations in plasma, the quadratic coefficient was corrected for this effect. Also, the linear coefficient is affected by the time interval $\left(t_{\text {lag }}\right)$ between starting the prothrombinase reaction in the cuvette and starting the recording of the optical density time curve. The actual linear coefficient (Ic) is obtained from the fitted linear coefficient $\left({ }^{(} \mathrm{c}_{\text {app }}\right)$ as follows: 
$\mathrm{lc}=\mathrm{Ic} \mathrm{c}_{\mathrm{app}}-2 \cdot \mathrm{qc} \cdot \mathrm{t}_{\mathrm{lag}}$

where $q c$ is the quadratic coefficient.

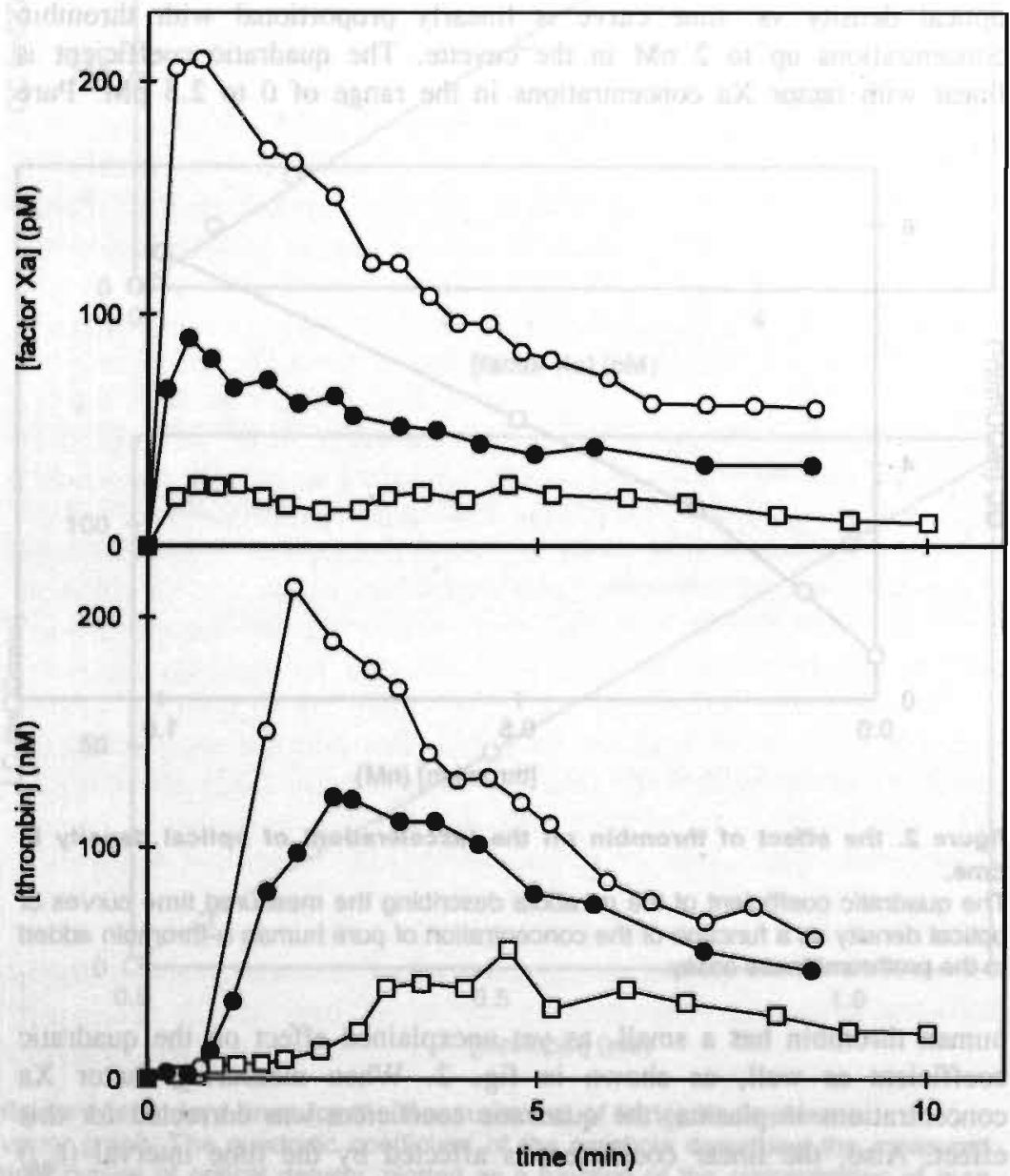

figure 3. factor $X a$ and thrombin generation in plasma triggered with varying amounts of tesue factor.

Coagulation was triggered by addition of $\mathrm{Ca}^{2+}(16.7 \mathrm{mM})$, PS/PC vesicles (1.5 $\mu M)$, and tissua factor in a dilution of 1/450 (O), 1/900 (०), and 1/2250 (0). The time courses of the concentrations of factor $X_{a}$ (upper penel) and thrombin (lower penel) were measured. 
triggering plasma with low concentrations of recombinant thromboplastin

The time courses of the concentrations of factor $\mathrm{Xa}$ in plasma were rneasured after triggering with three concentrations of recombinant tissue factor. Tissue factor in a final dilution of 1 in 450 , about $1 \mathrm{pM}$, gives rise to a clotting time of 40 seconds. We also used tissue factor dilutions of 1 in 900 and 1 in 2250. Fig. 3 shows that the peak of the factor Xa concentration decreases as a function of the tissue factor concentration. There is, however, no appreciable delay of factor Xa generation, since the peak amount of factor $\mathrm{Xa}$ is always measured within 20 seconds after triggering. The peak amount of thrombin is also decreased but not as much as for factor $\mathrm{Xa}$. The burst of thrombin generation is delayed for about two minutes with a tissue factor dilution of 1 in 2250 (equivalent to a concentration of $0.2 \mathrm{pM}$ ).

The rate of decay of factor $\mathrm{Xa}$ in plasma is relatively slow so that it remains available for more than 10 minutes.

When no tissue factor is present, factor $\mathrm{Xa}$ may be formed via the intrinsic route. That this pathway does not play a role initially is shown in fig 4, where factor $\mathrm{Xa}$ is not detectable for over 10 minutes.

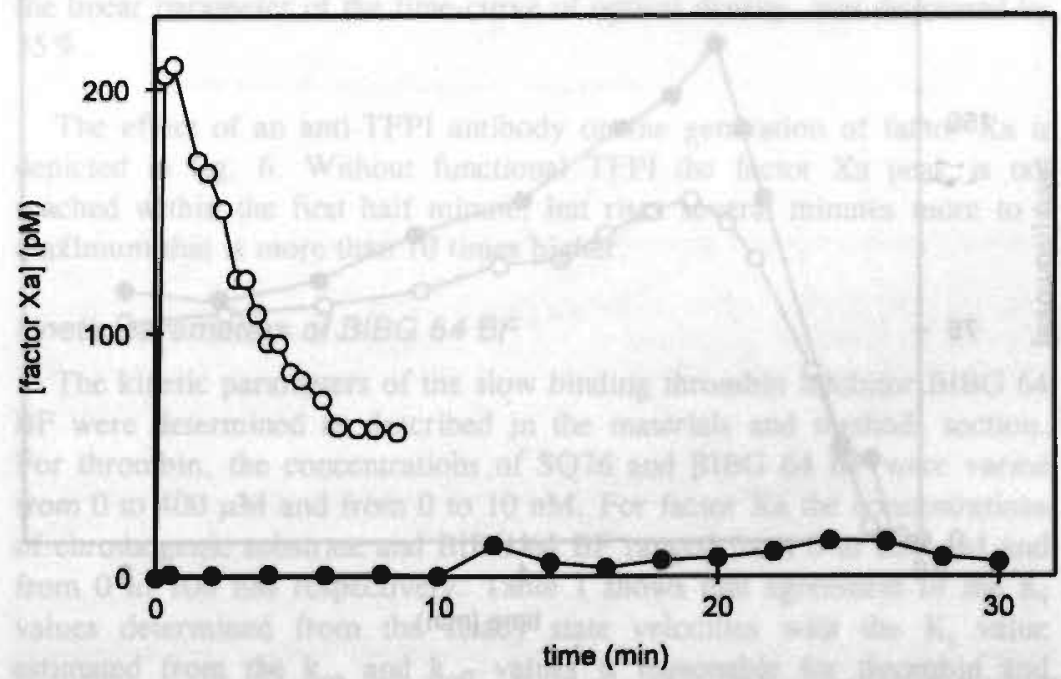

figure 4. factor $X a$ generation in plasma without triggering with thesua factor. Factor $X_{a}$ concentrations in plasma were measured after addition of $\mathrm{Ca}^{2+}(16.7$ $\mathrm{mM})$ and PS/PC (20/80) vesicles $(1.5 \mu \mathrm{M})$, with $(O)$, and without $(\theta)$ tissue factor (1 pM). 
The contribution of the alternative extrinsic pathway, or 'Josso loop', was investigated by measuring factor $\mathrm{Xa}$ generation in plasma from a patient with Hemophilia A with and without addition of the normal plasma concentration of purified human factor VIII (fig. 5). The peak concentration of factor $\mathrm{Xa}_{\mathrm{a}}$ was found to be the same in both cases, but the factor $\mathrm{Xa}$ concentrations decreased markedly more rapid when no factor

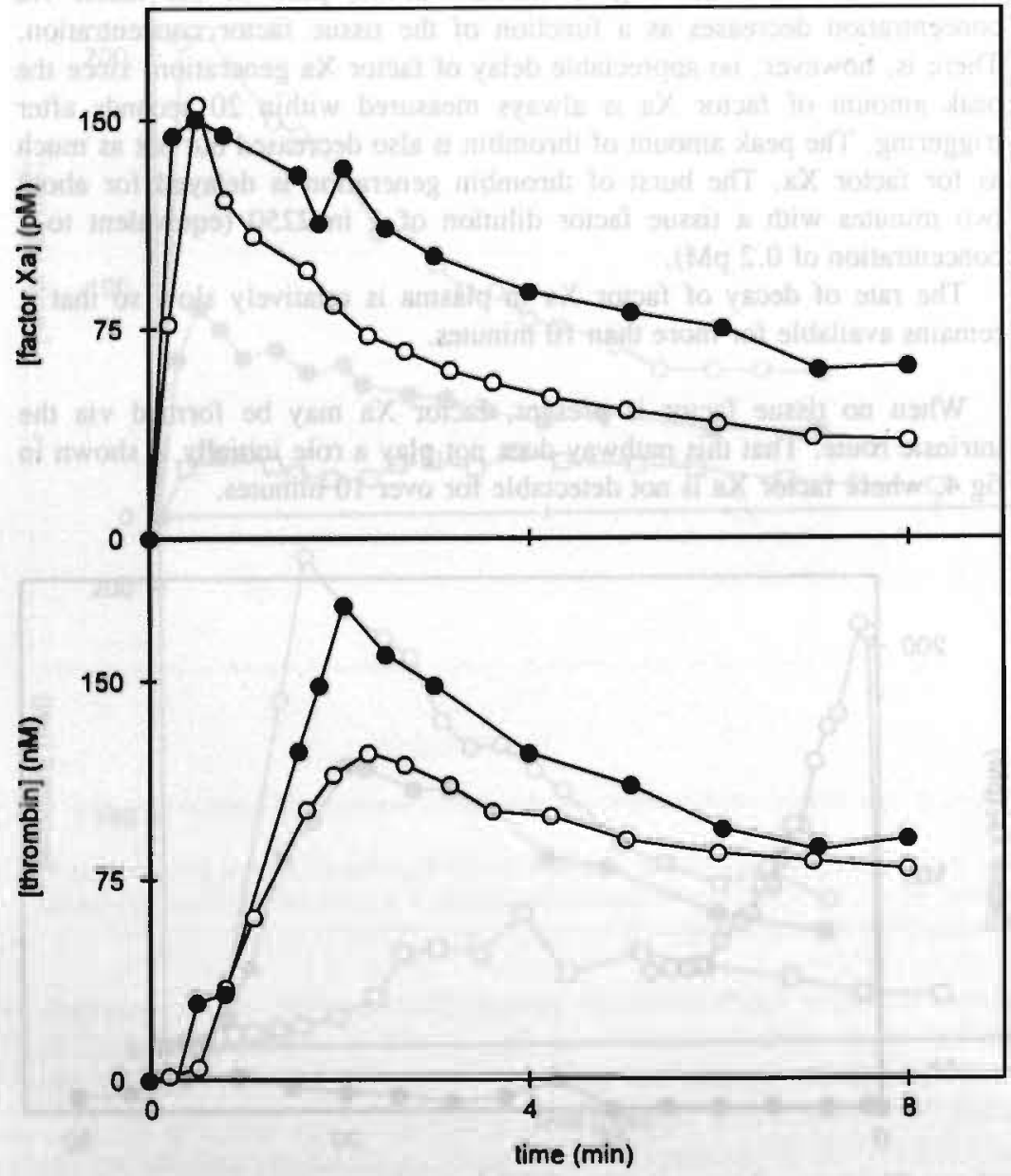

figure 6. factor $X a$ and thrombin generation in hemophilla $A$ plasma with and without purtiled human factor Vill.

Factor Xa (upper pert) and thrombin (lower pert) concentrations were measured in piasma from a hemophilia A pettent with $(\bullet)$ and without $(O)$ added humen factor VIII in a final concentration of $0.4 \mathrm{nM}$. 


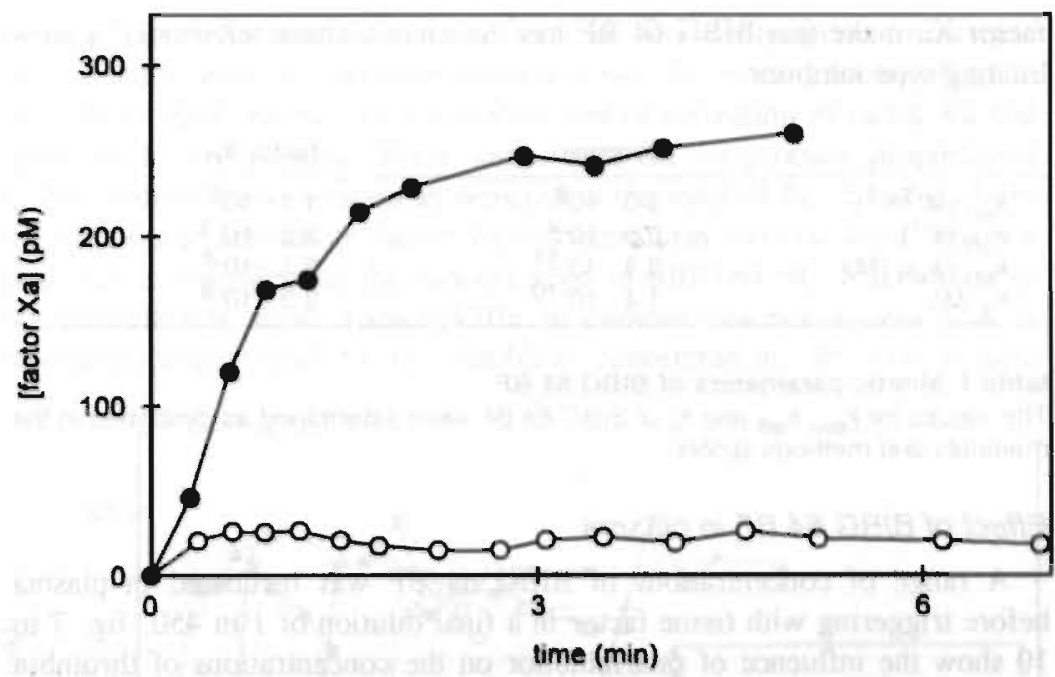

figure 6. factor Xa generation In plasma containing an anti-TFPI antlbody. Coagulation wes triggered by addition of tissue factor (1/2250) to plasma with ( $(\theta)$ and without (O) $24 \mu \mathrm{g} / \mathrm{ml}$ of a rabbit polycional enti-TFPI entibody.

VIII was present. The thrombin peak concentration, as determined from the linear parameter of the time-curve of optical density, was decreased by $35 \%$.

The effect of an anti-TFPI antibody on the generation of factor Xa is depicted in fig. 6. Without functional TFPI the factor $\mathrm{Xa}$ peak is not reached within the first half minute, but rises several minutes more to a maximum that is more than 10 times higher.

\section{kinetic parameters of BIBG 64 BF}

The kinetic parameters of the slow binding thrombin inhibitor BIBG 64 BF were determined as described in the materials and methods section. For thrombin, the concentrations of SQ76 and BIBG 64 BF were varied from 0 to $400 \mu \mathrm{M}$ and from 0 to $10 \mathrm{nM}$. For factor $\mathrm{Xa}$ the concentrations of chromogenic substrate and BIBG $64 \mathrm{BF}$ ranged from 0 to $600 \mu \mathrm{M}$ and from 0 to $100 \mathrm{nM}$ respectively. Table 1 shows that agreement of the $K_{i}$ values determined from the steady state velocities with the $K_{i}$ value estimated from the $k_{\text {on }}$ and $k_{\text {off }}$ values is reasonable for thrombin and excellent for factor $\mathrm{Xa}$. BIBG $64 \mathrm{BF}$ is a potent inhibitor of thrombin with a $\mathrm{K}_{\mathrm{i}}$ of around $100 \mathrm{pM}$. The association with factor $\mathrm{Xa}$ is more than 2 orders of magnitude weaker. The low $\mathrm{k}_{\text {off }}$ values for both thrombin and 
factor Xa make that BIBG 64 BF has the kinetic characteristics of a slow binding type inhibitor.

\begin{tabular}{lll} 
& thrombin & factor $X_{a}$ \\
\hline$k_{\text {on }}\left(M^{-1} s^{-1}\right)$ & $3.0 \cdot 10^{6}$ & $1.1 \cdot 10^{5}$ \\
$k_{\text {off }}\left(s^{-1}\right)$ & $2.5 \cdot 10^{-4}$ & $3.5 \cdot 10^{-3}$ \\
$k_{\text {on }} / k_{\text {off }}(M)$ & $8.3 \cdot 10^{-11}$ & $3.1 \cdot 10^{-8}$ \\
$K_{1}(M)$ & $1.4 \cdot 10^{-10}$ & $3.3 \cdot 10^{-8}$ \\
\hline
\end{tabular}

table 1. klnetic parameters of BIBG 64 BF

The values for $k_{\text {on }}, k_{\text {off }}$ and $K_{Y}$ of BIBG 64 BF were determined as described in the materials and methods section.

\section{Effect of BIBG 64 BF in plasma}

A range of concentrations of BIBG $64 \mathrm{BF}$ was incubated in plasma before triggering with tissue factor in a final dilution of 1 in 450 . fig. 7 to 10 show the influence of this inhibitor on the concentrations of thrombin and the factors $\mathrm{Va}, \mathrm{VIIIa}$, and $\mathrm{Xa}$. Increasing concentrations of this inhibitor induce a delay of thrombin and factor Va and VIIIa formation,

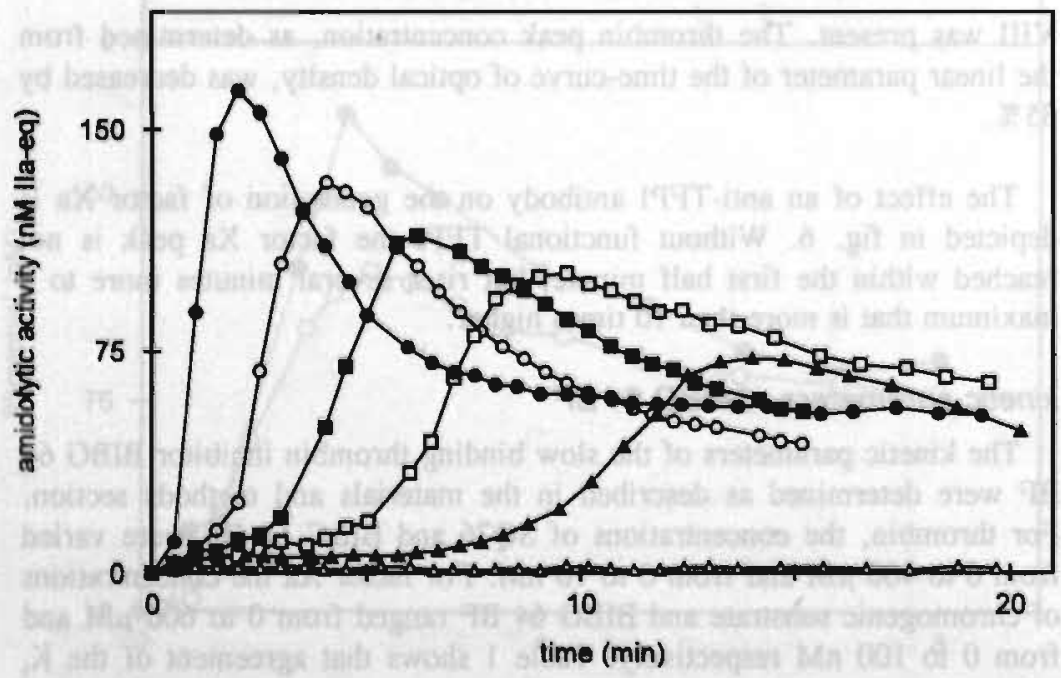

figure 7. thrombin generation In plasma containing various concentrations of BIBC 64 BF.

Thrombln generation wes measured in plasma conlaining BIBG 64 BF in a concentration of $200 \mathrm{nM}(\mathrm{O}), 300 \mathrm{nM}(\mathrm{D}), 400 \mathrm{nM}$ (D), $500 \mathrm{nM}(\Delta)$, and $750 \mathrm{nM}$ (A), or containing no BIESG 64 BF (๑). Coagulation was initialed with $\mathrm{Ca}^{2+}$ (16.67 $\mathrm{mM})$, PSTPS (20/80) vesicles (1.5 $\mu \mathrm{M})$ and tissue factor (1/450). 
whereas factor Xa formation is not delayed. This delay seems to increase exponentially with the inhibitor concentration. In concentrations of up to $500 \mathrm{nM}$ of BIBG $64 \mathrm{BF}$, an initial slow rate of activation of factor Va and factor VIlla is detectable. These initial rates are reciprocally proportional to the inhibitor concentration as depicted in the inset of fig. 8 and 9 . After the slow initial activation, factor Va concentrations increase burst-like to a peak that is dependent on the concentration of BIBG $64 \mathrm{BF}$. Inactivation of Va thereafter is slow. Factor VIIla in contrast reaches a peak that is inversely proportional to the inhibitor concentration. Its low plasma

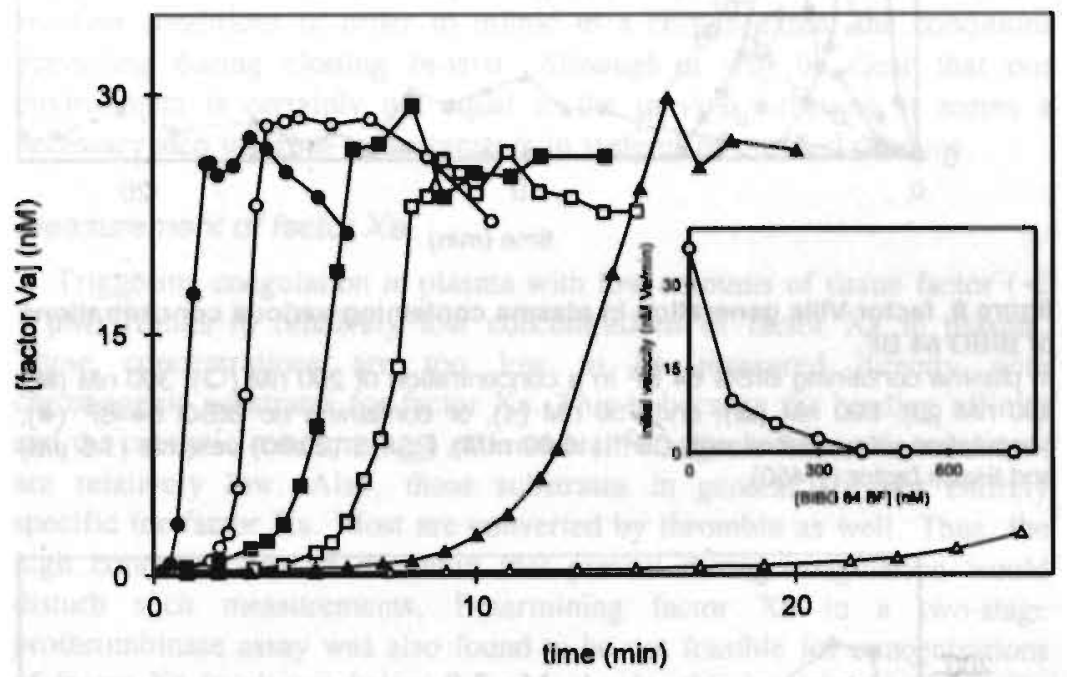

figure 8. factor Va generation in plasma containing various concentrations of BIBG 64 BF.

In plasma containing BIBG 64 BF in a concentration of $200 \mathrm{nM}(\mathrm{O}), 300 \mathrm{nM}$ (G), $400 \mathrm{nM}(\square), 500 \mathrm{nM}(\Delta)$, and $750 \mathrm{nM}(\Delta)$, or containing no BIBG $64 \mathrm{BF}(\Theta)$, coagulation was initiated with $\mathrm{Ca}^{2+}(16.67 \mathrm{mM})$, PS/PS $(20 / 80)$ vesicles $(1.5 \mu \mathrm{M})$ and tissue factor $(1 / 450)$.

concentration and its fast decay are responsible for this behaviour.

Thrombin is delayed to the same extent as are factor $\mathrm{Va}$ and factor VIIIa. Like factor Va thrombin increases burst-like after an initial slow generation. Thrombin peak values decrease as the amount of inhibitor increases. Factor Xa peaks are also inhibited somewhat by BIBG 64 BF. At BIBG 64 BF concentrations of $750 \mathrm{nM}$ and $1 \mu \mathrm{M}$ both thrombin and the activated cofactors are not measurable for more than 20 minutes. Factor $\mathrm{Xa}$, however, still reaches its peak concentration within 20 seconds after triggering. 


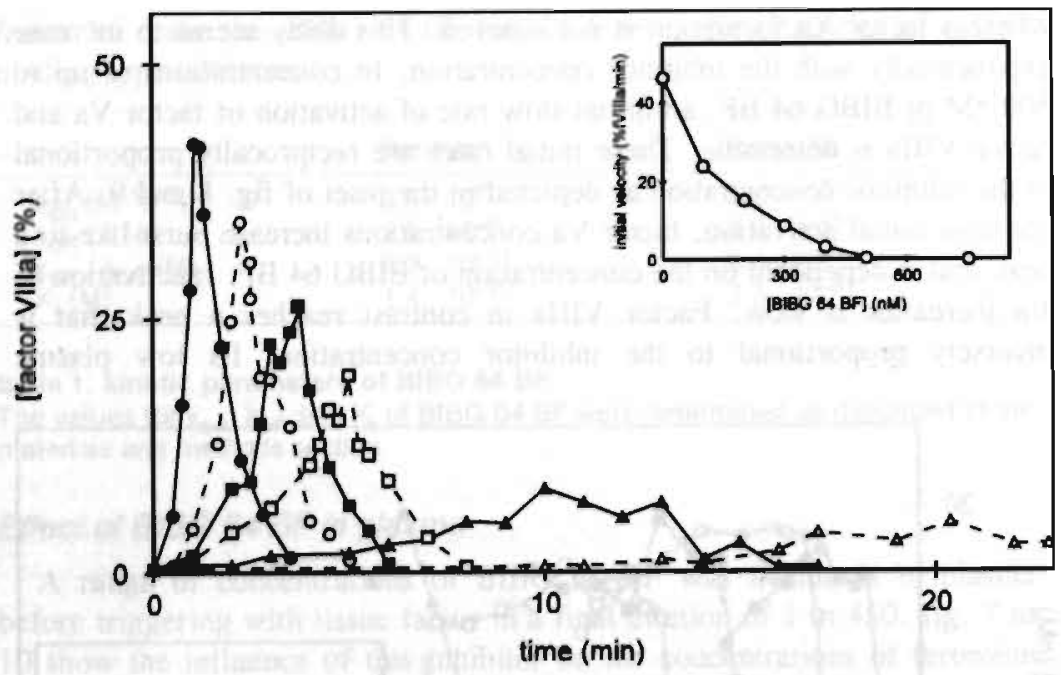

floure 8 . factor Vilia generation In plasma containing various concentrations of BIBO $84 \mathrm{BF}$.

In plasma containing BIBG $64 \mathrm{BF}$ in a concentration of $200 \mathrm{nM}(\mathrm{O}), 300 \mathrm{nM}(\mathrm{D})$, $400 \mathrm{nM}(\mathrm{C}), 500 \mathrm{nM}(\Delta)$, and $750 \mathrm{nM}(\Delta)$, or containing no BIBG 64 BF (๑), coagulation was initiated with $\mathrm{Ca}^{2+}(16.67 \mathrm{mM})$, PS/PS $(20 / 80)$ vesicles $(1.5 \mu \mathrm{M})$ and tissue factor $(1 / 450)$.

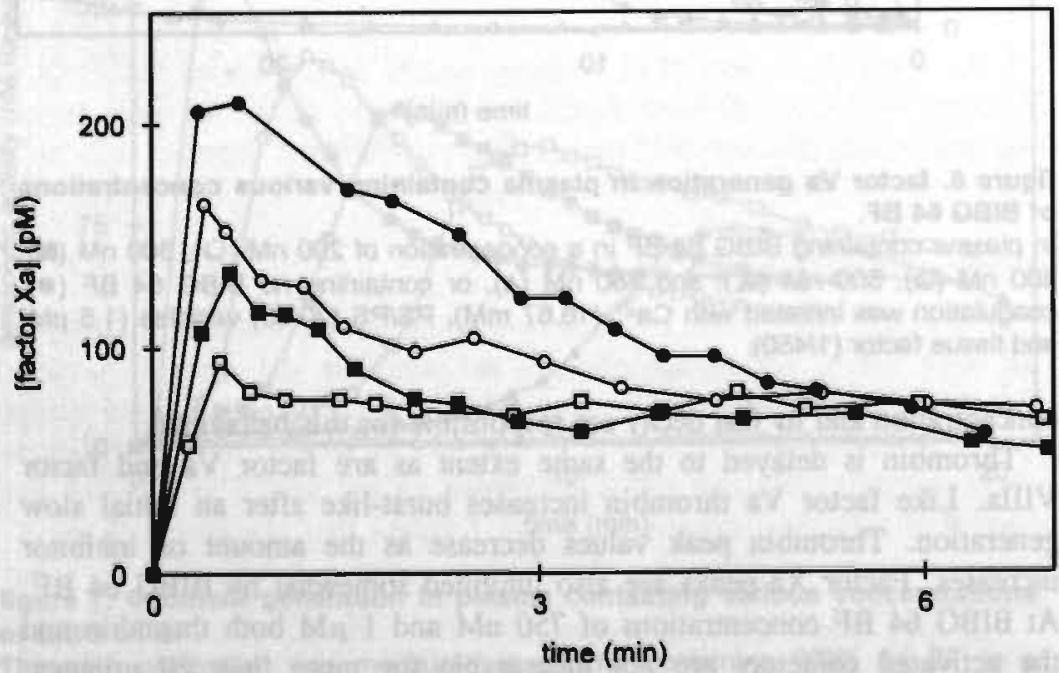

figure 10. factor $X a$ generation in plasma containing various concentrations of BIBQ $64 \mathrm{BF}$.

In plasma containing BIBG 64 BF in a concentration of $200 \mathrm{nM}(O), 400 \mathrm{nM}(\square)$, and $1000 \mathrm{nM}(\mathrm{D})$, or containing no BIBG 64 BF (๑), coegulation was initiated with $\mathrm{Ca}^{2+}(16.67 \mathrm{mM}), \mathrm{PS} / \mathrm{PS}(2 \mathrm{O} / 80)$ vesicles $(1.5 \mu \mathrm{M})$ and tissue factor $(1 / 450)$. 


\section{Discussion}

In-vivo clotting is usually initiated upon vessel-wall damage. The cloting factors circulating in blood plasma are then exposed to tissue factor present on the cell membranes of cells of the perivascular tissues. Procoagulant surfaces are provided by damaged cells and activated platelets. In the experiments described in this chapter we investigated the initial course of events in human plasma after addition of sub-picomolar concentrations of tissue factor. A phospholipid surface was provided by a limited amount of small procoagulant phospholipid vesicles. We used these reaction conditions in order to mimic to a certain extent the conditions prevailing during clotting in-vivo. Although it will be clear that our environment is certainly not equal to the in vivo situation, it seems a necessary step up from measurements in systems of purified proteins.

\section{measurement of factor Xa}

Triggering coagulation in plasma with low amounts of tissue factor ( $<$ $1 \mathrm{pM}$ ) results in relatively low concentrations of factor $\mathrm{Xa}$ in plasma. These concentrations are too low to be measured directly with chromogenic substrates for factor $\mathrm{Xa}$. This is because the binding affinity and the catalytic constant $\left(\mathrm{k}_{\mathrm{cal}}\right)$ of known chromogenic factor $\mathrm{Xa}$ substrates are relatively low. Also, those substrates in general are not entirely specific for factor Xa. Most are converted by thrombin as well. Thus, the high concentrations of thrombin that prevail during coagulation would disturb such measurements. Determining factor $\mathrm{Xa}$ in a two-stage prothrombinase assay was also found to be not feasible for concentrations of factor $\mathrm{Xa}$ in plasma below $0.5 \mathrm{nM}$. Again, this is mainly because the low plasma factor $\mathrm{Xa}$ concentration prohibits a high dilution of plasma in the prothrombinase assay. This gives thrombin generated in the plasma sample the opportunity to interfere with the assay. Our present assay combines the two stages of the prothrombinase assay into one step. Both formation of thrombin by prothrombinase and the liberation of pNA from S2238 by thrombin occur simultaneously. The linear dependencies of the thrombin formation rate on the factor $\mathrm{Xa}$ concentration, and the amidolytic activity on the thrombin concentration, make that the optical density increases according to a quadratic equation. The factor $\mathrm{Xa}$ concentration shows up in the quadratic coefficient of this equation where it is separated from the thrombin concentration which appears in the linear coefficient. Thrombin concentrations of several orders of magnitude higher than the factor $\mathrm{Xa}$ concentration do not influence the measurement of factor $\mathrm{Xa}$ in this case, so that a low dilution of a plasma subsample in the prothrombinase assay becomes possible. 


\section{factor Xa generation in plasma}

Factor Xa formation by the complex of tissue factor and factor VIIa on a phospholipid surface is a very efficient process. Factor $\mathrm{Xa}$ formation can be detected immediately after addition of tissue factor to plasma and reaches its peak within 20 seconds. The fact that at that moment only a fraction $(25$ to $200 \mathrm{pM})$ of the available factor X $(180 \mathrm{nM})$ has been converted, in combination with the relatively slow inactivation of factor $\mathrm{Xa}$ afterwards, strongly suggests that factor $\mathrm{Xa}$ generation is halted or severely inhibited from that point on. Indeed, addition of an anti-TFPI antibody causes the factor $\mathrm{Xa}$ concentration to rise for several minutes longer until it reaches a plateau at a concentration that is more than one order of magnitude higher. Thus TFPI appears to plays very important role in shutting off the VIla/TF activity early in the coagulation process.

Initially no factor $\mathrm{Va}$ is present, and factor $\mathrm{Xa}$ alone will have to activate enough thrombin to cause factor $V$ activation. The time necessary for sufficient thrombin formation is dependent on the concentration of factor $\mathrm{Xa}$, and thus on the concentration of tissue factor added. During this initial period, factor $\mathrm{Va}$ is the limiting factor of prothrombinase activity.

Factor $\mathrm{Xa}$ has a high affinity for lipid-bound factor $\mathrm{Va}$ (17). After factor $\mathrm{V}$ activation by thrombin in plasma triggered with low tissue factor concentrations, the factor $\mathrm{Va}$ concentrations are about two orders of magnitude higher than the factor $\mathrm{Xa}$ concentrations. Thus, virtually all factor $\mathrm{Xa}$ will be bound to factor $\mathrm{Va}$, which implicates that the rate of thrombin generation is determined by the factor $\mathrm{Xa}$ concentration at that moment. This amount is directly dependent on the tissue factor concentration used to trigger coagulation. Therefore, inhibition of factor $\mathrm{Xa}$ by any means would lead directly to a decrease in the rate of thrombin generation. This is confirmed by the experiments with the inhibitor BIBG $64 \mathrm{BF}$. The factor $\mathrm{Xa}$ concentration at the moment of the thrombin burst is about $190 \mathrm{pM}$ in the absence of inhibitor, and about $90 \mathrm{pM}$ in the presence of BIBG $64 \mathrm{BF}$ in a concentration of $400 \mathrm{nM}$. The maximal thrombin generation rates, calculated as described in chapter 4 , are $348 \mathrm{nM} / \mathrm{min}$ for the control experiment, and $190 \mathrm{nM} / \mathrm{min}$ in the presence of BIBG $64 \mathrm{BF}$.

Another point of consideration in this should be the presence of phospholipid vesicles in our plasma samples. We chose not to use saturating amounts of phospholipid vesicles in order to stay reasonably close to the in-vivo situation. $1.5 \mu \mathrm{M}$ of phospholipid bilayer corresponds to about $3 \mathrm{~cm}^{2} / \mathrm{ml}$ of phospholipid surface. Blood platelets in a 'normal' concentration of $250 \cdot 10^{9} / \mathrm{I}$, make for a surface of about $15 \mathrm{~cm}^{2} / \mathrm{ml}$. Thus, we may seem to underestimate the physiological phospholipid concentration somewhat. However, platelets, when activated under more or less physiological conditions using thrombin and collagen, attain a 
phosphatidyl serine content of no more than $5 \%$ in the outer mono-layer of their cell membrane (18), as compared to 20\% PS in our phospholipid vesicles. A concentration of $1.5 \mu \mathrm{M}$ of phospholipid in small vesicles with diameters $\leq 20 \mathrm{~nm}$ results in a vesicle concentration of about $300 \mathrm{pM}$. It has recently been shown that thrombin formation by the prothrombinase complex is so efficient that a single prothrombinase complex almost instantaneously converts all prothrombin molecules landing on a small phospholipid vesicle (19). Therefore, the concentration of phospholipid used in our experiments may start limiting the activity of prothrombinase if higher factor $\mathrm{Xa}$ concentrations are reached.

This has implications for the anti factor $\mathrm{Xa}$ activity of heparins. It has been shown that the prothrombinase activity in conditions very similar to the ones prevailing in our experiments is not or hardly inhibited by the presence of standard heparin up to concentrations of $0.05 \mathrm{U} / \mathrm{ml}$ (20). Combined with the low, and probably limiting concentrations of factor $\mathrm{Xa}$ we observed, this would indicate that the factor Xa generated in plasma is not readily inhibited by these concentrations of standard heparin. However, Pieters et.al. found that factor Xa concentrations can be inhibited considerably without much influence on prothrombinase activity in plasma (2). Considering the high concentrations factor Xa reached in their experiments it seems likely that the concentration of phospholipid has been rate limiting. Unfortunately, since human brain thromboplastin was employed as the source of phospholipid, the concentration and composition of the phospholipid were not well defined.

The observed slow decrease of factor Xa concentrations in plasma is partly explained by the action of the alternative extrinsic pathway, or Josso loop, the activation of factor IX by the factor VIla/tissue factor complex $(21,22)$, as shown in fig 5 . Without the presence of factor VIlla the initial decrease in the factor Xa concentration is markedly more rapid. Thus it is clear that the Josso loop contributes significantly to the concentration of factor $\mathrm{Xa}$ in plasma. The higher factor $\mathrm{Xa}$ concentrations in the presence of added factor VIII also lead to higher thrombin concentrations.

Even in hemophilia A plasma, decrease of factor Xa concentrations is relatively slow, with a halflife time of more than two minutes. It has often been shown that factor Xa bound in a prothrombinase complex is protected from activation by ATIII and ATIII-heparin $(23,24,25)$. Even the presence of non-activated factor $\mathrm{V}$ and a phospholipid surface is reported to bring some protection (26). The concentration of factor Xa seems to level off towards the end of the curve. This might be explained by continuing factor $X$ activation by the intrinsic tenase complex. However, we cannot completely exclude the possibility that part of the factor Xa bound to TFPI 
is liberated from this inhibitor during the prothrombinase assay, when the factor $\mathrm{Xa}$ containing sample is diluted 200 fold.

\section{BIBG 64 BF}

BIBG 64 BF is a synthetic boroarginine containing peptide. Peptides of this type were recently shown to be efficient, slow binding inhibitors of thrombin with a high degree of selectivity (27). The kinetic characteristics of BIBG 64 BF do not deviate much from those reported for other peptides of this kind (27). The $k_{\text {on }}$ value for the association between BIBG $64 \mathrm{BF}$ and thrombin is such that initially, with BIBG 64 BF in excess at a concentration of $400 \mathrm{nM}$ and thrombin concentrations being very low, the first order decay constant of thrombin to this inhibitor is $1.2 \mathrm{~s}^{-1}$, or 72 $\mathrm{min}^{-1}$, which is equivalent to a half-life time for thrombin of a little more than half a second. Furthermore, the complex of thrombin with BIBG 64 BF is essentially irreversible at the time scale of our experiments, with a halflife time of the complex of about 46 minutes. Still, thrombin concentrations can be measured very soon after addition of tissue factor to plasma in the presence of $400 \mathrm{nM}$ of inhibitor. Also the concentrations of the cofactors Va and VIIla slowly raise after triggering plasma. The rate of these activations is dependent on the concentration of inhibitor initially added. Thus, BIBG 64 BF is not fast enough to keep thrombin from activating the cofactors to a small extent. Small amounts of complete prothrombinase then form so that thrombin formation is proceeding somewhat more efficient. When all BIBG 64 BF has been 'titrated' away by thrombin generated in this way, the burst of thrombin generation may occur. Hirudin, a specific thrombin inhibitor with a more than ten fold higher $k_{\text {on }}$ does not let any thrombin 'leak' through its inhibition (28).

\section{cofactor activation}

It is clear from the experiments with BIBG $64 \mathrm{BF}$, as well as from the experiments with very low tissue factor concentrations, that cofactor activation is always concomitant with the burst of thrombin generation so that, as reported earlier by Pieters et.al. (28), factor $\mathrm{Xa}$ indeed does not appreciably activate the cofactors in vivo. It can, however, on the basis of the experiments described in this chapter, and of the experiments described by Pieters not completely be excluded that an initial activation of traces of the cofactors by factor $X_{2}$ may occur, which then might lead to a somewhat faster thrombin generation than by factor $\mathrm{Xa}$ alone followed by full-scale cofactor activation by thrombin. In that case very little activated factor VIII ( $<2 \mathrm{pM}$, the detection limit of the factor VIIla assay) must be enough to cause detectable factor $\mathrm{X}$ activation by intrinsic tenase. 
Factor $\mathrm{Va}$ and factor VIIla are structurally very much alike (29). However, functionally they differ in two important ways. First, factor $V$ is present in a much higher concentration than factor VIII, and second, factor $\mathrm{Va}$ is much more stable in plasma than factor VIIla. This has the effect that factor $\mathrm{Va}$ concentrations reach much higher values than factor VIIla concentrations do, and that those concentrations remain available for a much longer time. This difference is clearly demonstrated by fig. 8 and 9 . Increasing concentrations of the inhibitor BIBG 64 BF lead to decreasing initial rates of activation of these cofactors, as shown in the insets of fig. 8 and 9. In the case of factor $\mathrm{Va}$ this has no further effect than posponing the burst of factor $\mathrm{Va}$ formation. In the case of factor VIIla however, also the amount of activated cofactor generated decreases. By the time of the $\mathrm{Va}$ burst, all factor VIII has been activated in the case of higher inhibitor concentrations, so that hardly any factor VIIla is detectable.

When no heparin is present factor IXa in plasma does not decrease appreciably (30). Thus factor IXa 'waits' for factor VIIla to become available, just as factor $\mathrm{Xa}$ waits for factor $\mathrm{Va}$. In contrast to the prothrombinase situation, the amount of intrinsic tenase that is formed in plasma is probably not dependent on the concentration of enzyme (factor IXa) but on the concentration of cofactor, since its concentrations remain well below $1 \mathrm{nM}$.

\section{the emerging picture}

The experiments described in this chapter give evidence to several points relevant to coagulation in plasma. First, factor $\mathrm{Xa}$ is present immediately after addition of tissue factor to plasma. The height of its peak, which it reaches within 20 seconds, is dependent on the tissue factor concentration. In the case of high tissue factor dilutions, as used in our experiments, and likely occurring in physiological situations, the maximal concentration of factor $\mathrm{Xa}$ is low compared to concentration of unactivated enzyme. Second, the decrease of factor $\mathrm{Xa}$ concentrations in plasma is slow, so that enough factor $\mathrm{Xa}$ is available when factor $\mathrm{Va}$ is generated later on in the coagulation process, even when this moment has been artificially delayed by the presence of a thrombin inhibitor. This slow decrease is at least partly caused by the enduring activation of factor $\mathrm{X}$ by intrinsic tenase. Third, the initial rate of activation of thrombin, which is dependent on the factor $\mathrm{Xa}$ concentration, determines the initial rate of activation of the cofactors. Therefore, the amount of tissue factor added, indirectly determines the lag time of explosive thrombin formation. Fourth, the amount of factor $\mathrm{Xa}$ is limiting in the formation of the prothrombinase complex during the burst of thrombin formation. Thus, inhibition of factor Xa will decrease the maximal rate of the prothrombin 
converting enzyme. However, phospholipid may, under slightly different conditions, such as a higher concentration of tissue factor, take factor Xa's place as the limiting factor. Fifth, a slow rate of activation of factor VIII results in a lower maximal concentration of factor VIIIla. This may lead to a lower concentration of the intrinsic tenase enzyme.

The availability of accurate techniques to determine factor $\mathrm{Xa}$, factor $\mathrm{Va}$, and factor VIIla concentrations in plasma has given us the opportunity to start investigating the coagulation process in plasma in greater detail. Much more experimentation is necessary, however, to elucidate the roles of the many factors that may play important roles in the intricate blood coagulation reaction.

\section{Acknowledgements}

We would like to thank 'De Broeders van Den Beijaard' for their generous donation of blood.

\section{References}

1. Hemker HC, Willems GM, Beguin SA. A computer assisted method to obtain the prothrombin activation velocity in whole plasma independent of thrombin decay processes. Thromb Haemostas 1986:56:9-17.

2. Pieters J, Lindhout $\mathrm{T}$. The limited importance of factor $\mathrm{Xa}$ inhibition to the anticoagulant property of heparin in thromboplastin activated plasma. Blood 1989:74:1021-4.

3. Kessels H, Beguin S, Wagenvoord R, Hemker HC. A method for measuring activated factor VIII in plasma. Thromb Haemost 1990;66(4):430-4.

4. Edgington TS, Macloman N, Brand $K$, Ruf W. The structural biology of expression and function of tissue factor. Thromb Haemostas 1991:66(1):67-79.

5. Lindhout T, Govers-Riemslag JWO, Waan van de P, Hemker HC, Rosing J. Factor Va - factor Xa interaction. Effects of phospholipid vesicles of varying composition. Biochemistry 1982;21:5494-502.

6. Fujikawa K, Legax ME, Davie EW. Bovine factor $\mathrm{X}_{1}$ and $\mathrm{X}_{2}$ (Stuart factor). Isolation and chancterization. Biochemistry 1972;11:4882-91.

7. Fujikawn $K$, Legaz ME, Davie EW. Bovine factor $X_{1}$ (Stuant factor). Mechanism of activation by a protein from Russel's viper venom. Biochemistry 1972;11(26):4892-9.

8. Wagenvoord $R$, Hendrix $H$, Soria $C$, Hemker HC. Localization of the inhibitory site(s) of pentosan polysulphate in blood cosgulation. Tromb Haterestas 1988:60:220-5. 
9. Hendrix H, Lindhout T. Mertens K. Engels, W, Hemker HC. Activation of human prothrombin by stoichiometric levels of staphylocoagulase. J Bioll Chem $1983 ; 258: 3637-44$.

10. Miller-Andersson M, Gaffney PJ, Seghwehinn MJ. Preparation and stubility of a highly purified human thrombin standard. Thromb Res; 1980;20:109-22.

11. Mertens K, Bertim RM. Pathways in the ectivation of human cougulation fector X. Biocbem J 1980;185:647-58.

12. Lindlout T, Kop-Klaassen BHM, Hemker HC. Activation of decarboxyfactor $X$ by a protein from Russell's viper venom. Purification and partial characterization of activated decarboxyfactor $X$. Biochim Biophys Acta $1978 ; 533: 327-41$.

13. Rosing J, Tans G, Govers-Riemsing JWP, Zwad RFA, Hemker HC. The role of phospholipids and factor $\mathrm{V}_{\mathbf{a}}$ in the prothrombinase complex. J Biol Chem 1980;255(1):274-83.

14. Beguin S, Kessels H, Dol F, Hemker HC. The consuaption of antithrombin III during coagulation, its consequences for the calculation of prothrombinase activity and the standardisation of beparin sctivity. Thromb Haemostas $1992 ; 68(2): 136-42$.

15. Morrison JF. Walsh CT. The behavior and signifoance of slow-binding enzyme inhibitors. Adv Enzymol, 1988;61:201-301.

16. Williams JW, Morrison JF. The kinetics of reversible tighe binding inhibition. Methods in enzymology, 1979;63:437-67.

17. Giesen PLA, Willems GM, Hemker HC, Hermens WTh. Membrane-mediated assembly of the prothrombinase complex. J Biol Chem 1991;266(28):18720-3.

18. Bevers E, Comfurius P, van Rijn JMML, Hemker HC, Zwal RFA. Generation of prothrombin converting activity and the exposure of phosphatidylserine at the outer surface of platelets. Eur J Biochen 1982;122:429-36.

19. Giesen PLA, Willems GM, Hermens WTh. Production of thrombin by the prothrombinase complex is regulated by membrane-mediated transport of prothrombin. J Biol Chem 1991;266(3):1379-82.

20. Beguin S, Lindhout T, Hemker HC. The mode of action of heparin in plasma. Thromb Haemostas 1988;60:457-62.

21. Josso F. Prou-Wartelle O. Interaction of tissue factor and factor VII at the earliest phase of coagulation. Thromb Diath Hemorrh 1965:171:35-44.

22. Gsterud B, Rapaport SI. Activation of factor IX by the reaction product of tissue factor and factor VII: Additional pathway for initiating blood coagulation. Proc Natl Acad Sci USA. 1977;74(12):5260-4.

23. Lindhout T, Banch D, Schoen P, Franssen J, Hemker HC. Thrombin generation and inactivation in the presence of antithrombin III and heparin. Biochemistry 1986;25:5962-9.

24. Ellis V, Scully MF, Kaldzar VV. Ithibition of prothrombinase compiex by plasma proteinase inhibitors. Biochemistry 1984;23:5882-7. 
chapter 5

25. Schoen $P$, Lindhout $T$, Willems G, Hemker HC. Antithrombin II-dependem anti-prothrombinase activity of heparin and heparin fragments. J Biol Chem 1989;264:10002-7.

26. Barroweliffe TW, Havercroft SJ, Kemball-Cook G, Lindahl U. The effect of $\mathrm{Ca}^{2+}$, phospholipid, and factor $\mathrm{V}$ on the anci-factor $\mathrm{Xa}$ activity of heparin and its high affinity oligosaccharides. Biochem J 1987;243:31-7.

27. Letter C, Mersinger L, Ka abb R. The selective inhibition of thrombin by peptides of boroarginine. J Biol Chem 1990;265:18289-97.

28. Peters J, Lindhout T, Hemmer HC. In situ-generated thrombin is the only enzyme that effectively activates factor VIII and factor V in thromboplastinactivated plasma. Blood 1989;74:1021-4.

29. Kane WH, Davis EW. Blood coagulation factors V and VIII: Structural and functional similarities and shier relationship to hemorrhagic and thrombotic disorders. Blood 1988;71:539-55.

30. Peters J, Willems G, Hemker HC, Lindhout T. Inhibition of factor IX a and factor $\mathrm{X}$ by antithrombin III / heparin during factor $\mathrm{X}$ activation. J Biol Chem 1988:263(30):15313-5.

100 


\section{chapter 6}

\section{analysis of bleeding from bleeding time wounds*}

\section{summary}

The bleeding time test suffers from a large variability which sheds serious doubt on its clinical usefulness. It is dependent on many parameters, which is not favourable for its use as an epidemiological test, or as an indicator of pharmacologically important changes in haemostasis. By using a strictly 'protocolled' technique which measures the rate of bleeding in time, instead of bleeding time alone, we tried to minimize instrumental variability as much as possible This also allowed us to assess the usefulness of other parameters, such as the amount of blood lost. Our results indicate that of the parameters that can be determined from the obtained bleeding patterns, the bleeding time has the lowest variability. This variability however, be it inter or intra-individual, is still very large and in the same range as reported earlier in the literature. The high variability ensures a relatively high degree of overlap of the bleeding times between two populations, unless they are very far apart. Since bleeding time values are very likely dependent on a number of parameters that cannot be controlled, the power of the bleeding time as a clinical or pharmacological test is small and arguably not prone to much improvement by changing the technique of measuring.

\section{introduction}

Bleeding times are used for diagnostic and prognostic purposes since their first description at the beginning of the this century by Milian $(1,2,3)$. Many variations were introduced into the technique of measuring bleeding times (reviewed in ref. 4), which already hints at a generalized dissatisfaction with the technique. The modifications include different localisations of the skin puncture, including the finger, the earlobe and the volar side of the fore arm. The instruments used to make skin cuts range

\footnotetext{
- based on: Kessels H, Kester ADM, Hemker HC. submitted for publication
} 
from needles to various kinds of lancets often placed in some sort of mechanical stylet set to obtain a uniform depth. Sometimes, the instrument is not reported (5). The well known bleeding time according to Ivy (6) is measured at the volar surface of forearm. He was the first to increase venous pressure by inflating a blood-pressure cuff around the upper arm to a pressure of $\mathbf{4 0 ~} \mathrm{mm} \mathrm{Hg}$. Mielke (7) designed a template system in order to obtain bleeding time wounds of standard size and depth. Sutor (8) described a technique for continuous measurement of the rate of blood loss from bleeding time wounds, which allowed the assessment of more parameters than bleeding time alone. Rather interestingly, Milian, in his original first description of a bleeding time, also attempted to give more information than bleeding time alone, as he noted the rate of bleeding and the coagulation time of the individual drops of blood.

The reasons for the large number of modifications made to the bleeding time test are its large variability and poor reproducibility. These were partly due to poor standardisation of the test, and subsequent differences between labs and operators (4). The difficulty to reproducibly make bleeding time wounds of the same dimensions on identical locations has often led to the recommendation to have bleeding times of the same patient be recorded by the same operator. Not all of this variability is likely to stem from instrumental reasons however. A large number of uncontrollable variables do have an influence on the bleeding time as well. Among these may be differences in thickness of the epidermis, local skin vascularisation, haematocrit, number and function of platelets, medication and the state of the coagulation system.

No matter where high variability and mediocre reproducibility come from, they do have their influence on the power of the bleeding time as a diagnostic, pharmacological and epidemiological test. They lead to overlapping ranges of bleeding times of populations whose average value may be relatively far apart, and thus to decreased sensitivity and specificity of the test.

Our approach was to measure bleeding times in such a way that the maximum amount of information is obtained. For this we measured bleeding patterns, continuous recordings of the rate of bleeding from bleeding time wounds, using a technique based on a method originally described by Sutor et.al. (8), and later modified by Bowie et.al.(9). Blood, as it flows from the wound is taken up in a waterstream through a circuit of tygon tubing, and lead to a photometer, where the measured absorbance indicates the bleeding rate. We then investigated whether we were able to improve upon the variability of the present day bleeding time measurement, and whether other parameters of the bleeding pattern might be useful. 


\section{materials and methods}

\section{volunteers}

Volunteers had a mean age of $37.8 \pm 9.0$ years, 10 were male, 7 were female. None of them used any medication in the week preceding the experiment.

\section{bleeding time wounds}

A standard bleeding time wound is made on the volar surface of the forearm at about two thirds between the wrist and the elbow, and parallel to the antecubital crest, using a Knoll automatic lancet loaded with a Swann-Morton blade no.11. The depth of the incision is set to $2.5 \mathrm{~mm}$, which typically results in an actual depth of $3 / 4$ to $1 \mathrm{~mm}$ as estimated from the width of the wound in relation to the shape of the blade. Superficial veins and scar tissue are avoided. No pressure is applied on the automatic lancet.

\section{bleeding pattern rocording}

A roller pump propagates sterile distilled water containing $0.05(\mathrm{v} / \mathrm{v})$ tween 20 (Sigma Chemical Co, St Louis USA) through a circuit of tygone PVC tubing (fig. 1). A small lucite chamber with a longitudinal aperture on one side is part of the circuit. Immediately after the bleeding time wound has been made, the chamber is placed on top, so that blood from the wound is taken up into the fluid flowing through the chamber. The stream is interrupted by airbubbles at two second intervals in order to prevent tailing of the erythrocytes. After the chamber, the stream passes through about $1.5 \mathrm{~m}$ of tubing before entering a debubbling cuvette, in order to lyse the erythrocytes. Optical density is read at $546 \mathrm{~nm}$, using a single wavelength photometer. The flow rate of the water stream over the bleeding time wound was $46 \mu \mathrm{l} / \mathrm{s}$. Airbubbles entered at a rate of $26 \mu \mathrm{l} / \mathrm{s}$. The water stream was diluted further in the system, such that the flow rate increased to $139 \mu \mathrm{l} / \mathrm{s}$. The two second interval time between the airbubbles poses a theoretical limit to the time resolution of the bleeding time monitor. However due to some unavoidable mixing before the entrance of air bubbles and after debubbling in the cuvette, the actual time resolution of the system is a little worse than this $2 \mathrm{~s}$ theoretical limit. 


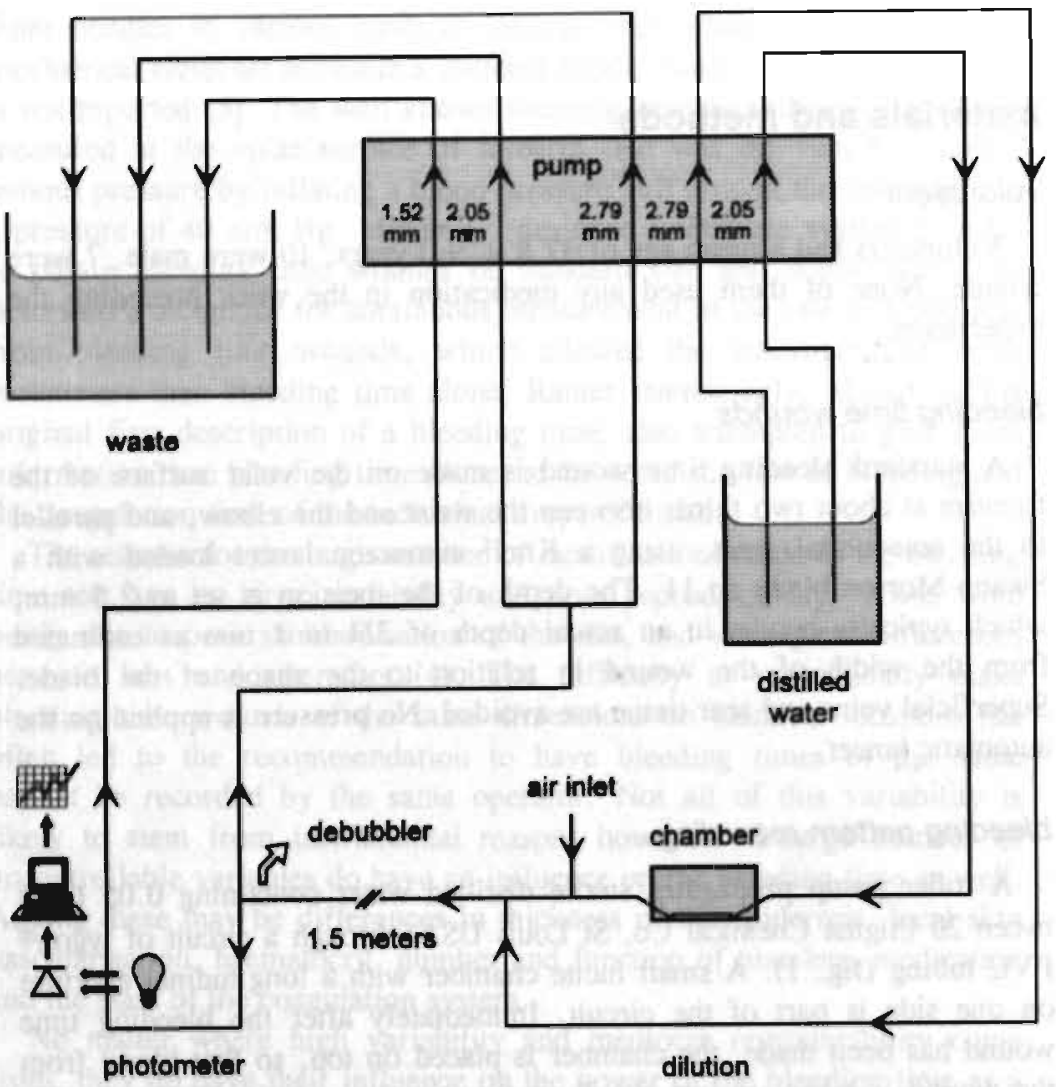

figure 1. circult diagram of the automated bleeding time monitor.

Tubing of specified diameters was used to flow distilled water over a bleeding time wound. Airbubbles are pulled into the stream immediately after the chamber, which is placed over the wound. A dilution step reduces optical density to measurable values. Before entering the debubbling cuvette, 1.5 meters of tubing ceuse a time delay long enough to lyse the erythrocytes.

Diameters of the various tubes in the roller pump were chosen such (fig. 1) that a slight negative pressure was present in the tubing. This serves two purposes. First, it is the driving force for air bubbles to enter the circuit. Second, it helps keeping the chamber well in place on the bleeding time wound. The concentration of tween 20 used does not have an influence on the haemostatic process, while reducing surface tension of the distilled water so as to facilitate the flow of the water through the circuit. A mild venostasis is created using a manometer cuff on the upperarm at a pressure of $40 \mathrm{mmHg}$. 


\section{bleeding pattern analysis}

The following parameters were extracted from the recorded optical density time curve: The bleeding time was defined as the time between making the bleeding time wound and the moment when the optical density value dropped below $20 \mathrm{mOD}$ units for the last time. Blood loss was calculated as the area under the optical density vs. time curves, and converted to $\mu \mathrm{g}$ of hemoglobin using a standard line of hemoglobin concentration vs optical density. Using the blood hemoglobin concentration of each volunteer, the volume of blood lost was found. Peak blood flow was determined from the highest point in the optical density vs. time curve, and average blood flow was calculated as the amount of blood lost divided by the bleeding time.

For each volunteer, four bleeding patterns were recorded, two on their left and two on their right arms. They were performed in random sequence and with minimal delay between them. All bleeding pattern determinations were carried out by the same operator.

\section{results}

Bleeding was quantitated in 17 healthy volunteers. Curves obtained show highly irregular patterns of bleeding with bumps and waves of all

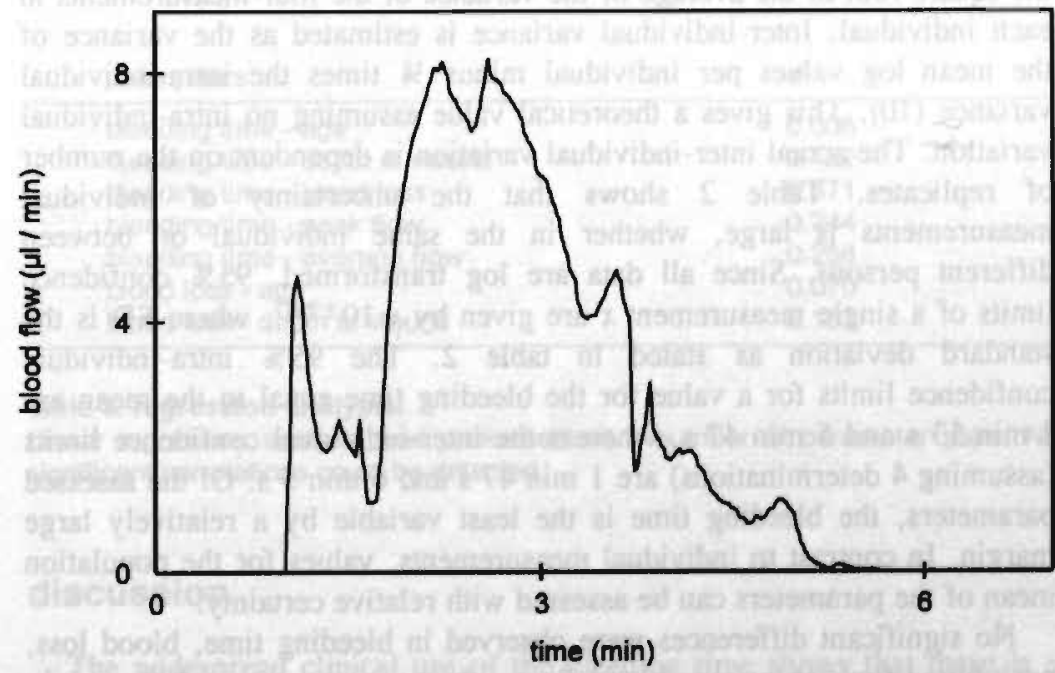

figure 2. example of a bleeding pattern.

The bleeding pattern wes recorded using the automated bleeding time monitor, as described in the materials and methods section. Optical density values were converted into blood flow (in $\mu l / \mathrm{min}$ ) using the blood hemoglobin concentration of the volunteer and the flow rate of distilled weter through the tubing circuit. 
frequencies, with no clear tendency to any standard or typical pattern. Fig. 2 shows an example of a bleeding pattern thus obtained.

None of the parameters determined from these bleeding patterns appeared to be normally distributed. Log transformed data tends to adhere better to the Gaussian distribution, which is confirmed by the ShapiroWilk W-statistic (table 1).

\begin{tabular}{lcc} 
parameter & W-statistic & significance level \\
\hline bleeding time & 0.8547 & 0.0376 \\
blood loss & 0.7994 & 0.0000 \\
peak flow & 0.8641 & 0.0000 \\
average flow & 0.8847 & 0.0000 \\
\hline $\log$ bleeding time & 0.9636 & 0.1226 \\
$\log$ blood loss & 0.9786 & 0.5764 \\
$\log$ peak flow & 0.9686 & 0.1759 \\
$\log$ average flow & 0.9704 & 0.2686 \\
\hline
\end{tabular}

\section{table 1. Shaplro Wilk Wetatistic.}

The Shapiro Wik W-statistic was calculated using the 2D program of the BMDP statistic software package. Velues closer to 1 indicate better adherence to the normal distribution, with a significance level as specified.

Subsequently, the intra-individual standard deviation was estimated as the square root of the average of the variance of the four measurements in each individual. Inter-individual variance is estimated as the variance of the mean $\log$ values per individual minus $1 / 4$ times the intra-individual variance $(10)$. This gives a theoretical value assuming no intra-individual variation. The actual inter-individual variation is dependent on the number of replicates. Table 2 shows that the uncertainty of individual measurements is large, whether in the same individual or between different persons. Since all data are $\log$ transformed, $95 \%$ confidence limits of a single measurement $x$ are given by $x \cdot 10^{ \pm 2 S D}$, where SD is the standard deviation as stated in table 2 . The $95 \%$ intra-individual confidence limits for a value for the bleeding time equal to the mean are $1 \mathrm{~min} 53 \mathrm{~s}$ and $5 \mathrm{~min} 47 \mathrm{~s}$, whereas the inter-individual confidence limits (assuming 4 determinations) are $1 \mathrm{~min} 47 \mathrm{~s}$ and $6 \mathrm{~min} 5 \mathrm{~s}$. Of the assessed parameters, the bleeding time is the least variable by a relatively large margin. In contrast to individual measurements, values for the population mean of the parameters can be assessed with relative certainty.

No significant differences were observed in bleeding time, blood loss, peak blood flow or average blood flow, when comparing sex, left or right arm, or the order in which the bleeding time wounds were made. 


\begin{tabular}{|c|c|c|c|c|}
\hline & $\begin{array}{l}\text { bleeding time } \\
\text { (min) }\end{array}$ & $\begin{array}{l}\text { blood loss } \\
\text { (uil) }\end{array}$ & $\begin{array}{l}\text { peak flow } \\
\text { ( } \mu / \text { / min) }\end{array}$ & $\begin{array}{c}\text { average flow } \\
(\mu / / \mathrm{min})\end{array}$ \\
\hline $\begin{array}{l}\text { mean } \\
\text { overall s.e.m. }\end{array}$ & $\begin{array}{l}3.30 \\
0.230\end{array}$ & $\begin{array}{c}10.6 \\
1.90\end{array}$ & $\begin{array}{l}7.12 \\
0.954\end{array}$ & $\begin{array}{l}2.85 \\
0.332\end{array}$ \\
\hline $\begin{array}{l}\text { mean }(\log ) \\
\text { intra individual SD }(\log ) \\
\text { inter individual SD }(\log )\end{array}$ & $\begin{array}{l}0.481 \\
0.122\end{array}$ & $\begin{array}{l}0.843 \\
0.296\end{array}$ & $\begin{array}{l}0.728 \\
0.254\end{array}$ & $\begin{array}{l}0.362 \\
0.208\end{array}$ \\
\hline $\begin{array}{l}\text { single measurement } \\
2 \text { replicates } \\
4 \text { replicates } \\
\text { co repiclates }\end{array}$ & $\begin{array}{l}0.170 \\
0.146 \\
0.133 \\
0.118\end{array}$ & $\begin{array}{l}0.444 \\
0.392 \\
0.363 \\
0.331\end{array}$ & $\begin{array}{l}0.353 \\
0.304 \\
0.276 \\
0.245\end{array}$ & $\begin{array}{l}0.304 \\
0.288 \\
0.246 \\
0.223\end{array}$ \\
\hline
\end{tabular}

table 2. Inter and Intra-individual standard doviations.

The values of the inter and intra-individual standard deviations wore celculated from the log transformed data obtained from bleeding pattem recordings, as described. The mean and overall s.e.m. velues are calculated directly from the non-trensformed data.

Linear correlations were calculated between bleeding time, blood loss, age, and depth of wound. None of these correlations were anywhere near significance (table 3). There is some correlation between bleeding time and blood loss, but this should be no surprise since the two are obviously interrelated. When eliminating this relationship by dividing blood loss by bleeding time so as to obtain the average blood flow during bleeding, the correlation disappears.

\begin{tabular}{ll} 
parameters & $r^{2}$ \\
\hline bleeding time - age & 0.008 \\
bleeding time - depth of wound & 0.132 \\
bleeding time - blood loss & 0.571 \\
bleeding time - peak flow & 0.244 \\
bleeding time - average flow & 0.258 \\
blood loss - age & 0.070 \\
blood loss - depth of wound & 0.103 \\
\hline
\end{tabular}

table 3. regression analyais.

Linear regression analysis was performed on a number of parameter pairs. No significant correlations could be delected

\section{discussion}

The widespread clinical use of the bleeding time shows that there is a great need for a good overall test of primary haemostasis. An important factor influencing the clinical applicability of the bleeding time has been 
its large inter-individual variability. This causes the range of normal values of bleeding times, and the range of values of bleeding times of individuals with a certain disorder to overlap considerably. As a result of this, the positive predicting value of a prolonged bleeding time has been far from optimal (see ref. 11 for a recent review).

On the other hand, bleeding time values can be used successfully in discriminating between some well defined populations. The average bleeding time in a group of people taking aspirin for instance is significantly longer than the average bleeding time in a similar group taking no medication (11). Given the narrowing of the confidence limits with the square root of the number of observations, it is possible to show the significance of any difference in population average, no matter how small, by increasing the number of measurements. However, the large variability of bleeding time values within one population renders a demonstration of significant differences between population averages only practical if those averages are far enough apart. This explains part of the difficulty of showing significant increases of bleeding times for certain disorders or medications such as hemophilia and several platelet inhibitors $(12,13,14)$.

It is therefore important, both for clinical and epidemiological usefulness of the bleeding time test, to lower the variability of the bleeding time values as much as possible. During the almost a century long history of the bleeding time, this has been an important motive for further development and refinement of the technique used. Much of the instrumental variability stemmed from the fact that the bleeding time wound was not made exactly in the same way, and having the same dimensions, by each worker, nor by the same worker at different times. It was improved upon by Mielke et.al. who made a device which did create bleeding time wounds with more or less controllable dimensions ( 7 . However, the range spanned by the confidence limits of a single measurement remained rather broad. We tried to minimize instrumental variability by using a strictly standardized measurement. By employing a pseudo-continuous recording of the velocity of the bloodflow from the bleeding time wound, bleeding time data could be obtained much more precisely. To standardize bleeding time wounds we used an automatic lancet set to a fixed depth. The actual depth of the wound could be determined from the width of the wound, and was found to vary somewhat. It did however not correlate with the bleeding time or any of the other assessed parameters.

As mentioned before, not all of the variability is due to the technique of measuring bleeding times, part is due to the intrinsic dependency on a whole range of factors. In the present study we attempted to keep the 
instrumental variability as low as possible. The other part of our approach was to measure not only bleeding time, but to record the complete bleeding pattern, i.e. the bleeding velocity as a function of time. This allowed us to determine other parameters related to bleeding as well: the amount of blood lost, and the average and peek velocities of blood flow.

The bleeding time values we measured lead to $95 \%$ confidence limits for individual measurements that are large, and do not deviate much from what has been reported earlier $(7,9)$. The variabilities of the other three parameters we investigated appear to be worse than the bleeding time. The intra individual variability, a property that has hardly been investigated in the past seems to do no better.

It is not always an easy task to attribute part of the total variation to a certain assignable cause. The usual way to proceed would be to determine the variation in a situation with, and in a situation without that cause. The condition that must be met in this case is that the alledged cause is a controllable parameter. Regrettably this is not the case when analyzing which part of the variability of bleeding times is instrumental, and which part is intrinsic. It is not possible to know exactly how much the technique of measuring bleeding times contributes to the overall variability of the results. The best that can be done is try and improve on the technique on some rational ground and compare to the results of older techniques. Bleeding time techniques have changed considerably over the years, and although progress has been made with respect to variability and reproducibility, it has not been overwhelming, especially during the last two decades. This leads one to suspect that there may not be much room for improvement. Considering the large number of variables other than the technique of measuring that may have an influence on bleeding times it is difficult to escape the conclusion that there may be an intrinsic limit to the variability of this test, and that current tests are not far off this limit.

\section{references}

1. Milian MG. Influence de la peau sur la coagulabiltite du sang. C R Soc Biol (Paris) 1901;53:576-8.

2. Milian MG. Contribution a l'etude de la coagulation du sang. C R Soc Biol (Paris) 1901;53:556-7.

3. Milian MG. Technique pour l'Etude clinique de la coagulation de sang. Bull Mem Soc Med HOp Paris 1901;18:777-83.

4. Bowie EJ, Owen CA. The bleeding time. Progr Hemost Thromb 1974;2(0):249-71. 
5. Duke WW. The relation of blood platelets to hemorrtagic disease. Description of a method for determining the bleeding time and coagulation time and report of three cases of hemorrhagic disease relieved by transfusion. JAMA 1910;55: $1185-92$.

6. Ivy AC Nelson D, Bucher G. The standardization of certain factors in the cutaneous "venostasis" bleeding time technique. I Lab Clin Med 1941;26:1812-22.

7. Mielke $\mathrm{CH}$, Kaneshiro MM, Maher IA, Weiner JM, Rapaport SI. The standardized normal Ivy bleeding time and its prolongation by aspirin. Blood 1969:34:204-15.

8. Sutor AH, Bowie EJW, Thompson JH, Didisheim P, Mentens BF, Owen CA. Bleeding from sansardized skin punctures: automated technic for recording time, intensity and pattern of bleeding. Am J Clin Pathol 1971;55:541-50.

9. Bowie EJ, Owen CA, Hansen RJ, Isancson J. Electronic method for quantiation of bleeding time. Am J Clin Pachol 1972;58: 255-60.

10. Fleiss $\mathrm{JL}$. The design and analysis of clinical experiments. New York: Wiley, 1986.

11. Rodgers RPC, Levin J. A critical reappraisal of the bleeding time. Semin Thromb Hemost 1990:16:1-20

12. Eyster ME, Gordon RA, Ballard JO. The bleeding time is longer than norma in hemophilia. Blood 1981;58(4):719-23.

13. Schulman S, Johnsson H. Heparin, DDAVP and the bleeding time. Thromb Haemostas 1991:65(3):242-4.

14. Praga C, Cortellaro M, Pogliana E. Standardized bleeding time in the study of drugs interfering with platelet function. Adv Exp Med Biol 1972;34:149-58. 


\section{chapter 7}

\section{summary and concluslons}

Thrombin, the end product of the coagulation cascade, plays a central role in the process of hemostasis. It is both the effector enzyme, able to clot fibrinogen and to activate platelets, and a central regulatory protein, being at the origin of several important positive and negative feedback loops of the coagulation system.

Qualitatively, the course of events during coagulation in plasma is largely known. Mostly, the reactions involved and their consequences have been deduced from observations in systems of purified proteins. Plasma, however, contains a large number of proteins, among which, presumably, a considerable number with unknown function. This implies that a fair number of reactions may be taking place simultaneously. It is a well known fact that the effort of analysis increases rapidly as the number of reactions that has to be taken into account grows bigger. Making. reliable quantitative predictions about reactions in plasma, therefore, is very difficult. Significant uncertainty accompanies even a qualitative deduction. As thrombin is involved in so many reactions simultaneously, the task of predicting its behaviour in vivo, from experiments carried out in purified systems becomes daunting. We therefore chose to stay close to the physiological milieu of the coagulation system, and set up measurements in plasma and whole blood. In doing so it was inevitable that we sacrificed, to a certain extent, the exact definition of the experimental system used. But it should be kept in mind that we could fall back on a solid base of knowledge of the proteins involved and their interactions, and that experiments in purified or partially purified systems still served as valuable tools for testing hypotheses.

Techniques for accurately measuring concentrations of activated clotting factors in plasma are a sine qua non of this kind of experiment. This is not always a triviality. Complicating factors, such as the interference of other clotting factors which are present in plasma, the low prevailing concentrations of several coagulation enzymes, and the instability of some of these proteins, often render existing assays unusable, so that new techniques had to be developed.

Chapter 1 gives a general introduction to the subject of this thesis. 
Chapter 2 describes a technique for the measurement of thrombin generation in freshly collected whole blood without added anticoagulants. In this way the reaction medium more closely approximates the physiological conditions of coagulation. The assay is based on the chromogenic measurement of thrombin concentrations after centrifugal discarding of cellular components from the blood sample, like it is done when preparing plasma. The difference is that this separation takes place in subsamples which are drawn from the clotting blood, and which have been diluted in buffer containing the chromogenic substrate for thrombin. In this way processing of the original blood sample can be avoided. This technique was used first to analyse the differences between coagulation in blood without an added anticoagulant, and blood collected on citrate as usual. The procedure of collecting blood on citrate and subsequent recalcification may, because of a number of reasons, influence the function of blood platelets and the coagulation system. It is shown that thrombin generation after triggering coagulation with low concentrations of thromboplastin occurs sooner in native whole blood than in citrated whole blood. This acceleration is not a consequence of a suboptimal $\mathrm{Ca}^{2+}$ to citrate ratio. Furthermore, the lag time of thrombin generation was shortened relatively more in the presence of heparin, so that the effect of heparin, as measured in citrated blood or platelet rich plasma is somewhat overestimated. Thus it is evident that anticoagulation of blood using citrate has a clear influence on the coagulation process. Possible explanations for this influence include a change of $\mathrm{pH}$, lowering of the concentration of $\mathrm{Mg}^{2+}$ ions, and a direct interaction of citrate with platelets.

Since activated platelets provide the negatively charged phospholipid surface necessary for efficient reactions in the coagulation system, and since thrombin, especially in combination with collagen, is the most potent physiological activator of platelets, the coagulation system and platelet activation are closely linked. This linkage, as well as a much clinical evidence for the antithrombotic action of anticoagulant drugs, also in the platelet rich (arterial) thrombus, suggest that affecting the concentration of free thrombin might be the principal mechanism of action of antithrombotic drugs. This hypothesis, however, seems to be falsified by the well known antithrombotic action of aspirin, a drug of which no influence on thrombin generation was known. Chapter 2 describes that intake of $500 \mathrm{mg}$ of aspirin delays and inhibits thrombin generation in non-anticoagulated, thromboplastin triggered whole blood. This observation lends support to the notion that inhibition of thrombin is on a common pathway of the various sorts of antithrombotic therapy. In this view it does not matter whether affecting the thrombin concentration be 
achieved by inhibition of thrombin formation (oral anticoagulation), increase of thrombin inactivation (heparin) or inhibition of platelet function (aspirin).

Determination of thrombin concentrations in plasma is a relatively simple technique in comparison to the measurement of other enzymes of the coagulation system. Furthermore we recently showed that this measurement can be automated considerably by measuring the time integral of the thrombin concentration, instead of the thrombin concentration itself, in clotting plasma. Chapter 3 describes a mathematical procedure to extract from both normal and integral thrombin generation curves information that accurately describes the state of the coagulation system and that would be difficult to obtain otherwise. Thrombin in plasma is inhibited by a number of serine protease inhibitors. The most important of these is antithrombin III. A minor part of the thrombin is inhibited by $\alpha_{2}$-macroglobulin. The complex of thrombin and $\alpha_{2}$-macroglobulin, however, introduces a significant difficulty in the analysis of thrombin generation curves, as it retains sorne activity towards the small chromogenic substrates used to measure thrombin concentrations. Therefore, the first step in the analysis of thrombin generation curves is the determination of the time course of the concentration of free thrombin. This is done by calculating the value of the first order decay constant for thrombin to $a_{2}$-macroglobulin directly from thrombin generation curves.

The decay constant of thrombin due to the other inhibitors has to be measured in separate experiments. The velocity of thrombin inhibition at any timepoint can be determined from these decay constants and the time course of the free thrombin concentration. From this, the velocity of prothrombin conversion, i.e. the activity of the prothrombin converting enzyme, can be calculated. In this way a lower thrombin concentration can be pin-pointed as inhibition of thrombin, or as inhibition of thrombin formation.

The thrombin potential is a parameter which is influenced by all sorts of antithrombotic medication. It is, therefore, a useful candidate to supplement or even replace some of the present clinically used parameters describing the state of the coagulation system. It is defined as the surface under a time curve of the free thrombin concentration, and can readily be obtained from thrombin generation curves.

Since carrying out thrombin generation experiments involves a significant amount of experimental work, it is not a likely procedure to be carried out routinely in a hospital laboratory. We recently developed a new, largely automated, method to monitor the time integral of the 
thrombin concentration in clotting plasma. Chapter 3 extends the analysis of thrombin generation curves to these time curves of the integral of the thrombin concentration, and shows how all the information obtainable from a classical thrombin generation curve, notably the thrombin potential, can, in an analogous manner, also be obtained from integral thrombin curves.

During the initial phase of blood clotting, traces of thrombin are generated. These thrombin traces provoke the generation of more thrombin by starting several positive feedback loops. Activation of coagulation factor VIII constitutes one of these feedback mechanisms. Chapter 4 describes a technique for measuring concentrations activated factor VIII (factor VIIla) in clotting plasma. This measurement is hampered by the fact that factor VIIla is generated only in very low concentrations, less than $1 \mathrm{nM}$, and that it is very instable, having a half life time shorter than 30 seconds. The complex of factor IXa and factor VIIla on a phospholipid surface has the ability to activate factor $\mathbf{X}$. In this process, factor IXa is the enzyme, and factor VIIIa functions as a cofactor, accelerating the activation reaction. The determination of factor VIIla concentrations is based on this property. Subsamples drawn from clotting plasina are diluted in a buffer containing excess factor IXa, factor $\mathrm{X}$, phospholipid vesicles and $\mathrm{Ca}^{2+}$ ions. In this system factor $\mathrm{Xa}$ is generated with a rate proportional to the concentration of factor VIIla. This factor $\mathrm{Xa}$ is subsequently measured using a chromogenic substrate. The measurements is complicated by the capability of free factor $\mathrm{Xa}$ to activate non-activated factor VIII present in a plasma sample. This increases the factor $\mathrm{X}$ activation velocity in the measurement system, and thus causes the concentration of factor VIIla to be overestimated. Furthermore, factor $\mathrm{Xa}$ is inactivated by antiproteases also originating from the plasma sample. These complicating factors necessitated the development of a novel technique in order to measure concentrations of factor VIIla in plasma in a quantitatively reliable manner. When a surplus of chromogenic substrate is present during factor $\mathrm{Xa}$ generation in the factor VIIla assay, the chromogenic substrate acts as a competitive inhibitor of factor $\mathrm{Xa}$, inhibiting all reactions of factor $\mathrm{Xa}_{\mathrm{a}}$ except chromogenic substrate hydrolysis. Thus, the 'side reactions' of factor Xa are inhibited and at the same time the rate of substrate conversion is a measure of the amount of factor $\mathrm{Xa}$ present.

The presence of chromogenic substrate during the factor Xa generating reaction results in timecurves of optical density that follow a parabolic pattern. Mathematical analysis of this parabola shows that the factor VIIla concentration appears in the quadratic coefficient, and can be obtained by 
a simple quadratic least squares fit procedure. The resulting assay of factor VIIla was shown to be linear with the factor VIIla concentration and to be specific for factor VIIla.

The principle of the presence of chromogenic substrate during. proenzyme activation, as developed for the measurement of factor VIIla, was subsequently applied, in the experiments described in chapter 5 , to the measurement of factor $\mathrm{Xa}$ concentrations in plasma. This was necessary because the concentrations of factor $\mathrm{Xa}$ in plasma after triggering with physiologically low concentrations of tissue factor appeared to remain very low. For this reason, and because of a too low specificity, direct measurement using a chromogenic substrate was not feasible. Measuring factor Xa via a two-stage prothrombinase assay was hindered too much by the high concentrations of thrombin that were generated simultaneously in clotting plasma. The presence of a chromogenic substrate for thrombin during the thrombin generating step of the assaly resolves this difficulty. since analysis of the parabolic time curves of optical densily showed that the factor Xa concentration only appeared in the quadratic coefficient of these curves. Thus, factor $\mathrm{Xa}$ can be said to be responsible for the acceleration chromogenic substrate conversion, whereas the plasma thrombin concentration appears only in the linear coefficient, causing the initial velocity of the optical density time curve. In this way, factor Xa and thrombin are effectively separated, and is it possible to measure factor $\mathrm{Xa}$ concentrations in the presence of thrombin concentrations that are up to four orders of magnitude higher.

We used this technique, together with the method for measuring factor VIIla, and assays for factor $\mathrm{Va}$ and thrombin published earlier, to investigate the events occurring during the early phase of coagulation in plasma. In these experiments, coagulation was triggered with recombinant tissue factor in a concentration range of 0.2 to $1 \mathrm{pM}$. These concentrations are much lower than what is usual in most existing tests of the coagulation system, but they are probably much closer to the values occurring in coagulation in vivo.

The first remarkable observation was that the peak concentration of factor $\mathrm{Xa}$, which was dependent on the tissue factor concentration, was reached within 20 seconds after triggering. In addition, the height of this peak was very low ( $25-200 \mathrm{pM})$ in comparison to the high concentration on non-activated factor $\mathrm{X}$ circulating in plasma $( \pm 180 \mathrm{nM})$. Still, the concentration is high enough to cause fast and efficient thrombin generation. The early occurrence of the peak value of the factor $\mathrm{Xa}$ concentration was shown to be a consequence of the presence of the recently discovered Tissue Factor Pathway Inhibitor (TFPI), which shuts 
down factor $\mathrm{Xa}_{\mathrm{a}}$ generation by the complex of VIla and tissue factor very soon after addition of tissue factor to plasma. This followed from an experiment in which TFPI was inhibited by anti-TFPI antibodies. A rise of the factor Xa concentrations was observed which lasted for several minutes, leading to peak concentration which was more than one order of magnitude higher than the peakconcentration in the absence of antibodies.

The factor $\mathrm{Xa}$ concentration in plasma declined slower than could be expected from its decay constant. Factor Xa seemed to 'wait' for factor $V$ activation, even when this was artificially retarded quite considerably by the presence of a thrombin inhibitor. Part of the apparent slow decrease was found to be due to on going activation of factor $\mathrm{X}$ by intrinsic tenase, the complex of factor IXa with its cofactor VIIIa. This was deduced from the measurement of factor $\mathrm{Xa}$ concentrations in plasma from a patient with hemophilia A, demonstrating a considerably faster decay of factor Xa. This experiment also serves as a direct demonstration of the role of the alternative extrinsic pathway, or 'Josso loop' in clotting plasma.

Apart from thrombin also factor $\mathrm{Xa}$ has the capacity to activate the cofactors V and VIII in purified systems. Experiments with the synthetic thrombin inhibitor BIBG $64 \mathrm{BF}$, which delays thrombin formation without influencing the onset of factor $\mathrm{X}$ activation, showed that cofactor activation was be concomitant with thrombin generation and not with factor Xa generation. The kinetic behaviour of the cofactors Va and VIIIa after slow activation was shown to differ markedly. The peak values of the concentration of factor VIIla were dependent on the rate of its activation, whereas maximal concentrations for factor Va were, apart from being 2 orders of magnitude higher, not influenced. This appears to be caused by the stability of factor $\mathrm{Va}$ in plasma, which contrasts with the high degree of lability of factor VIIla. Since the activation of factor V and VIII was not completely inhibited at the lower inhibitor concentrations, the minimal first order constant of inhibition necessary to shut down cofactor activation altogether can be estimated at $2 \mathrm{~s}^{-1}$. Finally, the concentrations of factor $\mathrm{Va}$ attained in plasma after the initial phase of the coagulation process are much higher than the factor $\mathrm{Xa}$ concentrations, so that the maximal rate of the extrinsic prothrombinase enzyme is probably limited by the factor Xa concentration.

A logical sequel to the experiments described in the chapters 2 and 5 seemed the investigation of coagulation in a system even closer to physiology: i.e. in blood flowing from a bleeding time wound. However, the bleeding time test suffers from a large variability which not only sheds serious doubt on its clinical usefulness, but also would introduce significant, and very difficult to handle, variations when investigating the 
involvement of the coagulation process in the hemostasis of a bleeding time wound. Our first goal was therefore minimizing the instrumental variability, as described in chapter 6 . We employed a strictly protocolled technique which measures the rate of bleeding in time, instead of only the time needed to stop bleeding. Blood flowing from a bleeding time wound is taken up into a tubing circuit and led to photometer, where the concentration of hemoglobin is measured. The $\mathrm{Hb}$ concentration is a measure for the rate of bloodflow from the wound. This method also allowed us to assess the usefulness of other parameters, such as the amount of blood losi, and the average and peak velocity of bloodflow from the wound. Our results indicate that of the parameters that can be determined from the obtained bleeding patterns, the bleeding time still has the lowest variability. This variability however, be it between individuals or between different measurements within a person, is still very large and in the same range as reported earlier in the literature. The high variability ensures a relatively high degree of overlap of the bleeding times between two populations, unless they are very far apart. Since bleeding time values are very likely dependent on a number of parameters that cannot be controlled, the power of the bleeding time as a clinical or pharmacological test is small and arguably not prone to much improvement by improvement of technique of measurement. This implicates that any analysis of the clotting process in blood from bleeding time wounds will be restricted with respect to a quantitative description.

In vivo clotting is usually initiated upon vessel wall damage. The clotting factors circulating in blood plasma are then exposed to tissue factor present on the cell membranes of cells of the perivascular tissues. Procoagulant surfaces are provided by damaged cells and activated platelets. The physical and biochemical conditions prevailing may be very different for different 'instances' of clotting. The flow conditions are influenced by the type and size of the vessel. The availability of tissue factor and procoagulant phospholipid surface is a function of the extent of the vessel wall damage. Important is also whether the actual clotting process occurs in the lumen of the vessel or in the extravascular tissue, where flow may be completely absent. All this makes it very difficult to extrapolate experimental data to the situation in vivo. Therefore, the type of experiments described in this thesis produces quantitative results that are, in principle, valid only for the circumstances under which they were performed. Although it may be tempting to generalize the conclusions reached to laws governing clotting as a whole, care has still to be taken to take into account the conditions prevailing at the particular time and place. 
The availability of accurate techniques to determine thrombin, factor $\mathrm{Xa}$, factor $\mathrm{Va}$, and factor VIIla concentrations in plasma and blood has given us the opportunity to start investigating the coagulation process in near physiological conditions in greater detail. It is a small step, however, in the task of elucidating the rules governing hemostasis in vivo. Many more experiments, together with thorough analyses and model building. are necessary, not only in plasma, but also in experimental systems incorporating the important factor of flow, and, ultimately, in in vivo situations. This, however, is only sensible when enough information has been gained by other means to make a meaningful interpretation of the data possible, just as it would not have been possible to place the experiments described in this thesis in perspective, without the extensive knowledge about the coagulation system obtained in systems of purified proteins. 


\section{samenvatting en conclusies}

Trombine, het eindprodukt van de stollingscascade, speelt een centrale rol in de hemostase. $\mathrm{Zij}$ is zowel het effector enzym, in staat om fibrinogeen te doen stollen en bloedplaatjes te aktiveren, als het belangrijkste regulerende eiwit, omdat zij aan de basis staat van enkele belangrijke positieve en negatieve terugkoppelingsmechanismen van het stollingssysteem.

In kwalitatieve zin is de loop van de gebeurtenissen tijdens de stolling in plasma grotendeels bekend. De betrokken reakties en de gevolgen van die reakties zijn voor het merendeel afgeleid uit waarnemingen in testsystemen met een zeer beperkt aantal gezuiverde eiwitten. Plasma echter bevat een groot aantal eiwitten, waaronder een aanzienlijk aantal met een nog onbekende functie. Dit betekent dat een fors anntal reakties tegelijkertijd kan optreden. Het is een bekend gegeven dat de complexiteit van analyse sterk toeneemt naarmate het aantal reakties waarmee rekening gehouden moet worden groter wordt. Derhalve is het uiterst moeilijk om betrouwbare kwantitatieve voorspellingen te doen omtrent reakties in plasma. Zelfs een kwalitatieve deductie gaat gepaard met een niet te verwaarlozen mate van onzekerheid. Omdat trombine in plasma betrokken is bij veel reakties die tegelijkertijd kunnen optreden, is het een lastige opgave haar gedrag in vivo te voorspellen uit de gegevens verkregen met experimenten in gezuiverde systemen. Om die reden hebben wij besloten ons onderzoek uit te voeren onder reaktieomstandigheden die dichter staan bij het fysiologische milieu van de stolling en hebben we meetsystemen opgezet in plasma en vol bloed. Daarbij is het onvermijdelijk iets van de exacte definitie van het experimentele systeem prijs te geven. Men moet hierbij echter bedenken dat we konden terugvallen op een solide basis aan kennis over de betrokken eiwitten en hun interakties, en dat proeven in systemen met gezuiverde eiwitten nog steeds een waardevol gereedschap zijn voor het testen van hypothesen.

De beschikbaarheid van technieken voor het accuraat meten van concentraties van geaktiveerde stollingsfactoren in plasma is een conditio sine qua non voor het onderzoek van de stolling onder meer fysiologische omstandigheden. Dit soort meetmethoden is niet altijd triviaal. Complicerende factoren, zoals interferentie van andere stollingsfactoren 
die in plasma voorkomen, de lage concentraties van verscheidene stollingsenzymen, en de instabiliteit van enkele van deze eiwitten, maken bestaande meetmethoden vaak onbruikbaar zodat nieuwe experimentele technieken moesten worden ontwikkeld.

Hoofdstuk 1 geeft een algemene introductie over het onderwerp van dit proefschrift.

In hoofdstuk 2 wordt een techniek beschreven voor het meten van trombinevorming in vers afgenomen bloed, dat geen bewerkingen heeft ondergaan en waaraan geen anticoagulantia zijn toegevoegd. Dit om zo dicht mogelijk bijde fysiologische omstandigheden te blijven waarin stolling optreedt. De meetmethode is gebaseerd op een chromogene meting van trombine na het centrifugaal verwijderen van de cellulaire componenten van bloed, zoals dat ook plaats vindt bij het preparen van plasma. Het verschil is echter dat deze scheiding pas gebeurt in monsters die zijn genomen uit het stollende bloed, zodat bewerking van het bloed omzeild kon worden. Deze techniek werd allereerst gebruikt om eventuele verschillen in de bloedstolling te analyseren tussen bloed waaraan geen anticoagulans werd toegevoegd, en bloed dat, zoals gebruikelijk, op citraat werd opgevangen. De procedure van het afnemen van bloed op citraat en vervolgens recalcificeren kan vanwege een aantal bekende en minder bekende effecten van citraat, de werking van bloedplaatjes en het stollings systeem beilnvloeden. De vorming van trombine na het op gang brengen van de stolling met lage concentraties tromboplastine bleek eerder plaats te vinden in bloed waaraan geen citraat was toegevoegd dan in gecitreerd bloed. Deze kortere latentietijd was niet het gevolg van een suboptimale $\mathrm{Ca}^{2+} /$ citraat ratio. Bovendien was de latentietijd relatief nog verder verkort wanneer heparine in het bloed aanwezig was, zodat het effect van het heparine, indien gemeten in gecitreerd bloed of plaatjesrijk plasma, enigszins wordt overschat. Het is derhalve duidelijk dat antistolling van bloed met citraat een aanmerkelijke invloed heeft op het stollingsproces. Mogelijke verklaringen hiervoor zijn een verandering van de $\mathrm{pH}$, het wegvangen van $\mathbf{M g}^{2+}$ ionen, of een directe interaktie van citraat met bloedplaatjes.

Omdat geaktiveerde plaatjes het negatief geladen fosfolipide oppervlak leveren dat nodig is voor efficiēnte reakties in het stollingssysteern, en omdat trombine de beste fysiologische aktivator van plaatjes is, hangen het stollingssysteem en plaatjesreakties nauw met elkaar samen. Deze onderlinge band en de aanwijzingen uit klinische studies voor de antitrombotische werking van antistollingsmiddelen, zelfs in geval van een plaatjesrijke (arteriēle) trombus, suggereren dat het belnvloeden van de 
concentratie vrij trombine het belangrijkste werkingsmechanisme rou kunnen zijn van antitrombotische medicijnen. Deze hypothese echter wordt schijnbaar gefalsifieerd door de bekende antitrombotische werking van aspirine, cen middel waarvan geen invloed op de trombinevorming bekend was. In hoofdstuk 2 wordt beschreven dat de inname van $500 \mathrm{mg}$ asprine door gezonde proefpersonen de trombinevorming zowel vertraagt als remt in bloed zonder anticoagulans. Deze observatie geeft steun aan het concept waarin remming van trombine gemeenschappelijk is aan de verscheidene soorten antitrombotische therapie. Het beinvloeden van de trombineconcentratie kan worden bewerkstelligd door remming van trombinevorming (orale antistolling), door het versnellen van de trombineremming (heparine), of door remming van de plaatjesfunctie (aspirine).

De bepaling van trombine concentraties in plasma is een relatief cenvoudige techniek in vergelijking met de meting van andere enizymen van het stollings systeem. Bovendien hebben we recentelijk anngetoond dat deze meting grotendeels kan worden geautomatiseerd door in plaats van trombineconcentraties, de tijdsintegraal van de trombineconcentratie in stollend plasma te volgen. Hoofdstuk 3 beschrijft een mathematische procedure om zowel uit normale als uit integrale trombine generatie curves, informatie te extraheren die de staat van het stollingssysteem accuraat beschrijft, en die moeilijk te verkrijgen zou zijn op een andere manier. Trombine in plasma wordt geïnaktiveerd door een aantal serine protease remmers. De belangrijkste hiervan is het antitrombine III. Een klein deel van alle trombine word geremd door $\alpha_{2}$-macroglobuline. Echter, het inaktieve complex van trombine en deze laatste remmer bemoeilijkt de analyse van trombine generatie curves, omdat dit complex nog enige aktiviteit heeft ten opzichte van de kleine chromogene substraten die gebruikt worden om trombine concentraties te meten. Derhalve is de eerste stap in de analyse van trombine generatie curves het bepalen van het tijdsverloop van de concentratie vrij trombine uit een curve die zowel de concentratie vrij trombine als de concentratie van het $\alpha_{2}$-macroglobuline trombine complex weergeeft. Dit wordt bewerkstelligd door een procedure die de waarde van de eerste orde afbraakkonstante van trombine voor $a_{2}$ macroglobuline direct bepaalt uit een trombine generatie curve.

De afbraakkonstante voor de inaktivering van trombine door de andere remmers moet worden gemeten in aparte experimenten. Uit de totale afbraakkonstante en de curve van de vrije trombineconcentratie kan de snelheid van trombine inaktivering op ieder tijdstip bepaald worden. Vervolgens kan dan hieruit de snelheid van protrombine conversie, ofwel de aktiviteit van het protrombine converterende enzym, berekend worden. 
Op deze wijze kan worden bepaald of een lagere trombineconcentratie het gevolg is van remming van trombine, of van remming van trombinevorming.

Een parameter die beinnvloed wordt door alle soorten antitrombotische medicatie is de trombinepotentiaal. Derhalve is dit een zeer bruikbare kandidaat is om bestaande, in de kliniek gebruikte parameters die de staat van het stollingssysteem beschrijven aan te vullen of zelfs te vervangen. De trombinepotentiaal is gedefinieerd als de oppervlakte onder de curve van de vrije trombine concentratie, en kan op een gemakkelijke manier worden berekend uit trombine generatie curves.

Omdat het uitvoeren van trombine generatie experimenten een anzienlijke hoeveelheid experimenteel werk met zich meebrengt, is dit geen procedure die op een gemakkelijke wijze zou kunnen worden toegepast in de routine van een ziekenhuis laboratorium. Recentelijk nebben we een nieuwe, grotendeels geautomatiseerde techniek ontwikkeld waarmee de tijdsintegraal van de trombineconcentratie in stollend plasma continu kan worden gevolgd. In hoofdstuk 3 wordt beschreven hoe alle informatie die verkregen kan worden uit een klassieke trombine generatie curve, en met name de trombine potentiaal, op analoge wijze, kan worden gedestilleerd uit een integrale trombine curve.

Tijdens de eerste fase van de bloedstolling zorgt een kleine hoeveelheid geaktiveerd factor X ervoor dat spoortjes trombine gevormd worden. Dit trombine zorgt voor de vorming van grotere hoeveelheden trombine door enkele positieve terugkoppelingsmechanismen op gang te brengen. Eén van deze mechanismen is de aktivering van stollingsfactor VIII. In hoofdstuk 4 wordt een techniek beschreven om de concentraties van geaktiveerd factor VIII (factor VIIla) in stollend plasma te meten. Deze meting wordt bemoeilijkt doordat factor VIIla slechts in zeer lage concentraties, minder dan $1 \mathrm{nM}$, wordt gevormd gedurende de stolling, en omdat het viterst instabiel is, met halfwaardetijd korter dan 30 seconden. Het complex van factor IXa en factor VIIla op een fosfolipiden oppervlak zorgt voor het aktiveren van factor $X$. In dit proces is factor IXa het enzym en functioneert factor VIIla als een cofactor die de reaktie versneld. De meetmethode van factor VIlla concentraties is gebaseerd op deze eigenschap. Monsters, genomen uit stollend plasma, worden verdund in buffer met een overmaat aan factor IXa, factor $\mathrm{X}$, fosfolipiden vesicles en $\mathrm{Ca}^{2+}$ ionen. In dit systeem wordt factor $\mathrm{Xa}$ gevormd met een snelheid die afhankelijk is van de factor VIIla concentratie. Dit factor Xa wordt vervolgens gemeten met behulp van een chromogeen substraat. Een cemplicatie bij deze meting is het feit dat het gevormde factor $\mathrm{Xa}_{\mathrm{a}}$ de capaciteit heeft om niet geaktiveerd factor VIII afkomstig; uit het 
plasmamonster te aktiveren. Dit verhoogt de vormingsnelheid van factor $\mathrm{Xa}_{\mathrm{a}}$ in het meetsysteem en leidt derhalve tot een overschatting van de factor VIIla concentratie. Bovendien bleek het gevormde factor Xa gedeeltelijk ten prooi te vallen aan protease remmers, eveneens afkomstig uit het plasma monster. Dit alles maakte de ontwikkeling van een nieuwe techniek noodzakelijk teneinde factor VIIla concentraties in plasrna op een kwantitatief betrouwbare manier te kunnen meten. Wanneer een hoge concentratie chromogeen substraat al tijdens de factor $\mathrm{X}$ aktiveringsstap in het meetsysteem aanwezig is worden alle reakties van factor Xa behalve de hydrolyse van het chromogeen substraat competitief geremd. Zodoende worden alle ongewenste nevenreakties van factor $\mathrm{Xa}$ geblokkeerd en is tegelijkertijd de snelheid van de conversie van chromogeen substraat een maat voor de hoeveelheid factor $\mathrm{Xa}$ die aanwerig is.

De aanwezigheid van het chromogeen substraat tijdens de factor $\mathrm{Xa}$ vormende reaktie resulteert erin dat de optische dichtheid volgens een parabool toeneemt in de tijd. Mathematische analyse toonde dat de factor VIIIa concentratie in de kwadratische coefficient verschijnt van de vergelijking die de parabool beschrijft. Deze concentratie kan vervolgens worden verkregen door middel van een eenvoudige kleinste kwadraten fit procedure. De aldus ontwikkelde meetmethode voor factor VIIla in plasma bleek lineair met de factor VIIla concentratie en specifiek voor factor VIIla.

Het principe van de aanwezigheid van chromogeen substraat gedurende proenzym aktivering, zoals dat werd ontwikkeld voor de meting van factor VIIIa in plasma, werd vervolgens, in de experimenten beschreven in hoofdstuk 5, toegepast op de meting van factor Xa concentraties in stollend plasma. Dit was noodzakelijk omdat de concentraties van factor $\mathrm{Xa}$ in plasma, na toevoegen van fysiologisch lage concentraties weefselfactor, erg laag blijven. Om die reden, en vanwege een te lage specificiteit was een directe meting met behulp van chromogeen substraat voor factor Xa niet haalbaar. Bovendien bleek het meten van factor Xa met een twee-staps protrombinase meting te veel hinder te ondervinden van de hoge concentraties trombine die gelijktijdig in stollend plasma worden gevormd. De aanwezigheid van chromogeen substraat gedurende de stap waarin trombine wordt gegenereerd bood oplossing, omdat, analyse van de kwadratische tijdcurves van de optische dichtheid liet zien dat de factor Xa concentratie slechts voorkomt in de kwadratische colfficient, terwijl de trombine concentratie alleen in de lineaire cosfficient zit. Factor $\mathrm{Xa}$ kan derhalve worden beschouwd als verantwoordeliik voor de versnelling van de omzetting van chromogeen substraat, terwijl de trombineconcentratie aanleiding geeft tot de initiele snelheid vant cie deze 
reaktie. Hierdoor zijn factor $\mathrm{Xa}$ en trombine effectief van elkaar gescheiden en kunnen factor $\mathrm{Xa}$ concentraties worden gemeten in de aanwezigheid van trombine in concentraties die tot 4 orden van grootte hoger zijn.

Deze meettechniek werd gebruikt, samen met de meetmethode voor factor VIIIa, en eerder gepubliceerde bepalingen van factor Va en trombine, om de gebeurtenissen in de eerste fase van de bloedstolling in plasma te onderzoeken. De stolling in plasma werd hierbij op gang gebracht door het toevoegen van weefselfactor in een concentratiebereik van 0.2 tot $1 \mathrm{pM}$. Deze concentraties zijn veel lager dan gebruikelijk is bij de meeste bestaande stollingstesten, doch ze komen hoogstwaarschijnlijk veel dichter in de buurt van de waarden die bij stolling in vivo voorkomen.

De eerste opmerkelijke waarneming was dat de piekconcentratie van factor $\mathrm{Xa}$, die afhankelijk was van de concentratie toegevoegd weefsel factor, al binnen 20 seconden bereikt werd. De hoogte van de piek was bovendien erg laag ( 25 tot $200 \mathrm{pM}$ ) in verhouding tot de concentratie van niet geaktiveerd factor $X$ in het plasma $( \pm 180 \mathrm{nM})$. Toch was die concentratie hoog genoeg om een snelle en efficięnte trombinevorming te bewerkstelligen. Het vroege maximum van factor $\mathrm{Xa}$ bleek het gevolg van de aanwezigheid van de recent ontdekte fysiologische remmer Tissue Factor Pathway Inhibitor (TFPI), die, zeer snel na het toevoegen van weefselfactor aan plasma, de factor Xa vorming door het factor VIla/TF complex stillegt. Toevoegen van anti-TFPI antilichamen leidde er namelijk toe dat cen minuten durende stijging van de factor $\mathrm{Xa}$ concentratie werd geobserveerd. De maximale factor $\mathrm{Xa}$ concentratie die werd bereikt was meer dan een orde van grootte hoger dan de factor Xa piek in de afwezigheid van de antilichamen.

De afname van de factor $\mathrm{Xa}$ concentratie in plasma was trager dan verwacht werd op basis van de uit de literatuur bekende afbraakkonstane. Factor Xa 'wachtte' als het ware tot er voldoende factor $V$ was geaktiveerd, zelfs wanneer dit moment artificieel was uitgesteld met behulp van een trombineremmer. Het trage verdwijnen van factor $\mathrm{Xa}$ wordt gedeeltelijk verklaard door een voortdurende relatief trage factor $X$ aktivering door het intrinsieke tenase enzym, het complex van IXa met zijn cofactor VIIlla. Dit werd afgeleid uit metingen in plasma van een patient met hemofilie A, waarin de afname van de factor Xa concentratie aanmerkelijk sneller bleek te zijn. Deze proef laat op directe wijze de rol zien die de alternatieve extrinsieke route, ook wel de 'Josso lus' genoemd, speelt in stollend plasma.

In gezuiverde systemen heeft naast trombine ook factor Xa de capaciteit om de cofactoren V en VIII te aktiveren. Proeven met de synthetische trombineremmer BIBG $64 \mathrm{BF}$, die de trombinevorming vertrasgt zonder 
de snelheid van factor Xa vorming noemenswaardig te beinvloeden, toonden dat in stollend plasma aktivering van de cofactoren V en VIII gelijktijdig plaatsvond met de trombinevorming, en niet met de vorming van factor Xa. Tussen het kinetische gedrag van factor Va en VIIla in plasma blijken opmerkelijke verschillen te bestaan. Omdat de snelheid van inaktivering van factor VIIla in plasma erg hoog is, terwijl factor Va slechts zeer langzaam geremd wordt, zijn de piekwaarden van de factor VIIla concentratie, in tegenstelling tot die van factor $\mathrm{Va}$, sterk afhankelijk van snelheid van aktivering. Omdat bij lagere concentraties remmer de aktivering van factor V en VIII niet volledig werd geremd, en een initiěle snelheid van aktivering kon worden gemeten, kan de minimale eerste orde snelheidskonstante die cen remmend proces dient te hebben ten einde de cofactor aktivering volledig te blokkeren geschat worden op $2 \mathrm{~s}^{-1}$. Tenslotte kan worden opgemerkt dat de concentraties van factor $\mathrm{Va}$ in plasma die worden bereikt na de initiēle fase van de stolling veel hoger zijn dan de concentraties van factor $\mathrm{Xa}$, zodat de maximale snelheid van het protrombinase complex in die fase wordt bepaald door de factor $\mathrm{Xa}$ concentratie.

Een logisch vervolg op de serie proeven beschreven in de hoofdstukken 2 en 5 leek het onderzoek van de bloedstolling in een systeem dat nog dichter staat bij de fysiologische situatie: bloed stromend uit cen bloedingstijd wondje. De bloedingstijd echter, kent een grote variabiliteit die niet alleen twijfel zaait over diens nut als een klinische test, maar die ook significante en lastig te omzeilen variaties zou introduceren bij onderzoek naar de rol van het bloedstollingsproces in de hemostase van een bloedingstijd wondje. Derhalve was ons eerste doel het zoveel mogelijk minimaliseren van de instrumentele variabiliteit van een bloedingstijd bepaling, hetgeen beschreven is in hoofdstuk 6 . Hiertoe maakten we gebruik van een techniek, uitgevoerd volgens een strict protocol, die de snelheid meet van bloeding in de tijd, in plaats van uitsluitend de tijd benodigd voor het stoppen van de bloeding. Bloed dat uit een bloedingstijd wondje stroomt wordt door een slangensysteem naar een fotometer gevoerd, waar de hoeveelheid hemoglobine wordt gemeten. $\mathrm{De} \mathrm{Hb}$ concentratie is dan een maat voor de uitstroomsnelheid van het bloed. Deze techniek maakte het mogelijk ook de bruikbaarheid van andere parameters te bepalen, zoals de totale hoeveelheid verloren bloed en de maximale en gemiddelde uitstroomsnelheid van het bloed. Onze resultaten laten zien dat van alle parameters afgeleid uit de gemeten bloedingspatronen, toch de bloedingstijd de laagste variabiliteit kent. Deze variabiliteit echter is zowel bij metingen tussen individuen als bij verschillende metingen bij dezelfde persoon nog steeds aanzienlijk en in de 
zelfde orde van grootte als in eerder gepubliceerde onderzoeken. De hoge variabiliteit zorgt voor een relatief hoge mate van overlap van bloedingstijden tussen verschillende populaties, tenzij hun gemiddelde erg ver uit elkaar ligt. Omdat bloedingstijden hoogstwaarschijnlijk afhankelijk zijn van een aantal niet controlleerbare parameters, is de kracht van de bloedingtijd als een klinische of farmacologische test niet erg groot en wellicht niet vatbaar voor veel verbetering als gevolg van veranderingen in de meettechniek. Dit impliceert dat analyse van het proces van bloedstolling in bloed stromend uit een bloedingstijd wondje zijn beperkingen heeft ten aanzien van een kwantitatieve beschrijving.

Stolling in vivo wordt gewoonlijk op gang gebracht door een beschading van de vaatwand. Weefselfactor, aanwezig op de celmembranen van het perivasculaire weefsel, komt dan in contact met de stollingsfactoren die in het bloed circuleren. Beschadigde cellen en geaktiveerde bloedplaatjes leveren de procoagulante oppervlakken die nodig zijn voor efficiente reakties. De fysische en biochemische condities die zich voordoen kunnen zeer verschillend zijn voor verschillende stollingsvoorvallen. De stromingscondities worden beïnvloed door grootte en het type van het bloedvat. De mate van beschikbaarheid van weefselfactor en procoagulant fosfolipiden oppervlak wordt bepaald door de grootte van de vaatwandbeschadiging. Van belang is ook de plaats waar de stolling optreedt, hetzij in het lumen van het bloedvat, hetzij in het perivasculaire weefsel, waar stroming volledig afwezig kan zijn. Dit alles maakt extrapolatie van experimentele gegevens naar de in vivo situatie erg lastig. Derhalve levert het soort proeven beschreven in dit proefschrift kwantitatieve resultaten die in principe alleen geldig zijn voor de omstandigheden waarin de proeven werden uitgevoerd. Hoewel de verleiding groot kan zijn de conclusies te generaliseren naar wetmatigheden die gelden voor bloedstolling in het algemeen, moet men zich nog steeds rekenschap geven van de precieze omstandigheden op een gegeven plaats en tijdstip.

De beschikbaarheid van nauwkeurige meettechnieken om concentraties van trombine, factor $\mathrm{Xa}$, factor VIIla en factor $\mathrm{Va}$ in plasma en bloed te bepalen, heeft ons de mogelijkheid gegeven een begin te maken met het in detail bestuderen van het proces van de bloedstolling onder bijna fysiologische omstandigheden. Dit is echter niet meer dan een kleine stap in het ophelderen van de wetten die hemostasis in vivo bepalen. Veel meer experimenten, in combinatie met de juiste analyses en modelvorming. zijn nodig, niet alleen in plasma, maar ook in experimentele systemen waarin de belangrijke factor stroming is opgenomen, en, uiteindelijk, in de in vivo situatie zelf. Dit is echter alleen verstandig wanneer genoeg 
informatie is verkregen op andere wijze. om een betekenisvolle interpretatie van de gegevens mogelijk te maken, net zoals het niet mogelijk zou zijn geweest om de in dit proefschrift beschreven experimenten in hun juiste context te plaatsen zonder de uitgebreide kennis van het stollingssysteem verkregen in meetsystemen met gezuiverde eiwitten. 


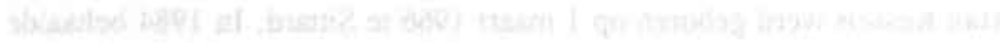

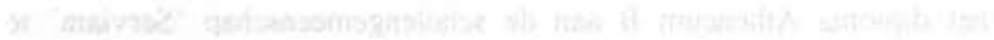

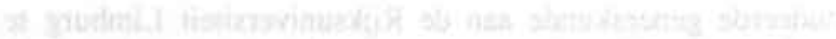

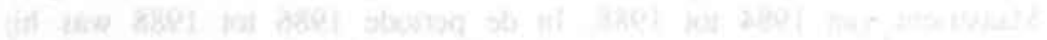

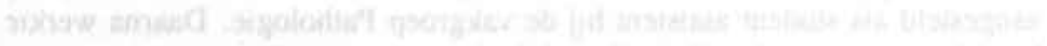

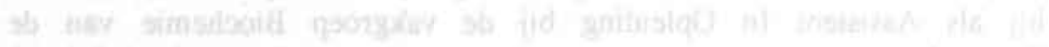

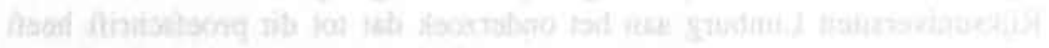




\section{curriculum vitae}

Han Kessels werd geboren op 1 maart 1966 te Sittard. In 1984 behaalde hij het diploma Atheneum B aan de scholengemeenschap 'Serviam' te Sittard. Hij studeerde geneeskunde aan de Rijksuniversiteit Limburg te Maastricht van 1984 tot 1988 . In de periode 1986 tot 1988 was hij aangesteld als student assistent bij de vakgroep Pathologie. Daarna werkte hij als Assistent In Opleiding bij de vakgroep Biochemie van de Rijksuniversiteit Limburg aan het onderzoek dat tot dit proefschrift heeft geleid. 


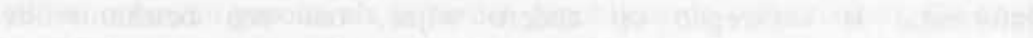

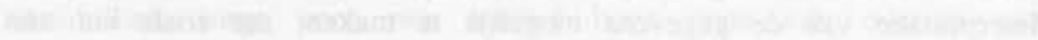

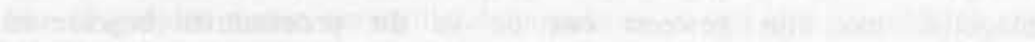

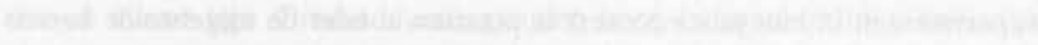

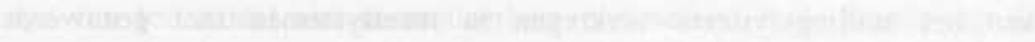
than

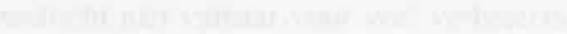




\section{dankwoord}

Dit proefschrift luidt voor mij het einde in van een periode van vijf jaar werken in Mastricht. Het was een fijne tijd, en ik wil iedereen die daaraan heeft bijgedragen graag bedanken. Sommigen wil ik, in verband met dit proefschrift, nog even in het bijzonder noemen.

Prof. Hemker, Coen, ik wil je allereerst natuurlijk bedanken voor de gelegenheid die je me gegeven hebt om, onder jouw begeleiding, in je lab te komen werken, eerst als student, en later als promovendus. Ik denk dat de vrijheid die je me vanaf het begin gegeven hebt een goede leerschool zal blijken.

Suzette, jij hebt me, om het zo maar cens te zeggen, ingewijd in de praktische geheimen van de bloedstolling, toen ik als niets vermoedende student een keuzevak bij je kwam lopen. Je hebt dat zo goed gedaan dat ik. na die paar weken al zeker wist dat ik in het onderzoek verder wilde.

Simone, als er iemand is geweest die in de afgelopen jaren z'n stempel heeft gedrukt op de sfeer in het lab dan ben jij het wel. Een vrolijke stempel wel te verstaan. Bovendien was je altijd bereid om me te helpen als ik weer eens 750 buisjes moest vullen voor de proef van de volgende dag.

Khaled, jouw grote verdienste is dat, sinds jij bij ons op het lab werkt, niemand ook maar de minste gelegenheid krijgt om stiekem in slaap te vallen.

Theo en George, jullie wil ik bedanken voor het feit dat het werkelijk nooit voorkwam dat jullie geen tijd voor me hadden als ik weer eens om advies kwam.

Peter en Danny, fijn dat jullie de (zware) taak van paranimf op je durfden te nemen. Peter, ik hoop dat ik niet alsnog de rekening krijg van alle koffie die ik bij jullie op het lab gedronken heb...

Harry, Harry en Peter, tijdens onze discussies zijn, ondanks (dankzij?) het bier, de nodige bruikbare ideeẻn geboren. 
Trees, Mariet en Gertie, jullie stonden steeds voor me klaar als ik weer eens een klein of minder klein klusje voor jullie had.

I want to thank Prof. Smits, Dr. Barrowcliffe, Prof. Vermylen, Prof. Ramaekers and Prof. Vrieze for critically evaluating this thesis.

Rob en Hans, Ron en Jo, bedankt voor de eiwitten die ik altijd van jullie gekregen heb.

Peter Laudy, jouw hulp op pascal en fotometer gebied was onmisbaar.

Hu Kai, Paul, Frederique, Dirk, Ma Xi, Vicky, Tomas, Richard, en Rachana, ook jullie droegen bij aan de gezellige sfeer op het lab.

Theo, Suzette, Peter, Harry, Sanne, Johan en George, ik ben jullie erkentelijk voor de tijd die jullie hebben gestoken in het kritisch doorlezen van (delen van) het manuscript.

Tenslotte wil ik alle leden van de vakgroep Biochemie en iedereen die op directe of minder directe wijze een bijdrage heeft geleverd en die ik niet met name heb genoemd, van harte bedanken. 
